University of Louisville

ThinkIR: The University of Louisville's Institutional Repository

$5-2021$

\title{
Correctional officers' response to stress: an exploration of the associations between violence and trauma exposure, coping mechanisms, and PTSD.
}

Katie Lorraine Hughes-Taylor

University of Louisville

Follow this and additional works at: https://ir.library.louisville.edu/etd

Part of the Criminology and Criminal Justice Commons

\section{Recommended Citation}

Hughes-Taylor, Katie Lorraine, "Correctional officers' response to stress: an exploration of the associations between violence and trauma exposure, coping mechanisms, and PTSD." (2021). Electronic Theses and Dissertations. Paper 3618.

https://doi.org/10.18297/etd/3618

This Doctoral Dissertation is brought to you for free and open access by ThinkIR: The University of Louisville's Institutional Repository. It has been accepted for inclusion in Electronic Theses and Dissertations by an authorized administrator of ThinkIR: The University of Louisville's Institutional Repository. This title appears here courtesy of the author, who has retained all other copyrights. For more information, please contact thinkir@louisville.edu. 


\title{
CORRECTIONAL OFFICERS' RESPONSE TO STRESS: AN EXPLORATION OF THE ASSOCIATIONS BETWEEN VIOLENCE AND TRAUMA EXPOSURE, COPING MECHANISMS, AND PTSD
}

\author{
By \\ Katie Lorraine Hughes-Taylor \\ B.S. University of Louisville, 2016 \\ M.S. University of Cincinnati, 2017

\begin{abstract}
A Dissertation
Submitted to the Faculty of the College of Arts and Sciences

of the University of Louisville

in Partial Fulfillment of the Requirements

for the Degree of

Doctor of Philosophy

in Criminal Justice

Criminal Justice

University of Louisville

Louisville, Kentucky
\end{abstract}

May 2021 
Copyright 2021 by Katie Lorraine Hughes-Taylor.

All rights reserved 

CORRECTIONAL OFFICERS' RESPONSE TO STRESS: AN EXPLORATION OF THE ASSOCIATION BETWEEN VIOLENCE AND TRAUMA EXPOSURE, COPING MECHANISMS, AND PTSD

By

Katie Lorraine Hughes-Taylor

B.S. University of Louisville, 2016

M.S. University of Cincinnati, 2017

A Dissertation Approved on

April 19, 2021

by the following Dissertation Committee:

Dissertation Chair, Kristin Swartz, Ph.D.

Deborah Keeling, Ph.D.

Bradley Campbell, Ph.D.

Andrew S. Denney, Ph.D. 


\section{DEDICATION}

This dissertation is dedicated

to my parents, Donnie and Bobbie Hughes,

my brother, Cole Hughes,

and my loving husband, Justin Taylor,

who have given me

immeasurable love and support.

To all correctional officers who

fearlessly serve, day after day. 


\section{ACKNOWLEDGMENTS}

I would like to thank Dr. Kristin Swartz, who has been a teacher, mentor, and friend for the better part of ten years. She has given me innumerable educational and research opportunities that will stay with me not only through the rest of my career, but also throughout my life. I would also like to thank my other committee members, Dr. Deborah Keeling, Dr. Bradley Campbell, and Dr. Andrew S. Denney. Your support, encouragement, and comments have meant so much to me throughout this process. I want to express thanks to my husband, Justin, for the love and understanding he has given me throughout my doctoral education. He has been a light and a place of calm in a stressful but exciting time. Also, many thanks to my parents, Bobbie and Donnie Hughes, for their total support in another five years of schooling after the bachelors. Finally finished, y'all! Thanks to my brother, Cole, who let me vent more times than I can say. Many thanks and much love to my Nini and Mamaw. Thank you to my Mississippi family, John, Joanne, $\mathrm{NaNa}$, Ryan, Maggie, and Sadler for accepting me into the family and immediately supporting my Ph.D. journey. Finally, thank you to the many Kentucky correctional officers who made this study possible by sharing their jobs with me for the last four years. 


\title{
ABSTRACT \\ CORRECTIONAL OFFICERS' RESPONSE TO STRESS: AN EXPLORATION OF THE ASSOCIATIONS BETWEEN VIOLENCE AND TRAUMA EXPOSURE, COPING MECHANISMS, AND PTSD
}

\author{
Katie Lorraine Taylor
}

April 19 ${ }^{\text {th }}, 2021$

The current study examines correctional officer coping mechanisms and whether they impact the likelihood of an officer developing PTSD symptoms. Additionally, research questions focus on whether problem-focused or emotion-focused coping mechanisms moderate the relationship between exposure to trauma and PTSD symptoms. The data for the current dissertation comes from a larger National Institute of Justice grant determined to examine mindfulness as an intervention for correctional officer PTSD within Kentucky Department of Corrections. Approximately 245 officers from seven adult institutions participated in the study and completed a lengthy survey. Main variables for the current analysis include two dependent variables, both of which measure PTSD symptoms. Key independent variables come from a coping assessment, the Violence, Injury, and Death Exposure Scale (VIDES), and controls such as age, gender, marital status, security level, correctional experience, and rank are also included. Results indicated that there were multiple problem- and emotion-focused coping mechanisms directly related to PTSD symptoms among officers. Analyses revealed only one coping mechanism, denial, significantly moderated the relationship between exposure to trauma and PTSD 
symptoms as reported in one PTSD assessment. Implications and directions for future research are also discussed. 


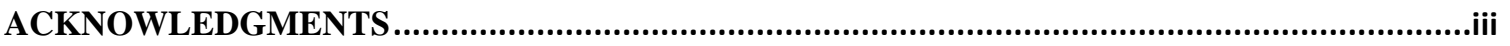

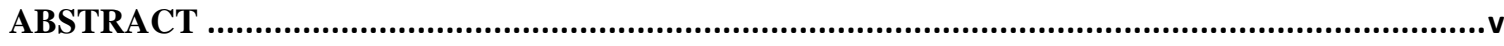

LIST OF TABLES......................................................................................................................... ix

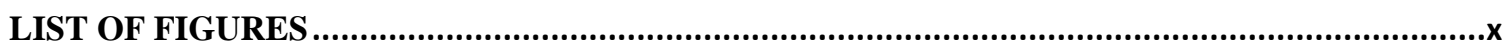

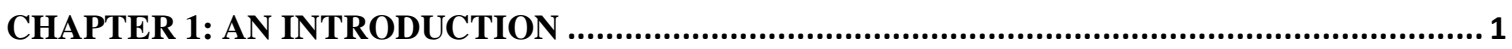

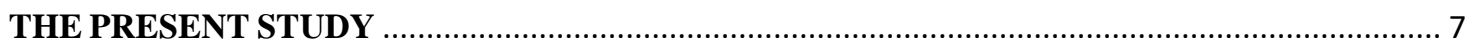

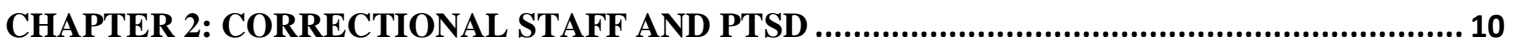

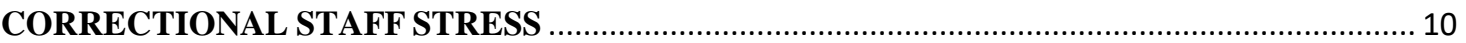

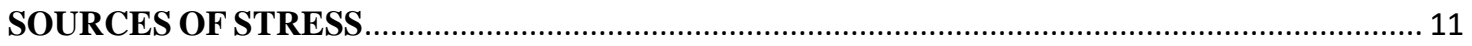

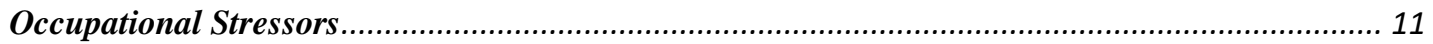

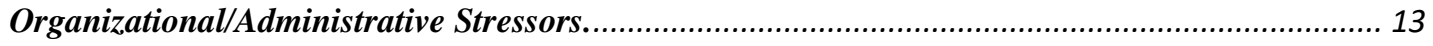

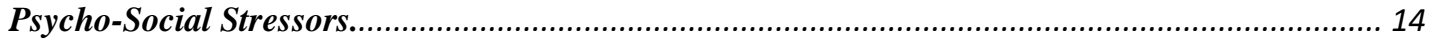

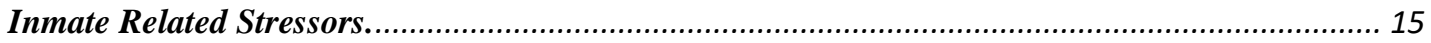

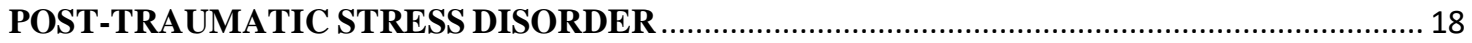

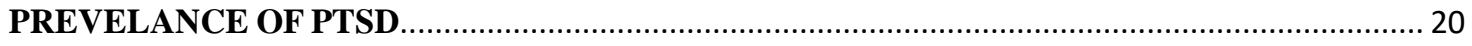

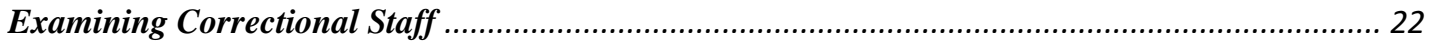

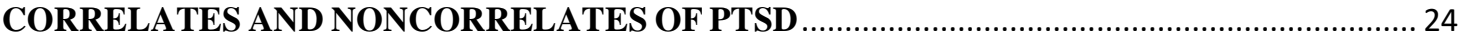

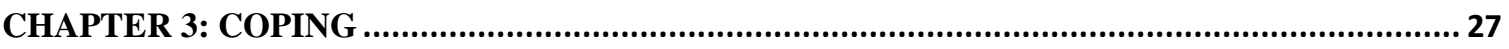

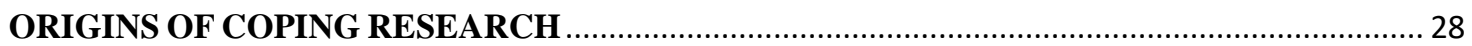

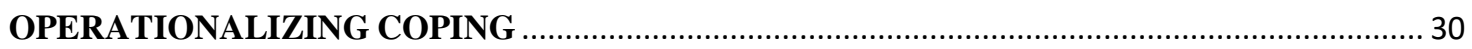

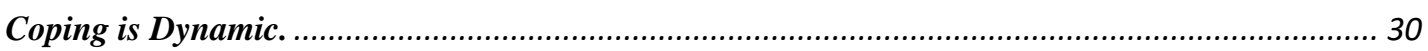

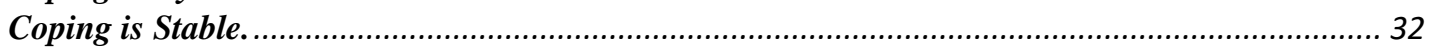

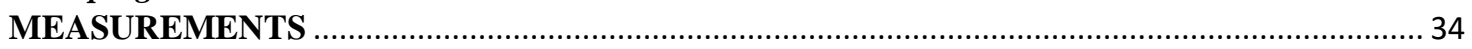

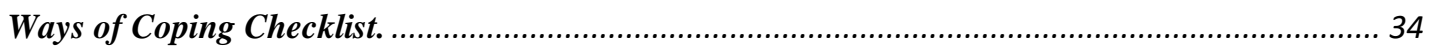

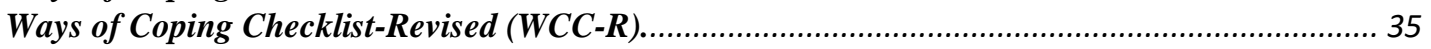

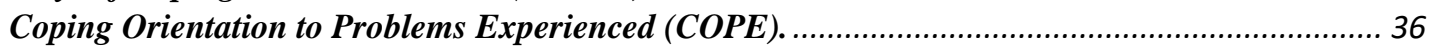

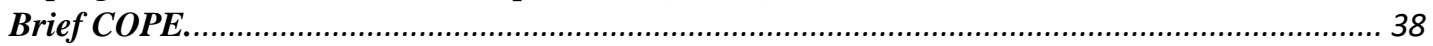

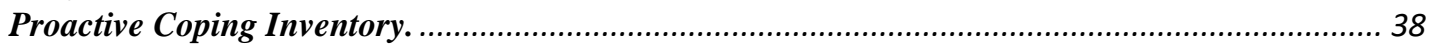

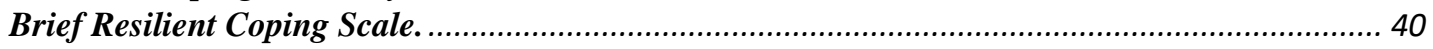

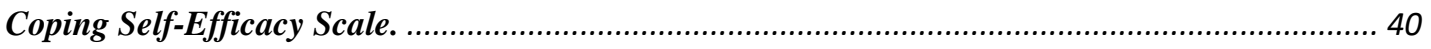

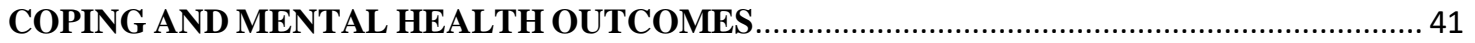

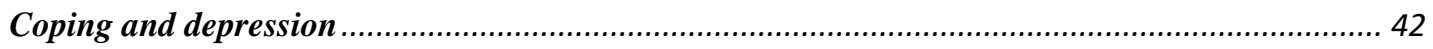

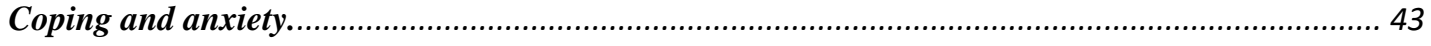

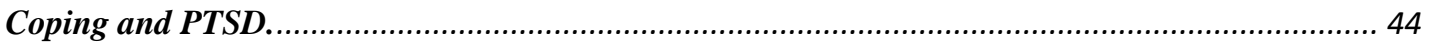

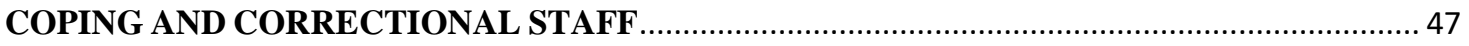

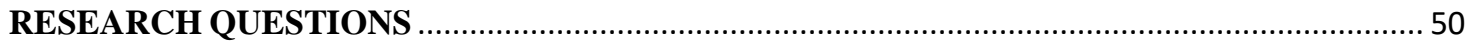

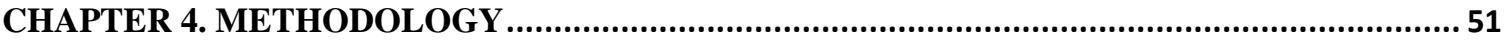




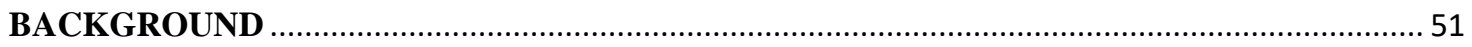

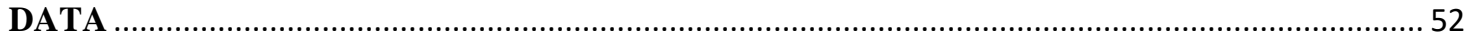

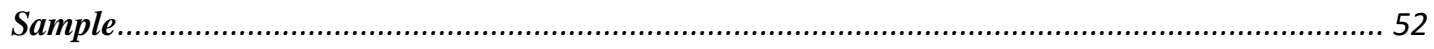

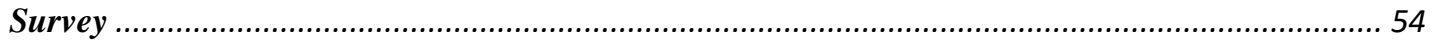

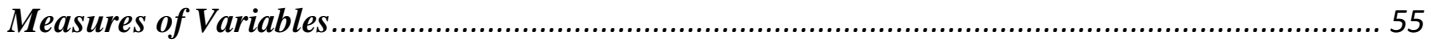

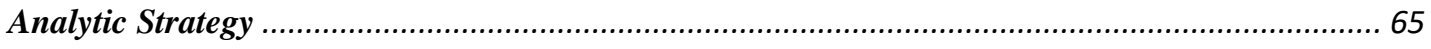

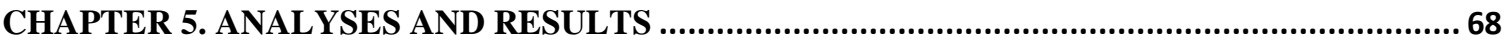

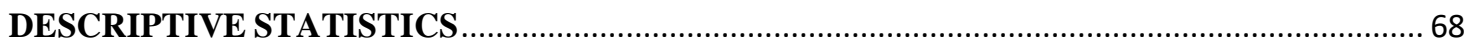

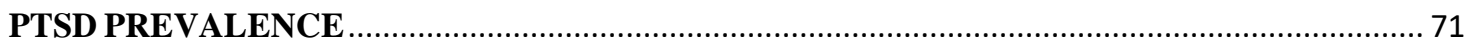

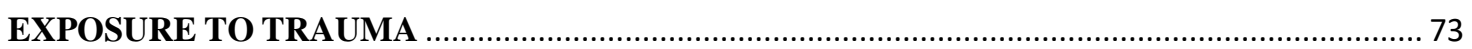

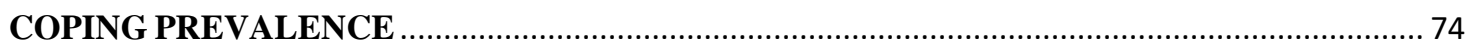

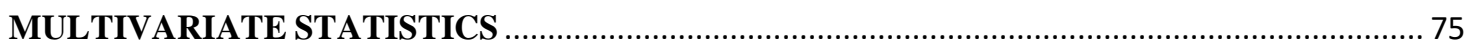

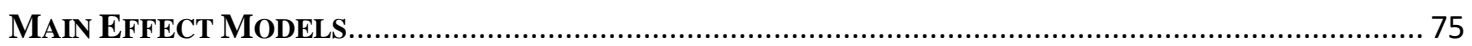

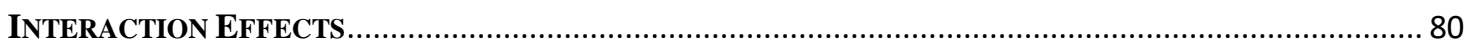

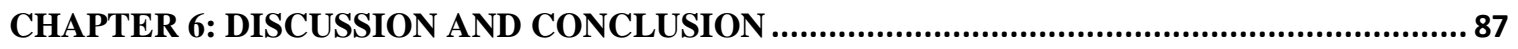

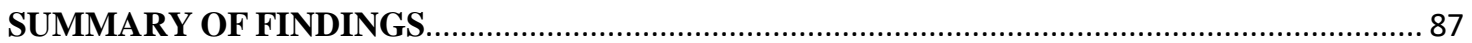

Research Question 1: Problem-Focused Coping and PTSD ............................................... 90

Research Question 2: Emotion-Focused Coping and PTSD ............................................ 93

Research Question 3: Exploration of Problem-Focused Coping as a Moderator........................ 95

Research Question 4: Exploration of Emotion-Focused Coping as a Moderator ........................ 97

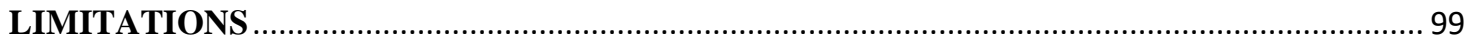

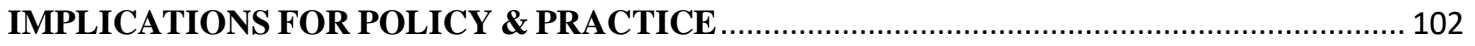

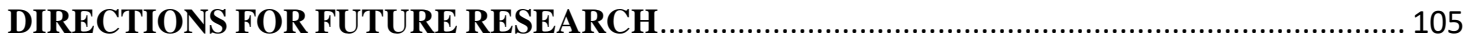

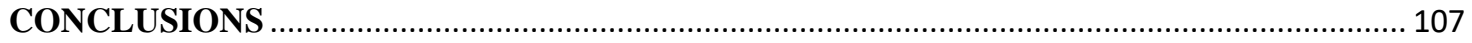

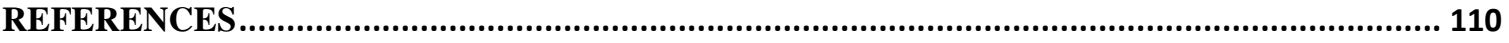

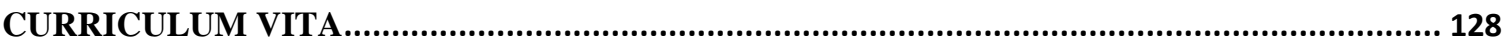




\section{LIST OF TABLES}

TABLE

2.1. Examples of PTSD Prevalence Rate in First Responder Populations

4.1. TSI-2 Trauma Score Interpretation

4.2. PCL-5 \& DSM-V Criteria for PTSD

4.3. COPE Inventory Subscales

4.4. Exposure Score Interpretation

4.5. Proposed Main Effects Models

5.1. Descriptive Statistics

5.2. Prevalence Rates of PTSD Symptoms, TSI-2

5.3. Prevalence rates of PTSD Symptoms, PCL-5

5.4. VIDES Prevalence

5.5. Main Effects Models for TRAUMA

5.6. Main Effects for PCL-5

5.7 Problem-Focused Interaction Effects with TRAUMA

5.8. Emotion-Focused Interaction Effects with TRAUMA

5.9. Problem-Focused Interaction Models with PCL-5

5.10. Emotion-Focused Interaction Models with PCL-5

6.1. Summarization of Findings
PAGE

22

58

60

63

65

66

70

71

72

73

77

79

81

83

83

86

99 


\section{LIST OF FIGURES}

$\begin{array}{ll}\text { FIGURES } & \text { PAGE }\end{array}$

4.1. Moderation Analysis Pathway

67 


\section{CHAPTER 1: AN INTRODUCTION}

Correctional staff, including security staff, program staff, and medical staff, face a multitude of issues in their work environment. While each of these groups of correctional staff have different and uniquely important specializations, due to the population with which they work, all participate in the supervision of potentially violent individuals who are being held against their will as punishment for their crimes. However, security staff supervise inmates at the closest level, with maintaining control and the safety of all other staff and inmates their top priority. Due to their specific duties as security staff, they are likely to be at the highest risk for being exposed to chronic, direct trauma and violence. In a nationwide sample, Spinaris et al. (2012) found that corrections professionals experienced 28 exposures to violence, injuries, or deaths. Denhof and Spinaris (2016) further found that approximately $28 \%$ of correctional officers within a statewide sample had extreme exposure levels to violence, injury, and death while on the job. Further, security staff are expected to serve in various roles in an environment where they have limited resources and are significantly understaffed. All of the factors - managing a difficult population, exposure to chronic violence and trauma, limited resources, and understaffing — culminate in a difficult work environment that ultimately impacts correctional officers' physical and mental health. While well overdue, correctional researchers and correctional practitioners have finally begun to focus on these health consequences. 
Though research regarding posttraumatic stress disorder (PTSD) among combat veterans, police officers, firefighters, and other first responders has accumulated a considerable amount of knowledge in recent decades, PTSD among correctional staff has received much less attention. In fact, correctional officer health and wellness had been largely understudied until recent decades. A very important review, written by Jaime Brower, focused specifically on correctional officer wellness and safety. Brower (2013) outlined the important stressors that correctional officers face, as well as identifying prevalent issues within the population due to the job, such as mental and physical health. One of the more heavily researched mental health disorders among correctional staff is PTSD. Correctional staff suffer higher rates of PTSD than the general public, and correctional officers specifically have the highest rates of PTSD within the correctional system. Being a correctional officer has also been listed within the top ten most dangerous occupations in the United States, according to a Forbes (2015) article. Prevalence rates have been examined at the state level (Denhof \& Spinaris, 2016; Swartz et al., 2017) and the national level (Spinaris et al., 2012). Previous studies have consistently found the prevalence rates of PTSD among correctional officers to be approximately 1 in 3 officers (Denhof \& Spinaris, 2016; Spinaris et al., 2012; Swartz et al., 2017).

Researchers have also found that there are direct relationships between prison factors and the likelihood of developing PTSD. For example, multiple studies have found that the more violent and traumatic events correctional staff experience, the more likely they are to develop PTSD (Spinaris et al., 2012; Swartz et al., 2017). Security staff, those officers who wear a uniform and supervise inmates directly, are also more likely to 
develop PTSD than program staff or medical staff. Denhof and Spinaris (2013) also examined subgroups of correctional professionals and found that those with prior military history were more likely to have PTSD, as well as males and correctional officers who worked at institutions supervising males. Pre-existing conditions, such as anxiety and depression also increase the likelihood of developing PTSD (Breslau et al., 1991; Davidson, 2000).

Correctional officers have been determined to suffer from a multitude of mental health disorders, including anxiety, depression, and PTSD. One study found that $29 \%$ of correctional officers suffered from PTSD symptoms, while $31 \%$ and $24 \%$ had major depressive disorder and generalized anxiety disorder, respectively (Carleon et al., 2018a, b). Additionally, Lerman (2017) found that depression is often a way of life for correctional staff, and 1 in 3 officers had experienced at least one PTSD symptom. Although the job they do is invaluable, they often do not receive the mental health care they need to help them cope with the stressors of the job, which ultimately affects their health and relationships both at and away from work. Unfortunately, being considered "tough" within the correctional system prevents officers from seeking professional help. Asking for help with mental health has been and continues to be seen as a weakness within the correctional profession. The more pervasive problem comes from entrenched paranoia and mistrust, including the mistrust of medical professionals. This is shown in Lerman (2017), where approximately 8,300 correctional staff from California were surveyed about their wellbeing. Lerman (2017) found that many officers have concerns about utilizing Employee Assistance Programs (EAPs). 
One of the biggest concerns that officers have when thinking about using EAPs is confidentiality, or lack thereof. Officers also worry about negative consequences from management and judgement from their coworkers. On the more extreme end, officers had concerns about their employment being terminated as a result of utilizing EAPs. Brower (2013) notes that correctional officers may have access to both internal and external EAPs. Unfortunately, both of these programs have their own issues. Internal EAPs may be more accessible for officers, but since internal EAPs can be considered an extension of the institution, issues of mistrust and confidentiality come to the forefront again. While external EAPs can alleviate issues of confidentiality, there are often other constraints such as needing to travel to offices, which is hard with correctional officer schedules and mandatory overtime. To avoid the negative connotations and possible consequences, whether formal or informal, officers opt to handle issues on their own instead of reaching out for help.

Due to staffing issues, correctional staff are often working mandatory overtime in an understaffed and overstressed environment. Lerman (2017) found that $70 \%$ of officers did not think that there were enough staff members to ensure safety and security. These factors, as well as the traditional environment of a prison, contribute to a cycle that has officers leaving the job at a high rate or suffering through the job without proper help to manage their mental health. Individuals who are suffering from PTSD are at an increased risk of suicide, hospitalization, and alcohol abuse (Davidson, 2000). Research suggests that PTSD is not only psychological but will manifest itself as physical symptoms as a result of stress (Davidson, 2000; Pitman, 1997). These increased levels of stress put correctional officers at a higher rate of experiencing stress-related illnesses 
such as high blood pressure, diabetes, and heart disease (Lerman, 2017). If correctional staff continue to suffer from PTSD, their mental and physical health can become affected, which can lead to other issues. These issues include problems with family, friends, and the inability to perform their duties within the prison. This, in turn, contributes to unsafe conditions for other officers, inmates, and broader society.

Studies have begun to identify specific risk factors for developing PTSD, such as gender, and comorbidity of other psychological disorders. However, there remain many unanswered questions. For example, research has just begun to explore what could potentially insulate an individual from developing PTSD after trauma exposure. Resiliency and certain personality traits have been determined as possible protective factors (Aupperle et al., 2012; McCrae, 1992). What has not yet been adequately explored is whether, and how different, coping mechanisms could insulate an individual from developing PTSD after exposure to trauma.

Coping mechanisms are important because they are directly related to an individual's resiliency in the face of violent and traumatic events. Both negative and positive coping mechanisms have direct relationships to an individual's reaction to trauma. Negative coping can include denial, substance use/abuse, and withdrawing from others. Positive coping examples are thinking positively, planning, and active coping. Coping mechanisms have been studied in general since the 1960s, but have become a topic of more recent research in the fields of psychology, medical personnel, and other first responder populations, including those in the military (Delahaij \&Van Dam, 2017; Folwell \& Kauer, 2018; Kirmeyer \& Diamond, 1985). There have been multiple coping assessments that have been developed and validated throughout the years. These 
assessments have been used to determine an individual's coping type. Other assessments measure which coping mechanisms are most popular. Finally, these assessments also help determine which coping mechanisms are likely to help individuals when they face stress.

Of the multiple assessments and studies that have been completed, two types of coping mechanisms have emerged: problem-focused and emotion-focused. Problemfocused coping mechanisms are generally utilized when the individual seeks to regain control over the situation by acting. Problem-focused coping mechanisms can include planning, restraint, and active coping. The other type of coping mechanisms, emotionfocused mechanisms, are utilized when an individual has determined they cannot control the situation, and proceed with emotions to avoid the problem instead of seeking to solve it. Coping mechanisms allow individuals to either directly face their problem, or figure out ways to avoid it. After being exposed to violence and trauma, individuals will have to process what they have experienced. If certain coping mechanisms, such as active coping, using emotional or social support, and positive reinterpretation and growth insulate individuals from developing PTSD, those coping mechanisms should be taught to correctional officers. Coping and PTSD has been briefly explored in relation to survivors of natural disasters. For example, Cadamuro et al. (2014) found that children who utilized social support as a coping mechanism had improved cognitive performance after a disaster. Other studies have found that religious-based coping mechanisms, which are determined to be emotion-focused in coping experts, help individuals in their ability to recover after trauma. Therefore, teaching officers certain positive coping mechanisms can allow them to have a larger toolkit to combat PTSD after inevitably being exposed to trauma in the prison environment. In turn, correctional officers want to learn and develop 
better techniques to cope with the stressors of the job (Lerman, 2017; Ricciardelli et al., 2020). Lerman (2017) found that $88 \%$ of their sample wanted to learn stress management training, and $82 \%$ wanted trauma and PTSD training. The intersection of coping mechanisms and the likelihood of PTSD is the crux of the current analysis. The present study focuses on the traumatic experiences of officers, their coping mechanisms, and their possible development of PTSD.

\section{THE PRESENT STUDY}

Correctional officers have experiences that can impact whether they develop PTSD and while the research has demonstrated that individual experiences can impact a PTSD diagnosis, what has not yet been fully explored are individual differences that may cause a person to be at a higher risk to developing PTSD. There are many hypotheses about what factors place an individual at a higher or lower risk for developing PTSD, including personality and resiliency. Contractor et al. (2015) found that trauma-exposed veterans who had high levels of PTSD were more likely to have diminished agreeableness, conscientiousness, emotional stability, and openness to new experiences than those who did not have high levels of PTSD. With regards to resiliency, Aupperle et al. (2012) found that the ability to disengage after a traumatic event could serve as a resiliency factor for preventing PTSD. What has not yet been explored, and is the topic of the current dissertation, is if and how coping mechanisms are associated with the likelihood correctional officers develop PTSD symptoms as a result of working in prison. That is, do certain coping mechanisms or a correctional officer's coping repertoire place them at a higher risk for developing PTSD? There is currently no literature examining the association between a correctional officer's coping mechanisms and their likelihood of 
developing PTSD following traumatic events encountered while on the job. The current study will examine the relationship between PTSD and coping mechanisms among correctional staff. There are two main goals of the current dissertation. The first goal requires using two measures of PTSD and this goal will explore the associations between problem-focused and emotion-focused coping mechanisms and the development of PTSD symptoms. The second goal of the current study is to examine whether any of the coping mechanism have a moderating effect on the relationship between total trauma exposure and PTSD. It is important to determine the relationship between coping and PTSD because coping literature indicates that certain coping mechanisms may impact whether an individual develops PTSD. Additionally, those with certain coping mechanisms may still suffer from PTSD but may not have as severe of symptoms. Essentially, it is the aim of this dissertation to determine if problem-focused and emotion-focused coping mechanisms are associated with the amount of PTSD symptoms experienced by correctional officers and whether some coping mechanisms can minimize the effects of exposure to trauma on their mental health. Further study on this topic is key to assist with addressing the crucial areas of correctional officer safety, job burnout, chronic absenteeism, and turnover.

In order to facilitate understanding of the current analysis this dissertation is divided into chapters. Chapter two summarizes the stress and PTSD literature within the general population, the first responder population, and PTSD in correctional staff. Chapter three focuses on the evolution of measuring coping mechanisms in relation to various mental health outcomes, an in-depth explanation of coping and how coping how been previously examined among correctional officers. The chapter concludes by 
highlighting the importance and need to focus on correctional officers and their coping mechanisms. This is especially important in copings relation to mental health, such as PTSD. Chapter 4 explains the background of the data collection, the types of assessments used to collect data, and all of the variables being used in the current analysis. This chapter also explains the statistical analyses that will be performed and outlines the limitations of the study. 


\section{CHAPTER 2: CORRECTIONAL STAFF AND PTSD}

\section{CORRECTIONAL STAFF STRESS}

Due to the difficult population they supervise and the conditions under which they work, correctional staff have a very stressful job. Further, since stress, especially chronic stress can lead to many negative physical and mental health outcomes, understanding stress and its consequences among correctional officers is an important issue. Hans Selye (1976) defines stress as the "nonspecific response of the body to any demand" (p. 74). He explains that there are two main types of stress known as eustress and distress. Eustress is stress that is experienced as a result of positive stimuli, while distress is experienced when negative stress is experienced by the individual. Even though the body undergoes the same nonspecific responses despite experiencing eustress or distress, eustress does much less damage on the body (Selye, 1976). Therefore, the typical stress that correctional staff, and more specifically correctional officers experience, is distress. Complicating the issue, correctional officers experience stress from multiple sources. In the next section, the sources of correctional staff stress are discussed. Then, there is a discussion outlining posttraumatic stress disorder (PTSD) and its prevalence among first responders. Finally, a literature review outlining current knowledge of PTSD among correctional staff is presented. 


\section{SOURCES OF STRESS}

The sources of stress for correctional officers are varied. Due to the number of roles that correctional officers play at their job, they may feel the stress from different sources at the same time. For example, when confronting an inmate, they have to juggle the stress of probable injury and an occupational stressor of not having enough officers on shift to safely cover all posts. This is a compounding of stressors. In a literature review examining correctional officer wellness and safety, Bower (2013) classifies the major sources of stress as: 1) occupational; 2) organizational/administrative; 3) psychosocial; and 4) inmate related. Below a summary of each source of stress is provided.

Occupational Stressors. The first set of stressors correctional officers face are occupational stressors. Occupational stressors can include the nature of the closed work environment, role ambiguity, which occurs when employees are unclear or uncertain about their workplace expectations, physicality of the job, hyper-vigilance, and the code of silence that tends to permeate first responders, where in asking for help is seen as a sign of weakness (Bower, 2013). It is important to note that job stress and occupational stressors are terms that cannot be used interchangeably. Job stress is generally defined as how the employee feels about job-related hardness, tension, anxiety, and frustration. However, occupational stressors are the workplace stimuli that cause employees to experience job stress (Cullen et al., 1985). When on shift, correctional officers are essentially isolated from the outside world. They are typically not allowed to leave the institution once their shift starts and are not allowed to have their cell phones. Therefore, they are working within a closed work environment. Hogan, Lambert, Jenkins, and 
Wambold (2006) specifically examined occupational stressors on correctional staff and their organizational commitment. Hogan et al. (2006) found that occupational stressors such as increased role ambiguity and role conflict had significant negative effects on staff's organizational commitment. That is, the higher the levels of role ambiguity and conflict, the less organizational commitment they have. Lambert et al. (2005) researched the issues surrounding role stress and prison staff. Role stressors include role ambiguity, role conflict, and role overload. It was found in this study that all three of these role stressors were significantly related to job stress. Lambert et al. (2005) concluded that correctional staff want clear, concise roles that do not overlap with others. More so, correctional staff feel more stress when their roles conflict with one another. These lower job satisfaction and organizational commitment.

The physical demands of being a correctional officer can cause higher amounts of stress, including carrying their gear, standing and walking a majority of the day, and being able to physically control inmates should the necessity arise. Costello et al. (2015) found that chronic pain was prevalent in their sample of Irish correctional officers. Specifically, $48 \%$ of the respondents reported chronic pain, and that psychological distress was high among those who reported chronic pain (Costello et al., 2015). Correctional staff also report high levels of hyper-vigilance due to the nature of the job, which is also conducive to the development of PTSD symptoms. The final occupational stressor is common among other first responder populations, including police. This is the code of silence, which in essence, is the idea that asking for or receiving help is a sign of weakness (Bower, 2013). Correctional officer culture promotes being "strong and tough;” 
and therefore, there is a resistance to any sign of weakness, which using or needing mental health services, if often seen as a weakness.

Organizational/Administrative Stressors. Like many other occupations, correctional staff have to deal with stressors stemming from the organization for which they work. Cullen et al. (1985) completed a seminal study that examined multiple aspects of correctional officer stress. These include supervisory support and security level, among others. Bower (2013) also gives a long list of organizational and administrative stressors. An unexhaustive list includes lack of trust in administration, no input in decision-making, mandatory overtime, and limited services for correctional staff. The majority of the literature on organizational stressors focuses on correctional staff burnout, which is a result of chronic stress. Using items such as "The department values my input" and "Even if I did the best job possible, the department probably would not notice" to determine organization support, Griffin (2006) found that male correctional officers reported more concerns about the quality of supervision and it leading to increased amounts of stress. Lambert, Hogan, and Jiang (2010) reported a preliminary examination of the relationship between organizational structure and emotional burnout among correctional staff. They found that when there is little opportunity for input in decision making and lack of clear communication, correctional officer stress increased.

Another article by Lambert and Hogan (2010) examined organizational innovation. Organizational innovation is the implementation of new ideas and the use of feedback from employees to make changes that will ensure success (West, 2002). It was found that perceptions of organizational innovation had significant impacts on job stress 
among correctional officers. When perceived organizational innovation is higher, staff reported lower levels of stress. On the other hand, when perceived organizational innovation was low, staff reported higher levels of job stress. Finally, prisons are often understaffed and overworked. Correctional officers are no stranger to mandatory overtime, although it does have effects on job stress and can contribute to increased staff absenteeism and turnover. Lambert et al. (2005) describes two different types of absenteeism: unavoidable and avoidable. Unavoidable absenteeism is determined to be sickness, injury, or transportation issues. Avoidable absenteeism consists of excuses such as needing a day off, sleeping in, or attending a social event. The results of Lambert et al. (2005) found that job stress had a positive effect on absenteeism. Additionally, employees who reported chronic job stress also took time off to recover. The absenteeism then further contributes to the stress of the other officers who are at work, because now they are shorter staffed. The situation is cyclical.

Psycho-Social Stressors. Psycho-social stressors include individual-level stressors such as fear, over-aggressiveness, and lack of assertiveness (Bower, 2013). Work-family conflict is also included in the psycho-social stressors and has been extensively studied in the correctional system (for examples see; Higgins, Swartz, \& Roberts, 2021; Lambert \& Hogan, 2010; Lambert, Hogan, \& Barton, 2004; Lambert, Hogan, Camp, \& Ventura, 2006). This research has found that correctional officers are more likely to be impacted by work-family conflict than other staff members within the prison (Lambert et al., 2004). Additionally, certain components of work-family conflict, such as strain-based conflict, had significant impacts on job stress in which when strain-based conflicts 
increased, so too did job stress (Lambert et al., 2006). Increases in work-family conflict also led to increased levels of burnout among correctional officers. (Lambert \& Hogan, 2010). The most recent study involving work-family conflict found that work conflicts often "bleed over" into family life, and cause issues for officers and their relationships with their families, thus pushing them further into a reclusive correctional subculture (Higgins et al., 2021). Due to the serious misunderstanding and misinterpretations of what being a correctional officer really entails, (Sundt, 2009; Vickovic, Griffin, \& Fradella, 2013) the final psycho-social stressor described by Bower (2013) are media and political scrutiny, which can include publicity surrounding escapes and other perceived or actual injustices done inside the prison system.

Inmate Related Stressors. Correctional officers supervise many different types of inmates. While some are stoic and simply want to serve their time quietly, other inmates are motivated to cause issues for officers at every turn. Inmate-related stressors are defined as any stressor that comes from supervising inmates directly. The individuals whom correctional officers supervise are potentially violent, mentally unstable, and being held against their will, which puts correctional officers at a higher risk for experiencing injury due to inmate assaults. This increased risk of injury puts additional stress on correctional officers. Correctional officer injuries can be described as either within their control or outside their control (Goulette, Denney, \& Crow, 2020).

Goulette et al. (2020) found that correctional staff injuries at the hands of inmates can come from complacency, or being too comfortable with the inmates, which is inside the control of the officer. Some of the perceived causes of injuries outside the officers 
control included injuries that were just part of the job and supervising inmates with mental illness. In fact, supervising inmates with mental illness is one of the inmate related stressors Bower (2013) outlines in her report on correctional officer wellness.

The prison population is unfortunately chronically mentally ill, with over half of incarcerated individuals reporting some type of mental disorder (James \& Glaze, 2006). Therefore, not only do correctional officers play a role in supervising mentally ill inmates, but also treating inmates and sometimes preforming life sustaining acts, such as cutting down inmates who have hung themselves with clothes or bedsheets, or stopping the bleeding of an inmate who has self-harmed, while still trying to maintain their own safety. Data from Swartz et al. (2017) showed that, within the two previous years, the average correctional staff member $(\mathrm{N}=730)$ responded to 1.5 suicide attempts and less than one completed suicide. Kentucky correctional staff also witnessed and responded to approximately 2.4 physical assaults, such as an inmate stabbing another inmate with an institution made weapon, or a physical fight between inmates. Spinaris et al. (2012) found that $100 \%$ of the sample $(n=3599)$ experienced at least one violent or traumatic event while on the job. The most prevalent violent and traumatic events experienced among PTSD positive participants were being threatened with harm, witnessing physical harm, and witnessing someone being threatened with physical harm.

These inmate-related stressors, specifically the violent and traumatic events, are one of the main independent variables of the current analysis. As indicated above, violence and trauma are experienced by virtually all correctional officers. However, the type and severity of trauma experienced varies greatly. There are two main categories of trauma: direct and indirect. Direct trauma refers to trauma that is experienced or 
witnessed first-hand and indirect trauma refers to trauma that is second-hand or the individual learns about the trauma someone else suffers (Denhof, Spinaris, \& Morton, 2014). Both direct and indirect trauma has been associated with increased risk of PTSD (Denhof \& Spinaris, 2016).

One of the ways trauma and violence has been measured among correctional officers is through the use of the Violence, Injury, and Death Exposure Scale (VIDES). Developed by Denhof and Spinaris (2014) the VIDES measures both direct and indirect trauma. The items on the VIDES measure the various types of violence and trauma that officers face when supervising inmates, such as being harmed, threatened with harm, witnessing harm, and learning about harm from others. The VIDES also asks about responding to suicides of inmates, both attempted and completed, as well as deaths that are not a result of suicide. These are the very real traumas that correctional officers face on a daily basis.

These violent and traumatic stressors, of course, are not experienced on their own. Correctional officers deal with each of these stressors in addition to others. For example, not only do they have to worry about being injured on the job, they also have to worry about whether the administration will support them if they are injured, through their recovery time. These are organizational issues that are compounded with the inmate stressors that put officers at an increased risk for job burnout, depression, anxiety, and post-traumatic stress disorder symptoms. 


\section{POST-TRAUMATIC STRESS DISORDER}

Post-traumatic stress disorder has been said to have a relatively short history as a DSM recognized mental illness; however, since its inception it has been a focus of research and the complexities surrounding PTSD. The symptoms of PTSD are being further explored every day (Monson, Friedman, \& La Bash, 2007). The integration of the organic and psychological explanations of traumatic reactions was conducted by Abram Kardiner (1941). He was the first to identify the cognitive and behavioral disturbances that occur when an individual is traumatized. Kardiner's research on trauma centered mainly around the startle response of soldiers in World War I; and Kardiner is credited as being the founder of biopsychosocial approaches to understanding trauma. PTSD was first introduced into the DSM in its third installment in 1980. The criteria for a PTSD diagnosis are most recently outlined in the Diagnostic and Statistical Manual of Mental Disorders (DSM-V, 2013).

There are multiple criteria required for a PTSD diagnosis which are discussed below. Criterion A is the "exposure to actual or threatened death, serious injury, or sexual violence." The exposure can occur through directly experiencing the event, witnessing the event happen to another, learning that trauma had occurred to a close friend or family member, or experiencing repeated or extreme exposure to aversive details of traumatic events. Therefore, criterion A explains the manner through which the traumatic event occurs to the individual. The idea that one can have trauma from witnessing an event is a new addition to the diagnosis. While experiencing the event is considered to be direct trauma, witnessing or learning about an event causes indirect trauma. The DSM-V (2013) now recognizes that PTSD can come as a result of both direct and indirect trauma. Of 
course, not every person who experiences or witnesses a traumatic event develops PTSD; therefore, additional criteria are necessary. All of the following criteria must be experienced by the individual for at least one month in order to be considered for a PTSD diagnosis (DSM-V, 2013). Criterion B, then, starts the explanation of the symptoms that one must suffer from in order to be diagnosed. The symptoms that are listed under criterion B are described as intrusion symptoms, these are symptoms that interfere with everyday thought and often include recurrent, involuntary memories of the event. Individuals also report distressing dreams, dissociative reactions (flashbacks), and prolonged distress when exposed to internal or external resemblance of the traumatic event. Individuals must suffer from at least one intrusive symptom.

In addition to experiencing intrusive symptoms, those who are diagnosed with PTSD must also report at least one avoidance symptom. The two avoidance symptoms that are outlined in criterion $\mathrm{C}$ of the DSM-V include: avoiding distressing memories, thoughts, or feelings of the traumatic event; and avoiding external reminders, such as people, places, and things, of the traumatic event. As Kardiner (1941) noted, individuals who are traumatized often suffer from disturbances to their cognitive and behavioral responses. This finding is related to criterion D of the DSM-V diagnosis of PTSD. Criterion D requires individuals to have suffered two or more negative changes to mood and cognitions. These symptoms include the inability to remember important aspects of the traumatic event, persistent exaggerated negative beliefs, self-blame, persistent negative emotional state, declined interest in significant activities, detachment, and the inability to experience positive emotions such as happiness or loving feelings. Finally, Criterion E describes the last set of symptoms that an individual must display to be 
diagnosed with PTSD. These include significant changes in arousal and reactivity. These symptoms include unprovoked angry outbursts, self-destructive behavior, hypervigilance, exaggerated startle response, problems with concentration, and sleep disturbance. To be diagnosed with PTSD, the individual must experience two or more of these symptoms.

Additionally, the symptoms must cause significant distress or impairment in social and occupational functioning. Last, the diagnosis of PTSD can only be given if the above-mentioned disturbances and impairments are not due to any substance use or other medical condition. In addition to PTSD, there is a subtype that is specific to those with increased dissociative symptoms. In order to be diagnosed with the dissociative subtype, individuals must meet all the criteria for PTSD and experience either depersonalization or derealization. Depersonalization is described as the persistent or recurrent experience of feeling detached from one's body, feeling like one is in a dream, or a sense of unreality of self or body. Derealization is different, and more outwardly focused in that it is the persistent or recurrent experiences of unreality in surroundings. An example of this is feeling like the world is not real, or that one exists only in a dreamlike state. Now that the requirements for a PTSD diagnosis have been adequately explained, the prevalence of PTSD within the general population, and across multiple occupations is discussed.

\section{PREVELANCE OF PTSD}

The prevalence of PTSD differs across populations. The DSM-V (2013) reports that, in the United States, the lifetime risk of PTSD is 8.7\%. When looking at the 12month prevalence, approximately $3.5 \%$ of Americans are diagnosed annually. In other countries, such as in Europe and in Asia, the prevalence rate is lower, sitting between 0.5\% and 1.0\% (American Psychiatric Association, 2013). Although the overall 
prevalence of PTSD for Americans is relatively low, there are certain populations that are consistently at a higher risk for PTSD than the general population. Some of these populations include police officers, paramedics, firefighters, and combat veterans. Research on these populations has been conducted quite thoroughly. Table 2.1outlines a few example studies of the first responder populations and their prevalence of PTSD. As evidenced by the table, first responders experience PTSD at rates up to four times higher than that of the general population. This is likely, in part, due to the high and chronic exposure to trauma and violence through their line of work. For example. police PTSD rates have ranged from $13 \%$ to $19 \%$, and included examining regular duty-related stressors and specific traumatic events. For paramedics/ambulance personnel, the prevalence rates have ranged from $16 \%$ in South Africa to $21.5 \%$ in Sweden. Firefighters experienced higher rates of PTSD than paramedics, with percentages ranging from $26 \%$ among Australian firefighters to almost $32 \%$ in America. Finally, military veterans experienced the highest range of PTSD prevalence rates. These prevalence rates are from $24 \%$ to $58 \%$ among combat veterans. Correctional staff, like other first responder populations, suffer from chronic exposure to violence and trauma; however, as previously mentioned, this population has received much less attention from researchers. The next section focuses specifically on correctional staff. 
TABLE 2.1: Examples of PTSD Prevalence Rate in First Responder Populations

\begin{tabular}{|c|c|c|c|c|}
\hline Source & Sample & $\begin{array}{l}\text { PTSD } \\
\text { Rate }\end{array}$ & $\begin{array}{c}\text { Measurement } \\
\text { Tool }\end{array}$ & Setting \\
\hline $\begin{array}{l}\text { Robinson, Sigman, and } \\
\text { Wilson, } 1997\end{array}$ & $\begin{array}{l}100 \text { American } \\
\text { police officers }\end{array}$ & $13 \%$ & $\begin{array}{l}\text { Impact of Events } \\
\text { Scale- Revised } \\
\text { (IES-R) }\end{array}$ & $\begin{array}{l}\text { Duty-related } \\
\text { stressors }\end{array}$ \\
\hline $\begin{array}{l}\text { West, Bernard, Mueller, } \\
\text { Kitt, Driscoll, \& Tak, } \\
2008\end{array}$ & $\begin{array}{l}912 \text { American } \\
\text { police officers }\end{array}$ & $19 \%$ & $\begin{array}{l}\text { PTSD Checklist } \\
\text { (PCL) }\end{array}$ & $\begin{array}{l}\text { Specific } \\
\text { Event }\end{array}$ \\
\hline $\begin{array}{l}\text { Fjeldheim, Nothling, } \\
\text { Pretorius, Basson, } \\
\text { Gansen, Heneke, } \\
\text { Cloete, \& Seedat, } 2014\end{array}$ & $\begin{array}{l}131 \text { South African } \\
\text { paramedic trainees }\end{array}$ & $16 \%$ & $\begin{array}{l}\text { Davidson Trauma } \\
\text { Scale (DTS) }\end{array}$ & $\begin{array}{l}\text { Field } \\
\text { Experience }\end{array}$ \\
\hline $\begin{array}{l}\text { Jonsson, Segesten, } \\
\text { \&Mattson, } 2004\end{array}$ & $\begin{array}{c}362 \text { Swedish } \\
\text { ambulance } \\
\text { personnel }\end{array}$ & $21.5 \%$ & $\begin{array}{c}\text { PTSD } \\
\text { Questionnaire }\end{array}$ & Daily stress \\
\hline $\begin{array}{l}\text { Boffa, Stanley, Hom, } \\
\text { Norr, Joiner, \& } \\
\text { Schmidt, } 2017\end{array}$ & 893 U.S. firefighters & $31.8 \%$ & $\begin{array}{c}\text { Posttraumatic } \\
\text { stress disorder } \\
\text { checklist-Civilian } \\
\text { version (PCL-C) }\end{array}$ & $\begin{array}{l}\text { Routine } \\
\text { Duties }\end{array}$ \\
\hline Bryant \& Harvey, 1996 & $\begin{array}{l}751 \text { Australian } \\
\text { firefighters }\end{array}$ & $26 \%$ & $\begin{array}{l}\text { Impact of Events } \\
\text { Scale (IES) }\end{array}$ & $\begin{array}{l}\text { Firefighting } \\
\text { duties }\end{array}$ \\
\hline $\begin{array}{l}\text { Blake, Keane, Wine, } \\
\text { Mora, Taylor, \& Lyons, } \\
1990\end{array}$ & $\begin{array}{l}161 \text { combat } \\
\text { veterans }\end{array}$ & $24 \%$ & $\begin{array}{l}\text { Mississippi Scale } \\
\text { for Combat- } \\
\text { Related PTSD }\end{array}$ & $\begin{array}{c}\text { Seeking } \\
\text { treatment } \\
\text { post combat }\end{array}$ \\
\hline $\begin{array}{l}\text { Bovin, Marx, Weathers, } \\
\text { Gallagher, Rodriguez, } \\
\text { Schnurr, \&Keane, } 2016\end{array}$ & $\begin{array}{l}140 \text { combat } \\
\text { veterans }\end{array}$ & $58 \%$ & $\begin{array}{l}\text { PTSD Checklist } \\
\text { (PCL-5) }\end{array}$ & $\begin{array}{l}\text { Veterans } \\
\text { receiving care }\end{array}$ \\
\hline
\end{tabular}

Examining Correctional Staff. The research regarding trauma exposure and PTSD

research among correctional staff has come to the forefront in the last two decades. There have been numerous statewide studies and a very important national study examining the prevalence of PTSD and PTSD symptoms among correctional staff and in some cases, correctional officers specifically_-both within prisons and jails.

Within the United States, the rates of PTSD symptomology ranged from $7.9 \%$ among a jail staff population (Tartaglini \& Safrari, 1997) to $33.7 \%$ among a prison staff 
population (Denhof \& Spinaris, 2016). However, consistently studies have demonstrated that approximately $1 / 3$ of correctional officers suffer from PTSD symptoms (Denhof \& Spinaris, 2012; Denhof \& Spinaris, 2016; Swartz et al., 2017). Outside of the United States, the rates of PTSD symptomology vary from approximately $15 \%$ in the Netherlands (Kunst, Bogaerts, \& Winkel, 2009) to 60\% in France (Boudoukha, Altintas, Rusinek, Fantini-Hauwel, \& Hautekeete, 2013).

One of the seminal pieces regarding the prevalence of PTSD among correctional staff is a nationwide study conducted by Spinaris, Denhof, and Kellaway (2012). This study surveyed 3,599 correctional professionals and used the PTSD Checklist (PCL-5) to determine PTSD symptomology. The study found that $27 \%$ of all correctional staff in the sample experienced PTSD symptoms in the 30 days prior to the survey. Approximately $1 / 3$ of correctional officers, who work in security positions, were found to have PTSD symptoms. In a state-level study Denhof and Spinaris (2016) assessed 991 correctional professionals in Michigan. Again, this study showed approximately 1 in $3(33.7 \%)$ correctional officers met the diagnostic criteria for PTSD. Another statewide study examining correctional staff in Kentucky corroborated these statistics, finding once again that 1 in 3 correctional officers in Kentucky suffer from clinical levels of PTSD symptoms (Swartz et al., 2017). James and Todak (2018), who surveyed 355 Washington State DOC employees, also used the PCL-5 as the measure for PTSD. They found that approximately $19 \%$ of their sample met the criteria for diagnosable PTSD. As indicated above, research has consistently found that $1 / 3$ of correctional officers suffer from the symptoms of PTSD; however, the potentially relevant correlates of PTSD, among correctional staff, are still being explored. 


\section{CORRELATES AND NONCORRELATES OF PTSD}

A majority of individuals experience trauma in their lifetime, with $60.7 \%$ of men and $51.2 \%$ of women reporting at least one traumatic event (Kessler, Sonnega, Bromet, Hughes, \& Nelson, 1995). However, most individuals who experience a traumatic event do not develop PTSD symptoms or receive a PTSD diagnosis. Again, the DSM-V notes that approximate $8.7 \%$ of adults develop PTSD. Other studies have found this number to be slightly higher. The question then becomes, why do some individuals develop PTSD symptoms and others do not. The National Institute of Mental Health, known as the NIMH throughout, (2019) note that there are multiple risk factors for developing PTSD; and on the flipside, resiliency factors insulating or protecting individuals from PTSD. Risk actors, that have been identified by the NIMH, include lack of support after the traumatic event, experiencing an injury as a result of the event, previously experiencing childhood trauma, and having a history of mental illness or substance abuse. Resilience factors identified by the NIMH include having friend, family, or group support after the event, and being able to act and effectively respond despite being fearful. The NIMH also notes that employing positive coping mechanisms can act as a resiliency factor, and understanding the employment of coping mechanisms and their relationship to PTSD is the focus of the current dissertation.

Correctional officers experience more violent and traumatic events than the general public. Spinaris et al. (2012) found that $100 \%$ of their sample of correctional professionals experienced at least one violent and traumatic event. In addition to this, the national sample in Spinaris et al. (2012) reported that individuals were exposed to 28 
violent or traumatic events over the course of their career. As discussed above, with prevalence rates of PTSD among correctional officers consistently at approximately $33 \%$, first, research needs to identify the unique risk factors of the job that can explain why correctional officers are at such a higher risk of suffering from PTSD; and second, what, then, insulates the other $67 \%$ of correctional officers? Spinaris et al. (2012) found that those officers who had clinical levels of PTSD symptoms had all experienced violent and traumatic events at higher rates than those who did not have PTSD.

A small body of research has begun to explore the potential correlates of PTSD symptomology among correctional staff and just as importantly, factors that are not correlates of PTSD. For example, Swartz et al., (2017) found that common demographic factors, including age, gender, race, and education, were not correlates of PTSD symptoms among a representative sample of all institutional correctional staff in Kentucky. The results of Swartz et al. (2017) in regards to gender align with Denhof and Spinaris (2016), where gender also was not a correlate of PTSD. Further Dollard and Winefield (1998) found that age, gender, and education were not related to job strain among correctional officers.

However, this body of research has also identified several consistent and important correlates of PTSD symptomology as well. For example, the years of service working in corrections or tenure is positively associated with PTSD symptoms (Denhof \& Spinaris, 2016; Swartz et al., 2017). That is, the longer an individual works in corrections, the higher risk they are for suffering PTSD symptoms. Additionally, as mentioned previously, those who work in a security or custody position are also at a higher risk (Spinaris et al., 2012; Swartz et al., 2017), For example, Swartz et al. (2017) 
found that security staff had a prevalence rate of $34.3 \%$ and non-security staff had a prevalence was 23\%. Further, James and Todak (2018) found that officers who had higher levels of job ambiguity were also at a higher risk of developing PTSD. Swartz et al. (2017) found that there were institutional differences in relation to PTSD rates. In other words, security level had an impact on PTSD prevalence rates, and individuals who worked at maximum security facilities had the highest rates of PTSD symptoms among all the other facilities (Swartz et al., 2017). Last, and likely the most consistent and important predictor of PTSD symptomology is the number of violent and traumatic events experienced on the job. Specifically, the more exposure to trauma and violence, the more likely the officer is to suffer from PTSD symptoms (James \& Todak, 2018; Spinaris et al., 2012; Swartz et al., 2017;). Research has shown that certain violent and traumatic events have increased associations with PTSD. For example, Swartz et al. (2017) found that individuals who work at institutions where inmate on staff violence occurs, such as non-serious and serious assaults, were more likely to develop PTSD symptoms.

Though there has been research regarding mental illness among correctional staff, and PTSD among officers specifically, there is a still a lot of work to be done. In order to better understand and uncover the mystery of PTSD among correctional officers, more research must be conducted. Once PTSD is better understood among correctional officer populations, the goal becomes how to help officers do their job without suffering from the negative consequences of PTSD. One way to help officers may be to investigate their coping mechanisms and determine if they insulate an officer from developing PTSD. 


\section{CHAPTER 3: COPING}

In their book, Stress, Appraisal, and Coping, Folkman and Lazarus (1984), who are considered to be pioneers in both stress and coping research, define coping as "constantly changing cognitive and behavioral efforts to manage specific external and/or internal demands that are appraised as taxing or exceeding the resources of the person" (p. 141). Cognitive responses can include self-talk, self-blame, other-blame, focusing on planning, and acceptance (Folkman and Lazarus, 1984; Granefski et al., 2002; Lazarus, 1966). Behavioral responses include reaching out to others for support, confiding in friends, and avoiding triggers of stress (Astor-Dubin \& Hammen, 1984; Folkman \& Lazarus, 1984; Lazarus, 1966). Research about how individuals cope with a myriad of events and situations has been steadily explored since the mid-1900s. However, even after decades of research on coping mechanisms, the ways in which coping mechanisms are measured, the terminology used, the theories of coping, and the categorization of coping mechanisms vary greatly. For example, regarding the categorization of coping mechanisms the literature speaks to problem-focused coping or emotion-focused coping (Folkman \& Lazarus, 1984). These terms are also known as active coping or passive coping styles. Still, more types of coping styles exist, including approach and avoidancestyle measures of coping. The remainder of the chapter focuses on unpacking these variations with the coping literature and provides a foundational understanding of coping as it relates to the current study. 


\section{ORIGINS OF COPING RESEARCH}

The current section focuses on the origins of coping research. Specifically, the works of Selye and Lazarus, who are considered to be seminal coping researchers, are outlines. The main theories of stress and coping are presented. The origins of stress and coping research is attributed to the work of Hans Selye (1956; 1978). Selye is a Canadian endocrinologist who began to study stress within the body. Selye introduced stress as a psychological response pattern which was captured within his general adaption syndrome (GAS) model (Selye, 1956). The GAS model contains three concepts surrounding stress. First, stress is a defense mechanism. Second, Selye notes that stress includes three stages: alarm, resistance, and exhaustion. The alarm stage, when met with noxious stimuli, is what pushes the sympathetic nervous system to either fight the stressor or avoid it. However, the alarm reaction is not the entire response. Selye notes that a living organism cannot live in a state of constant alarm, and that if they try to, they will die within the first days. In order to survive, humans must push into the resistance stage. In the resistance stage, the fight or flight instinct pushes individuals to either push through the stressor or ignore the stressor. Finally, and most seriously, Selye's model states that if the stress is severe enough, or occurs over a long period of time, it can cause diseases of adaptation such as chronic high blood pressure and heart attacks (Selye, 1956). This is also known as the exhaustion stage. In some instances, the body's reaction to stress can be so severe and chronic that it can cause death. Selye provided a foundation for subsequent stress and coping research.

In 1966, Lazarus wrote Psychological Stress and the Coping Process. Lazarus

developed the transactional theory of stress and coping (TTSC). The TTSC posits stress 
as the product of a transaction. The transaction is between an individual and their multiple bodily systems including: the cognitive, affective, neurological, psychological, and physiological systems, and the individual's environment. Rather than a singular trait, Lazarus (1966) argues that stress and coping are a process. This process contains four stages beginning with the stressor, followed by the primary appraisal. Within the primary appraisal stage, the individual determines one of three options. The first is whether the encounter has any significance for them. Second, if it does have significance, is it a benign-positive encounter? In other words, is it desirable to the individual? The last determination is whether the encounter is harmful, threatening, or challenging to the individual. After the passing of the primary appraisal, if the individual determines to have a stake in the encounter, there is the secondary appraisal. During the secondary appraisal, the individual begins to assess their access to either coping strategies or resources to address the perceived threat or challenge of the stressor. Within the secondary appraisal, the individual can evaluate both their internal and external options. Internal options include concepts such as inner strength and will power. External options include the use of social support and seeking professional help with the situation. It is also during the secondary appraisal that the individual determines whether they are experiencing positive stress, also called eustress, or negative stress. The final stage of the process is executing a coping response that was made available during the secondary appraisal. (Carver, Scheier, \& Weintraub, 1989; Folkman \& Lazarus, 1984; Lazarus, 1966).

Lazarus and his colleagues believed that coping strategies fall into two categories: problem-focused coping and emotion-focused coping (Folkman \& Lazarus, 1984). Problem-focused coping is often used when the individual feels they have some 
sense of control over the situation. Possible coping responses that fall into this category include making a plan of action, defining and exploring the problem, and coming up with strategies to attack the problem. However, emotion-focused coping is used when individuals feel that they have little to no control over the present situation. With emotion-focused coping, individuals are likely to have coping responses such as avoidance, acceptance, seeking emotional support, and focusing on and venting emotions. Though there are multiple types of coping mechanisms, with emotion-focused and problem-focused being popular categories, there are many different ways that coping is operationalized. The next section focuses on details surrounding how coping is measured, including the beliefs that coping can be dynamic or stable.

\section{OPERATIONALIZING COPING}

As coping becomes more widely studied, researchers have created different ways of measuring how individuals cope, what coping mechanisms they use, and to what degree coping strategies affect other parts of individuals' daily lives, with debate over whether coping is dynamic or stable across an individual's life course.

Coping is Dynamic. The issue as to whether coping is dynamic or stable is especially relevant to the current study because depending on the outcome, correctional officers may need to learn adaptive coping mechanisms to better insulate themselves against the hardships of the job. If coping is dynamic, as the research in this section suggests, learning coping mechanisms is much easier. If coping is stable, as the research in the next section argues, then coping is more closely tied to personality and therefore it can be harder for officers to unlearn their maladaptive coping mechanisms that possibly 
predetermine them to have negative consequences as a reaction to stress. The first camp argues that coping is dynamic. It is believed that individuals, when under stress, view each encounter as unique and then react with their coping responses. In fact, Neufeld (1999) outlines five different models of dynamical systems of coping. While referred to by many different names across researchers, the interdependent model focuses on the process of stress and how the coping indirectly affects negative stimuli. This model argues that coping does not necessarily buffer the negative stimuli directly, but instead minimizes the elevation of the negative stimuli. (DeLongis, Lazarus, \& Folkman, 1988; Folkman, Lazarus, Gruen, \& DeLongis, 1986; Gruen, Folkman, \& Lazarus, 1988; Lazarus, Deese, \& Osler, 1952; Pearlin, Menaghan, Lieberman, \& Mullan, 1981). Next, in the dynamic attribute model, the system dimensions are defined in the terms of their rates of change at each point in time (Caplan, 1983; Lazarus, 1990; McGrath \& Beehr, 1990; Neufeld, 1999). In other words, the dynamic model is also about the process of stress and coping. It argues that coping cannot come before stress, and beyond that, stress cannot come without a stressor. Third, is the process like attribute model (Cohen \& Edwards, 1989; Lazarus, 1966; Lehman, 1972). The process like attribute says that each system dimension is always changing and remains in a state of flux. The fourth model, adaptational attributes, argues that the system dimensions are responsive to one another, and that they are accommodating to the behaviors of other system dimensions (Lazarus, 1990; Lazarus \& Folkman, 1984). Finally, the fifth, recursive attribute notes that differential equations composing a dynamic system involve functions related to their own values (Lazarus, DeLongis, Folkman \& Gruen, 1985; Lazarus \& Folkman, 1987). In other words, recursion deals with a repeating pattern (Neufeld, 1999). 
If coping is dynamic, then individuals can learn new ways of coping depending on multiple factors. These factors can be situational, such as the type of stressor being experienced. Other factors include whether the stressor comes from home or from work, who is involved, and how the individual perceives they are able to handle the stressor. The response to the stressor, which is the coping, is completely unique to the situation and the individual, meaning it could be changed. The idea that coping is dynamic gives hope to the idea that if individuals suffer because of their use of maladaptive coping mechanism, such as drug use, that they can learn to cope in healthier ways.

Coping is Stable. The second viewpoint of coping is that individuals are predisposed based on their personality to react a certain way to any stressor, which removes the dynamic aspect of coping. In other words, those who adhere to the second argument believe that people will only cope in their predetermined ways. At one point in time, coping and personality were even considered to be one in the same (Suls \& David, 1996). Today, while not seen as one in the same, coping and personality are still argued to be highly interconnected. One way that coping has been studied with personality is through the Big Five model (Costa \& McCrae, 1985). According to the Big Five model, there are five basic personality types that include neuroticism, extroversion, openness, agreeableness, and conscientiousness. There have been multiple studies that have shown that each personality type seems to be associated with particular coping types (McCrae \& Costa, 1986; O’Brien \& DeLongis, 1996; Watson \& Hubbard, 1996).

For example, individuals who score high on the neuroticism have been found to be less likely to use problem-focused coping strategies. These individuals tend to cope by 
using emotion-focused mechanisms, such as mental and behavioral disengagement, venting or emotion, and self-blame. People who tend to be neurotic also tend to not cope by means of positive appraisal and seeking social support (McCrae, 1992). Individuals who are described as fun, warm, sociable, and assertive are known as extroverts. Those who score high on extroversion tend to use problem-focused coping by seeking social support (O’Brien \& DeLongis, 1996; Watson \& Hubbard, 1996) and through positive reappraisal (McCrae \& Costa, 1986) more so than the neurotics.

Conscientious individuals tend to be hardworking and trustworthy. They are also known for being reliable. They have been found to use problem-focused coping mechanisms. Planning and suppression of activities that could take away focus from the problem at hand are often used. Conscientiousness is also associated with the lack of use of emotion-focused coping (Hooker et al., 1994; Watson \& Hubbard, 1996).

Those who fall under the agreeableness personality are often trusting, harmonious, and helpful (Bishop, Ton, Diong, Enkelmann, Why, Khader, \& Ang, 2001). Agreeable personality types have been shown to seek social support when under stress (Hooker et al., 1994). However, they tend to utilize emotion-based coping mechanisms more than problem-focused coping. Finally, those who are considered to be of the openness personality are seen has creative, receptive to ideas and feelings, and flexible (Bishop et al., 2001). The research surrounding the openness personality is mixed because many of the traditional coping skills have not been designed to measure coping mechanisms that tap being open. What little research there is shows that open individuals are more likely to use humor and emotion-focused coping (McCrae \& Costa, 1986). 
If coping is determined to be stable, similar to personality, then changing one's coping mechanisms may not be possible, or at the very least, difficult. Or if coping and personality are highly correlated, because of one's personality, the individual may be more predisposed to certain types of coping and more or less resistant to modifying their coping repertoire. The extent to which coping is stable could cause issues for programming and policy implementation because if the mechanisms cannot be changed, there is no use for programming to try and change them. Here, individuals are predetermined to cope in only the ways that fit their personality. In order to determine how individuals cope, regardless of whether coping is dynamic or stable, many different assessments have been created, tested, and validated. The next section focuses on a number of prominent coping scales.

\section{MEASUREMENTS}

Because stress and coping have been studied for decades, multiple assessments measuring how individuals cope with stress have been developed. Researchers have developed their assessments in a number of ways, including observing how individuals cope and how theories of stress propose individuals should cope with stress. Seven of the major assessments are discussed below. The items on these assessments range from 4 questions to 68 questions. The following assessments are presented in chronological order to show the progression of the measurement of coping over time.

Ways of Coping Checklist. In 1980, Folkman and Lazarus created the Ways of Coping Checklist (WCCL), which is also called the Ways of Coping Scale (Rexrode, Peterson, \& 
O’Toole, 2008) and the Ways of Coping Questionnaire (Scherer et al., 1988). The checklist contains 68 items. These 68 items seek to understand the range of behavioral and cognitive coping strategies that the participant uses when they endure stress. The WCCL has a binary response system, in which the participant will answer "yes" or "no" with a specific stressful event in mind. In the WCCL, the items are broken into two types of coping strategies: emotion focused and problem focused. As previously mentioned, emotion-focused strategies seek to ameliorate or manage the emotional distress the individual is experiencing. Folkman and Lazarus (1980) give examples such as "looked for a silver lining," "tried to forget the whole thing," and "accepted sympathy and understanding from someone." On the other hand, problem-focused strategies refer to strategies using cognitive problem-solving skills and behavioral skills to change or manage the origin of the stress. Examples of problem-focused items are "made a plan of action and followed it," "got the person responsible to change his or her mind," and “stood your ground and fought for what you wanted" (Folkman \& Lazarus, 1980).

Ways of Coping Checklist-Revised (WCC-R). However, in 1985, Folkman and Lazarus revised the WCCL. In a natural experiment, Folkman and Lazarus (1985) examined students' emotions and coping regarding their examinations at three separate timepoints. They analyzed students when the test was announced, after the exam but before grades were posted, and then a third time after grades were posted. It was in this study that Folkman and Lazarus used the revised Ways of Coping Checklist. There were multiple changes from the original WCCL. Specifically, they removed items that they had deemed to be repetitive or confusing to the participants, which left the checklist with 
66 items instead of its original 68. In addition to removing two items, the WWCL-R removed the binary response system. In its place, Folkman and Lazarus used a 4-point Likert scale where $0=$ "does not apply and/or not used," $1=$ "used somewhat," $2=$ "used quite a bit," and 3= "used a great deal."

In their seminal study, Folkman and Lazarus (1985) also eliminated 9 items due to their high skewness and restricted variance. After factor analysis, there were eight scales remaining - six emotion-focused scales, one problem-focused scale, and one scale that contained both problem- and emotion-focused items. The problem-focused scale includes items such as "I try to analyze the problem in order to understand it better" and "I'm making a plan of action and following it." The six emotion-focused scales include wishful thinking ("Wish that I can change what is happening or how I feel"), distancing ("Try to forget the whole thing"), emphasizing the positive ("I'm changing or growing as a person in a good way"), self-blame (“Criticize or lecture myself”), tension-reduction, ("I jog or exercise") and self-isolation ("Keep others from knowing how bad things are"). The final scale is the mixed problem- and emotion-focused scale and contains items such as "Accept sympathy and understanding from someone" (Folkman \& Lazarus, 1985; Vitaliano et al., 1985).

Coping Orientation to Problems Experienced (COPE). In 1989, Carver, Scheier, and Weintraub developed another scale for measuring coping strategies. The development of this scale came as a response to what Carver et al. (1989) believed to be problems with previous coping scales. The first problem identified by Carver and colleagues (1989) was that while previous measures were diverse, they did not sample specific domains of 
theoretical interest. Carver argues that previous scales had been developed empirically and not theoretically. Second, Carver felt that some of the items in pre-existing scales were ambiguous and that this ambiguity would cloud results and increase the lack of clarity surrounding coping. An example of this ambiguity is an item in the WCC that says "I did something which I didn't think would work but at least I was doing something." Carver et al. (1989) argues that this is vague because the researcher will not know what is more important in the response, whether the individual did something or that they did not think it was going to work. The measurement he and his colleagues developed, called the Coping Orientation to Problems Experienced (COPE) Inventory, was developed specifically with theory development in mind.

The COPE Inventory consists of 13 subscales. Carver et al. (1989) included scales based on theory, as well as, scales that had previously been of value or impact coping one way or another. Some of the 13 scales include items such as, active coping, planning, denial, acceptance, use of humor, and behavioral disengagement. This inventory asks respondents to keep items separate from one another when answering and to indicate what they would do when confronted with stressful situations. The response choices ranged from: "I don't usually do this at all" = 1, "I usually do this a little bit" = 2, "I usually do this a medium amount" $=3$, and "I usually do this a lot" $=4$. Carver and colleagues gave the COPE to 978 undergraduate students to explore factor loadings and test-retest reliabilities. The original factor analysis found that 12 of the 13 scales had eigenvalues greater than 1.0. Interestingly, the items for active coping and the items for planning loaded on the same factor. Carver notes that the Cronbach's alphas were acceptable, where only one fell below .6, which was the mental disengagement scale. The 
COPE Inventory has since been updated to reflect what was found in analyses. There are now considered to be 15 scales of four items for a total of 60 items within the scale.

Brief COPE. In addition to developing COPE, Carver also developed an abbreviated version called Brief COPE. (Carver, 1997). This measure contains 14 subscales that contain two items, for a total of 28 items. This measure contains the same instructions that are given in the original COPE. The response scale varies slightly from the original COPE and ranges from "I haven't been doing this at all" = 1, "I have been doing this a little bit" = 2, "I have been doing this a medium amount" $=3$, and "I have been doing this a lot" $=4$. The development of this scale is in part due to the extensive nature of the original COPE. Carver noticed respondents becoming increasingly frustrated with both the repetitiveness and the length of his original measure. Therefore, he cut the number of subscales and reduced the redundancy of the items. Carver, when using data from the assessment, found that the items and subscales were within acceptable levels of reliability. He concludes that the Brief COPE is a suitable measure for researchers who are looking to cut down on their number of items due to respondent disengagement.

Proactive Coping Inventory. In 1999, Greenglass and colleagues presented a paper outlining their new instrument for measuring coping called the Proactive Coping Inventory (PCI). The PCI is based on the idea that coping is multidimensional and is present on multiple levels within an individual. These levels include both the cognitive and behavioral level. Individuals who score highly on the PCI are considered to be proactive. Schwarzer (1999b) identifies proactive people as those who are resourceful, 
responsible, and principled. Not all individuals will have the proactive belief system necessary to score high on the PCI. Greenglass et al. (1999) argues that there are two elements that are necessary to have the proactive belief system. First, a proactive individual's life course is determined by their own factors. They do not bow to external factors for their life. Second, the proactive individual is determined to have copious resources. When an individual embodies these elements, they are more likely to score highly on the PCI. At the same time, if an individual is weakened by external forces in their life, they are more likely to score lower on the PCI. Being a proactive individual means that the person is more likely to see trouble ahead and take active steps to prevent the trouble. Individuals can detect potential stressors and can manipulate their environment to ease the distress that they may cause. Individuals who are determined to be less proactive do not have these same skills; and therefore, are unable to navigate around their potential stressors (Greenglass et al., 1999).

The PCI consists of 55 items. Similar to previous coping instruments, the PCI has a scale of one to four, "Not true at all" (1), "barely true" (2), "somewhat true" (3), and "Completely true" (4). There are seven subscales used to measure the different proactive approaches to coping. The subscales include proactive coping, preventive coping, reflective coping, strategic planning, instrumental support seeking, emotional support seeking, and avoidance coping. Greenglass et al. (1999) conducted their study using the PCI with 252 college students in Canada. The PCI was found to be reliable within the sample tested. 
Brief Resilient Coping Scale. Perhaps one of the shortest instruments used to measure coping is the Brief Resilient Coping Scale (BCRS) developed by Sinclair and Wallston (2004). This instrument contains only four items. The four items are: "I look for creative ways to alter difficult situations," "Regardless of what happens to me, I believe I can control my reaction to it," "I believe I can grow in positive ways by dealing with difficult situations," and "I actively look for ways to replace the losses I encounter in life." The response options range from "Does not describe me at all" (1) to "Describes me very well" (5). The scores of the four previous items are then added together to produce the resilient coping item in which the highest score is 20 and the lowest score is 4 . High scores, usually ranging from 17-20 indicate the respondent is highly resilient when it comes to coping. Lower scores, generally from 4-13, indicate the respondent is not very resilient when it comes to coping. Much like with the PCI, Sinclair and Wallston (2004) argue there are characteristics individuals who are considered resilient possess, including being goal directed, believing in their ability to overcome adversity, and succeeding when challenged.

Coping Self-Efficacy Scale. Chesney et al. (2006) created the Coping Self-Efficacy Scale (CSE). The CSE Scale was designed to measure an individual's confidence in their coping mechanisms during stressful life events and challenges. While originally used with populations such as patients with acquired immunodeficiency syndrome (AIDS), other researchers have used the CSE Scale with different populations such as athletes (Nicholls, Polman, \& Levy, 2010) and victims of domestic terrorism (Benight, Freyaldenhoven, Hughes, Ruiz, Zoschke, \& Lovallo, 2000). The CSE Scale is made up of 
26 items. Respondents are given the following statement and then asked to rate their ability to perform the item: "When things aren't going well for you, or when you're having problems, how confident are you that you can do the following." Two examples of items include: "make unpleasant thoughts go away" and "do something positive for yourself when you are feeling discouraged." Responses range from "Cannot do at all" (0) to "Certain I can do" (10). When scoring, the final score is found by summing the response for each measure. The higher an individual's score is, the higher level of selfefficacy they have when it comes to using their positive coping strategies. On the other hand, individuals with lower scores have lower amounts of self-efficacy when it comes to their coping strategies.

While the previous list of coping assessments is not exhaustive, they have been used to study multiple populations including students, clinical populations, community populations, victims of natural disasters, terroristic acts, car accidents, domestic violence and individuals who are classified as first responders.

\section{COPING AND MENTAL HEALTH OUTCOMES}

It has been established that increasing amounts of stress have an effect on an individual's mental and physical health. Though not as heavily researched as stress, there is a body of literature dedicated to exploring coping and its effects on various physical and mental health outcomes such as overall well-being, PTSD, depression, and anxiety. Research has shown that using positive or adaptive coping mechanisms is related to better physical and mental health (Moskowitz et al., 2009; Roesch et al., 2005). The same research has also determined that utilizing negative or maladaptive coping can lead to 
negative outcomes (Moskowitz et al., 2009; Roesch et al., 2005). Coping, therefore, has been shown to have a relationship with mental health and physical health. The coming sections further details how coping is related to various mental health outcomes such as depression, anxiety, and PTSD.

Coping and depression. Depression can be the result of many factors, including imbalances in brain chemicals to major life events. Although major life events can often be a catalyst for a depressive episode, there are some who do not develop depression after said events, which indicates the presence of other factors such as event characteristics and individual characteristics such as personality and coping mechanisms influence whether an individual experiences depression. A study on women who had never been depressed before found that rumination and other maladaptive coping mechanisms, such as intrusive thoughts, emotional numbing, and escape, were related to depressive symptoms (Thompson et al., 2010).

Another study examining both school teachers and military spouses found of those who were depressed were using more maladaptive coping mechanisms, such as venting, behavioral disengagement and self-blame, than adaptive coping mechanisms (Faulk et al., 2013). Padden et al. (2011), which also focused on military spouses and depression, found that those spouses who utilized venting, a maladaptive coping mechanism, have overall decreased physical and mental health). Faulk et al. (2013) notes that this increase in venting among military spouses could be related to their elevated rates of depression, which is three times the rate of depression in the general population (Mansfield et al., 2010; Padden et al., 2011). Therefore, it is established that maladaptive 
coping mechanisms can place an individual at a higher risk for depression. It has also been found that adaptive coping mechanisms may mitigate the effects of depression on an individual. Kolchakian and Sears (1999) found that optimism and social support were correlated with depression, in that as optimism and social support use increased, depressive symptoms decreased within the sample. Another study found that thinking positive decreased depressive symptoms three days post-rape, and that withdrawing from others, in other words not utilizing social support, increased the likelihood of depressive symptoms (Fraizer \& Burnett, 1994). The current section has focused on coping mechanisms and their relationship to depression. As shown above, the research is fairly consistent in finding that negative or maladaptive coping mechanisms increase depression symptoms among those who have never been depressed before and those who have experienced a major life event (Billings \& Moos, 1981). The next section focuses on coping and its association with anxiety.

Coping and anxiety. Most individuals feel anxious and worry from time to time, and how one copes with that anxiousness can have an impact on the intensity of anxious feelings. The current section focuses on how certain coping mechanisms interact with anxiety. In a study of college students after the terrorist attacks on September $11^{\text {th }}, 2001$, Liverant et al. (2004) found that maladaptive coping strategies were a predictor of initial anxiety at two months after the attacks. These maladaptive coping strategies included denial, behavioral disengagement, and venting of emotions.

Another maladaptive coping mechanism that has been negatively associated with anxiety is mental disengagement. In a study examining nursing students during the 
Covid-19 pandemic, Savitsky et al. (2020) found that students who utilized mental disengagement had higher levels of anxiety. Coincidentally, nursing students who used humor had significantly lower levels of anxiety. Therefore, it can be shown that positive or adaptive coping mechanisms can insulate individuals from anxiety. In a study on chronic illness, lupus, Auerbach, Beckerman, and Blanco (2013) found that women who used instrumental social support were less likely to experience anxious symptoms. Though the literature surrounding coping and anxiety is not as comprehensive as that of coping and depression, the research continues to show that individuals who engage in maladaptive coping mechanisms are more likely to suffer from increased negative consequences of anxiety. The next section focuses on the research that has been done regarding coping and its association with PTSD and PTSD symptom severity.

Coping and PTSD. The research regarding PTSD and coping has spanned multiple populations including individuals who have severe mental illness, abused and assaulted women, those in traffic accidents, current military members, veterans, and other first responders. Because a majority of individuals experience a traumatic event in their lifetime, how one copes with trauma, and PTSD, has been at the forefront of the coping literature. For example, in a study examining severe mental illness and comorbid PTSD, McNeill and Galovski (2015) found that individuals who reported increases in avoidance style coping mechanisms were more likely to experience PTSD. This is unsurprising, as maladaptive coping mechanisms have been found to cause increased levels of psychological distress (McNeill \& Galovski, 2015). In a study looking at victims of 
traffic accidents, it was found that individuals who utilized emotion-focused coping after the accident had higher levels of trauma later on (Jeavons et al., 2000). Another study examining trauma-exposed adults in Korea found that individuals who are able to use both emotion-focused and problem-focused coping in a flexible manner had less PTSD symptoms (Park, Chang \& You, 2015).

First responders have been long studied in the trauma literature due to their increased exposure to violent and traumatic events. Firefighters, police officers, and current and veteran military personnel have all been studied. Lee, Park, and Sim (2018) compared coping mechanisms between a sample of 212 firefighters and the general population in South Korea. They found that firefighters who used problem-focused coping showed fewer posttraumatic stress symptoms (PTSS) (Lee et al., 2018). In another study looking at firefighters, Chamberlain and Green (2010) found that seeking instrumental social support or practical support from others predicted lower PTSD.

Police officers are one of the more heavily studied first responder populations. Kirmeyer and Diamond (1985) sought to examine police officer stress and how they cope based on their behavior patterns. They specifically examined Type A behavior patterns and Type B behavior patterns. Type A people are characterized by three basic dimensions: hostility-aggression, impatience, and achievement-striving (Kirmeyer \& Diamond, 1985). Type B people, on the other hand, have more relaxed, non-competitive, and patient behavior types. The hypothesis was that individuals who were Type A were going to choose more focused and problem-solving types of coping mechanisms and Type B individuals would not react in this way. Kirmeyer and Diamond (1985) found their hypothesis to be true, in that Type A people do employ coping mechanisms that are 
focused on the problem. They also found that Type B individuals were more likely to intentionally act in a slower manner to appraise the entire situation, while also maintaining emotional distance. While Kirmeyer and Diamond (1985) focused on the personality of police officers, Aaron (2000) found generally that it may not be the stressors that cause problems with officers but instead the coping mechanisms utilized. He found that officers who utilized avoidant style coping mechanisms had increased psychological distress.

Among military personnel, research has found that avoidant coping is associated with more negative outcomes, while active coping is associated with more positive outcomes. Khazem et al. (2015) worked with an active duty population and studied the relationship between coping mechanisms and suicidal desire. Using the Brief COPE to uncover coping mechanisms and the Beck Scale for Suicidal Ideation, the authors determined that maladaptive coping mechanisms, such as denial, substance use, and selfblame, were the only set of mechanisms that predicted suicidal ideation among active military personnel (Khazem et al., 2015). Boden et al. (2012) found that as active coping among military veterans increased and avoidant coping decreased, PTSD symptoms incrementally decreased. Witvliet et al., (2004), which is also mentioned above, also found that negative religious coping was related to increased PTSD symptoms among veterans.

First responders, such as firefighters, police officers, and military have been studied extensively. These occupations are what first comes to mind when one thinks of first responders. One population that does not often come to mind, but meet the definition of first responder are correctional officers. Correctional officer coping had not been 
extensively studied. The research that has been conducted however, will be discussed in the following section.

\section{COPING AND CORRECTIONAL STAFF}

In rather recent years, there has been a new interest in understanding how correctional staff are affected by their job, more specifically how the job affects their mental and physical health. Much of this body of research has focused on the prevalence of and factors associated with posttraumatic stress disorder (PTSD). While studying PTSD has become more of a focus in the correctional literature, the mechanisms through which correctional staff cope and how these coping mechanisms affect PTSD, among other mental health issues, has yet to be explored. As demonstrated in the previous section, coping research has largely been studied in the wake of a singular traumatic event, such as an accident, natural disaster, or terrorist occurrence. Recently, there has been an increased emphasis on studying chronically traumatic jobs such as emergency medical technicians and paramedics, firefighters, and police officers. Lacking in the literature, however, are the effects of repeated or chronic trauma and coping among correctional staff. Traditionally, research has focused on the negative work outcomes of extended stresses including job burnout and low job satisfaction (Dignam, Barrera, \& West, 1986; Carlson, Anson, \& Thomas, 2003; Lambert, Altheimer, \& Hogan, 2006). There are less than a handful of studies that directly examine correctional officer stress (Lambert, Hogan, \& Allen, 2006; Lambert, Hogan, \& Tucker, 2009; Lambert et al., 2020 Owen, 2006;).

Lambert, Hogan, and Allen (2006) sought to examine the correlates of correctional officer job stress, with specific interest of the impact of organizational 
structure. The results indicated that correctional staff suffer from greater stress when they do not have control over everyday matters. Lambert and colleagues also found that being a supervisor also contributed to higher rates of stress. Owen (2006) explored the occupational stressors that correctional supervisors face. He found that when supervisors report high job satisfaction, high levels of social support, and an internal locus of control, they experience lower levels of stress. He notes that because this sample explores only supervisors, it will differ than studies that include line officers, who are more likely to feel the environmental and organizational stressors. This does not mean that supervisors do not feel stress. As one officer said "I'm supervising paperwork versus people." (Owen, 2006). The stressors of officers and the stressors of supervisors can be different. Lambert, Hogan, and Tucker (2009) explored correlates of role stress among correctional staff. Role stress is also known as role strain and can include vague, ill-defined duties that cause stress for the officer. Lambert et al. (2009) found that role stress is decreased when individuals are able to have input into decision making and have instrumental communication. They also discovered that individuals who see their supervisors as encouraging and accessible reported less role stress. Therefore, officers who have disingenuous supervisors often report higher rates of role stress. Most recently, Lambert et al. (2020) found that individuals who have input in decision making and had high quality supervision were less likely to report job stress. However, role overload and fear of victimization both increased job stress among this officer sample.

To date there has been no research seeking to understand the relationships between correctional staff's coping skills and their likelihood of having or developing PTSD symptoms. Additionally, there are no studies that examine coping with specific 
types of stress including occupational or role stress. Finally, there are no identified studies that use coping to moderate the relationship between violent and traumatic events experienced and the development of PTSD symptoms. This is the basis of the current dissertation. 


\section{RESEARCH QUESTIONS}

There are multiple main research questions for the current dissertation. They are as follows:

RQ1: Are problem-focused coping mechanisms associated with the number of PTSD symptoms experienced by correctional officers?

RQ2: Are emotion-focused coping mechanisms associated with the number of PTSD symptoms experienced by correctional officers?

RQ3: Do the problem-focused coping mechanisms that are associated with PTSD symptoms moderate the relationship between the amount of trauma/violence exposure and PTSD symptoms?

RQ4: Do the emotion-focused coping mechanisms that are associated with PTSD symptoms moderate the relationship between the amount of trauma/violence exposure and PTSD symptoms? 


\section{CHAPTER 4. METHODOLOGY}

\section{BACKGROUND}

The previous chapters illustrate the need for further examination into how correctional officers cope with the stress of the job and how various coping techniques may either insulate or place an officer at a higher risk for suffering from PTSD. While, strides have been made to better understand the major stressors that correctional officers endure when they work in an institution and some of the consequences of these stressors, many unanswered questions remain. By examining the association between PTSD, coping mechanisms, and experiencing violence and trauma, the current dissertation seeks to expand the knowledge regarding correctional officers and their ability to insulate themselves from the negative effects of the difficult nature of their job. This chapter presents information regarding data collection, research methods, measures, and analysis plan for the current study.

In 2015, Dr. Kristin Swartz of the University of Louisville and the Kentucky Department of Corrections (KYDOC) conducted a statewide study to ascertain the prevalence of PTSD among their staff working within their state adult correctional institutions. This study sampled over 700 correctional staff including security, program, administrative, and medical personnel. The results of the 2015 study showed that approximately $30 \%$ of all correctional staff suffered from clinical levels of PTSD symptoms. This finding holds consistent with other studies that have explored the 
prevalence of PTSD among correctional staff (for examples, see, Denhof \& Spinaris, 2016; Spinaris et al. 2012).

Now understanding the pervasiveness of PTSD among correctional staff, Swartz et al. (2017) recommended further investigation into what a department of corrections can do to help reduce the negative impacts of stress and trauma from the job on staff's mental and physical health, including PTSD. In partnership, KYDOC and Dr. Swartz applied for a National Institute of Justice (NIJ) grant titled: “Effects of MindfulnessBased Stress Reduction in Correctional Officers: A Biopsychosocial Approach, to explore whether a mindfulness-based stress reduction intervention, designed specifically for correctional officers, could reduce various biological, psychological, and sociological measures of stress, with PTSD being only one of many measures of stress. The NIJ grant was awarded in January of 2018 and the data for the current dissertation comes from the large amount of survey data collected for this project.

The following section outlines the data used within the current analysis including details regarding the sample. Next, there is an explanation of the dependent variable: the measure of PTSD symptomology among correctional officers. Then, the independent variables are explained including the coping subscales from Carver et al. (1989), followed by the control variables. Finally, the analysis plan is presented.

\section{Sample}

\section{DATA}

The current dissertation contains data collected from approximately 245 correctional officers. Officers from seven of Kentucky's adult correctional facilities were randomly selected to participate. The institutions include: Eastern Kentucky Correctional Complex (minimum/medium security), Kentucky State Penitentiary (maximum security), 
Kentucky State Reformatory (medium security), Little Sandy Correctional Complex (medium/maximum security), Luther Luckett Correctional Complex (minimum/medium security), Northpoint Training Center (medium security), and Western Kentucky Correctional Complex (medium security). Complete data, which included three collection time points, were collected from six of the seven listed institutions. Only preintervention data was collected at the seventh institution. Data collection began in fall of 2018 and was abruptly concluded due to the emergence of the novel Coronavirus (COVID-19) in spring of 2020. At this point in time, the mindfulness intervention was being delivered to half of the participants from the seventh data collection site.

The above institutions were chosen based on recommendations from Swartz et al. (2017). Swartz's research team collected data from every state prison in Kentucky; and from this data, the researchers were able to determine which facilities had the highest rates of PTSD symptomology. While Swartz's original study focused on all correctional staff, the current study examined specifically correctional officers, which includes security staff at many ranks--officers, sergeants, lieutenants, and captains. The principal investigator chose to focus this study on security staff, because officers were more likely to suffer from PTSD than program staff. Overall, program staff had a PTSD prevalence between $26 \%$ and $27 \%$, while approximately $34 \%$ of security staff were experiencing PTSD symptoms. Due to monetary and personnel limitations, the principal investigator chose to focus this study on the population that suffered from the highest rates of PTSD - uniformed correctional staff and at those facilities that suffered from the highest prevalence of PTSD. Therefore, it was determined that officers would be randomly selected to participate at the facilities with the highest PTSD prevalence rates. Prior to 
arriving at the institution, the principal investigator received a list of all security staff and a percentage of the staff were randomly selected to hear the study proposal and were invited to participate. Those who chose to participate, signed an informed consent and gave basic demographic information such as hand dominance, gender, height, weight, and shift information to the research assistants. This information was needed to prepare the actigraphy watches and additional research materials. Individuals were then randomly assigned to the experimental or control group. All individuals, regardless of assignments, were asked to complete surveys at three separate timepoints including preintervention, postintervention, and a four-month follow up, with the four-month follow up being six months after the preintervention survey. Again, the survey data includes responses from approximately 245 correctional officers from seven Kentucky prisons.

\section{Survey}

The survey was designed by the researchers and includes multiple scales and assessments - some of which were created specifically for this study and many of which were pre-existing validated scales or assessments. The survey was administered to security staff while on shift and surveys were completed in the presence of the researchers. The main survey, at the preintervention phase, was an extremely comprehensive survey which took the officers approximately 90 minutes to complete and included questions regarding: demographics, work-life balance, mental health, and multiple assessments regarding stress and PTSD. These assessments included job satisfaction, job burnout, emotionality, personality, perceived stress, coping, and exposure to violent and traumatic events. The survey packet also included a brief medical history survey to aid in the interpretation of the biological data. The final piece of the 
preintervention survey was the Trauma Symptom Inventory-2 (TSI-2), which provides one of the dependent variables for the current dissertation. After survey completion, the data therein was entered into SPSS for analysis by the researcher. Data was then cleaned and checked at random by someone who had not entered any data into the SPSS file to ensure accuracy.

\section{Measures of Variables}

Dependent Variables. There were two PTSD scales completed by the

participants. They completed the Trauma Symptom Inventory 2 (TSI-2) PTSD symptoms

Checklist (PCL-5). The TSI-2 was created by John Briere in 2011 and has been validated across multiple populations. The assessment asked respondents to frame their responses within the time frame of the previous six months. The TSI- 2 is one of the most popular assessments to measure PTSD symptoms because it only requires a $5^{\text {th }}$ grade reading level, can be given in a group setting, and can be administered with or without a clinical psychologist (Elhai, Gary, Kashdan, \& Franklin, 2005). The TSI-2 is unique in that it also includes a scale to determine if the respondent is exaggerating or downplaying their symptoms. While the TSI-2 is a not a diagnostic tool, the assessment does have a very high predictive validity. Approximately $91 \%$ of patients who take the TSI- 2 and are found to have clinical levels of PTSD symptoms who then visit a clinician are diagnosed with PTSD (Briere, Elliott, Harris \& Cotman, 1995; Edens, Otto, \& Dwyer, 1998).

The TSI-2 has 136 items that measure anxiety, depression, suicidality and PTSD symptomology. Briere (2011) named the PTSD measure of the TSI-2 the TRAUMA factor. The TRAUMA factor is the dependent variable for the current analysis. The TRAUMA factor includes four separate scales that make up the different requirements for the PTSD diagnosis. They are anxious arousal (AA), intrusive experiences (IE), 
defensive avoidance (DA), and dissociation (DIS). There are two additional subscales known as anxious arousal-anxiety and anxious arousal-hyperarousal and they comprise the anxious arousal (AA) scale. The separate scales that make up Briere's TRAUMA factor directly parallel the definition of posttraumatic stress disorder as outlined by the Diagnostic and Statistical Manual.

The anxious arousal (AA) scale is designed to show the respondent's level of anxiety symptoms. These symptoms can be mental and physical including fears, panic, tension and jumpiness. Briere notes that elevated AA scores have been found in those who have been assaulted or exposed to serious accidents. The first of the AA subscales is anxious arousal-anxiety (AA-A). This subscale focuses on measuring worrying, irrational fears, nervousness and fears surrounding death or injury. Briere does not state that AA-A parallels a specific criterion within the DSM-V diagnosis. The second subscale, anxious arousal-hyperarousal (AA-H), measures symptoms that are related to the overactivation of the sympathetic nervous system (Briere, 2011). The sympathetic nervous system is responsible for symptoms like jumpiness, hypervigilance, irritability, and sleep disturbance, all of which are anecdotally common among correctional officers. The AA$\mathrm{H}$ scale is a direct parallel to the criterion "D" group of symptoms from the DSM-V (American Psychiatric Association, 2013). High scores on the main AA scale and the AA-A and AA-H indicate higher levels of anxious symptoms.

The next scale in the TRAUMA factor is intrusive experiences (IE). The intrusive experiences (IE) scale is measuring criterion "B" from the DSM-V (American Psychiatric Association, 2013). Criterion "B" is intrusion symptoms that consist of unwanted memories, nightmares, and flashbacks. These intrusions are generally triggered by events 
happening in the respondent's immediate environment. As correctional officers experience many violent and traumatic events within the prison walls, the prison itself can become a place that is extremely triggering for these intrusive experiences. The defensive avoidance (DA) scale measures the respondents' attempts to suppress or eliminate painful thoughts or memories. The DA scale also has respondents report if they avoid situations or other stimuli that would bring up the painful thoughts or memories (Briere, 2011). The defensive avoidance scale directly measures criterion " $\mathrm{C}$ " from the DSM-V (American Psychiatric Association, 2013).

The last scale of the TRAUMA factor in the TSI-2 is dissociation (DIS). The dissociation scale measures a myriad of dissociative symptoms including depersonalization, cognitive disengagement, and out-of-body experiences. In the DSM-V, dissociation is listed under possible symptoms that need to be experienced under Criterion "B." Not every individual who witnesses a traumatic event will suffer from dissociative symptoms, but the dissociative symptoms are common enough that DSM-V does list a subtype of the PTSD diagnosis as "PTSD with dissociative symptoms." These dissociative symptoms can include either depersonalization or derealization.

In order to calculate the TRAUMA factor, which serves as the measure of PTSD symptomology named TRAUMA, the raw score of each scale is determined. After the raw scores are determined, Briere (2011) provides a table in which the researcher is able to convert the raw score into a trauma score. The trauma score conversion is different for individuals based on their gender and age group. The greater a respondent's trauma score, the more likely the individual will meet the diagnostic criteria for PTSD. Therefore, one of the dependent variables in the current analysis is a continuous variable, TRAUMA 
which measures the level of PTSD symptoms experienced by the respondent from the TSI-2. In other words, the higher the TRAUMA score, the more pervasive the symptoms of PTSD the respondent is experiencing. In order to clarify the pervasiveness of symptoms on an individual level, respondents are placed into categories created by Briere (2011) based on their TRAUMA score. Individuals who had a TRAUMA score of 59 or less were considered to be in normal range, with no clinical implications of PTSD. If the respondent's TRAUMA score ranged from 60 to 64 they were considered problematic, and likely to have clinical implications of PTSD. Finally, those respondents whose trauma score was equal to or over 65 , were considered to be clinically elevated and represented a significant concern. Respondents who were categorized as "problematic" or "clinically elevated" are considered to be "of PTSD concern" and a PTSD diagnosis from a clinician is likely.

TABLE 4.1 TSI-2 Trauma Score Interpretation

TRAUMA Score Clinical Implication Analysis

\begin{tabular}{lll}
\hline $\mathrm{T}=\leq 59$ & Normal & Normal range; No clinical implication \\
$\mathrm{T}=60-64$ & Problematic & Likely to have clinical implications \\
$\mathrm{T}=\geq 65$ & Clinically Elevated & $\begin{array}{l}\text { Extreme likelihood of clinical } \\
\text { implications }\end{array}$
\end{tabular}

The PCL-5 is the second measure of PTSD completed by the respondents. The PCL-5 is a 20-item questionnaire that focuses exclusively on PTSD. Developed by Weathers and colleagues in 2015, the PCL-5 has three main purposes, which include screening individuals for PTSD, monitoring symptom change among individuals before and during treatment, and making provisional PTSD diagnoses. The PCL-5 is a self- 
report PTSD assessment. It takes approximately 5-10 minutes to complete and does not require a clinician. The PCL-5 asks the individual to recall their feelings about stressful events over the past month. The prompt given to the respondents is "In the past month, how often have you been bothered by...," then the item. The assessment is scored on a Likert scale where $0=$ "Not at all," 1 = "A little bit," 2 = "Moderately," $3=$ "Quite a bit," and 4 = "Extremely." The PCL-5 is measured by summing the responses. The measure is then considered to be a continuous measure of symptom severity. However, there is some literature that suggests there is a cutoff point, at which the respondent is very likely to be diagnosed with PTSD. The initial research has determined this cutoff to be appropriate with scores between 31 and 33 (Weathers et al., 2013)., The existing literature notes that there must be more research done to better determine the validity of the cutoff point. For example, in a study examining correctional staff in Washington state, James and Todak (2018) used a PCL-5 score of 38 as a cutoff for diagnosable PTSD. The questions of the PCL-5, like those of the TSI-2, can be tied directly to the criterion found in the PTSD diagnosis. The prompt for the PCL-5, listed above, provides the requirement of criterion "A" of the PTSD diagnosis, by indicating that the respondent has recently experienced, witnessed, or learned about a traumatic event. Questions one through five of the PCL-5 directly parallel criterion " $\mathrm{B}$ " of the DSM-V, in which the intrusion symptoms are explained. Questions six and seven focus on the avoidance symptoms, which are criterion "C." The next set of questions, seven through fourteen, focus on criterion " $\mathrm{D}$ " which describes the inability to recall important events, negative feelings, and placing blame on one's self. Finally, items fifteen through twenty focus on criterion "E," which is unprovoked anger, sleep and concentration disturbances, and hypervigilance. 


\section{PCL-5 Items}

1. Repeated, disturbing, and unwanted memories of a stressful experience

2.Repeated, disturbing dreams of the stressful experience

3. Suddenly feeling or acting as if the stressful experience were actually happening again?

4. Feeling very upset when something reminded you of the stressful experience?

5. Having strong physical reactions when something reminded you of the stressful experience?

6. Avoiding memories, thoughts, or feelings related to the stressful experience?

7. Avoiding external reminders of the stressful experience?

8. Trouble remembering important parts of the stressful experience?

9. Having strong negative beliefs about yourself, other people, or the world?

10. Blaming yourself or someone else for the stressful experience or what happened after it?

11. Having strong negative feelings such as fear, horror, anger, guilt or shame?

12. Loss of interest in activities that you used to enjoy?

13. Feeling distant or cut off from other people?

14. Trouble experiencing positive feelings?

15. Irritable behavior, angry outbursts, or acting aggressively?

16. Taking too many risks or doing things that could cause you harm?

17. Being "super alert" or watchful or on guard?

18. Feeling jumpy or easily startled?

19. Having difficulty concentrating?

20. Trouble falling or staying asleep?
B- intrusion symptoms that consist of unwanted memories, nightmares, and flashbacks

$\mathrm{C}$ - avoiding distressing memories, thoughts, or feelings of the traumatic event, and avoiding external reminders, such as people, places, and things, of the traumatic event.

D- inability to remember important aspects of the traumatic event, persistent exaggerated negative beliefs, self-blame, persistent negative emotional state, declined interest significant activities, detachment, and the inability to experience positive emotions such as happiness or loving feelings

E- unprovoked angry outbursts, selfdestructive behavior, hypervigilance, exaggerated startle response, problems with concentration, and sleep disturbance.

Key Independent Variables. The key independent variables, or those that are the focus of this dissertation are derived from two scales or assessments: 1) Carver et al.'s (1989)

COPE Inventory; and 2) the Violence, Injury, and Death Exposure Scale (VIDES)

created by Denhof and Spinaris in 2014. First, the COPE Inventory is used to measure the various coping mechanisms self-reported by the correctional officers. The COPE includes 
15 subscales that measure problem-focused and emotion-focused coping mechanisms. The COPE Inventory determines how often the respondent utilizes the coping mechanisms described in the item. The items are then grouped into subscales. Although there are 15 subscales within the COPE Inventory, the current analysis has chosen to focus on a select number of subscales. The subscales for the current analysis were determined based on two criteria. First, these coping mechanisms fall into the two categories designated by Carver as problem-focused or emotion-focused. Second, only subscales that had alphas over .6 were included in the analysis. The subscales being utilized in the current analysis are humor, positive reinterpretation and growth, to be known as positive growth, planning, active coping, denial, emotional support, social support, restraint, acceptance, and religion. Table 4.3 outlines the subscales being used, the items within the subscale and the Cronbach's alpha for each scale.

Based on Carver et al. (1989), a majority of the subscales have been determined to be either problem-focused coping mechanisms or emotion-focused coping mechanisms. The problem-focused coping mechanisms are planning, active coping, social support, and restraint. Positive reinterpretation and growth, denial, emotional support, acceptance, and religion are outlined by Carver as the emotion-focused coping mechanisms. In the seminal 1989 article, Carver and colleagues did not identify humor as an emotion-focused or problem-focused coping mechanisms. Though some researchers have argued that humor falls into both categories (Kuiper et al. 1993; Lefcourt et al.1997), the majority of the research has labeled humor as emotion-focused coping mechanism (Abel, 2002; Rim, 1988). Humor ultimately was placed into the emotionfocused category for this analysis due to a majority of studies categorizing it as emotion- 
focused previously. Each of the listed coping mechanisms have appropriate alphas, with the lowest alpha being restraint at .606 and the highest alpha being religion at 927 .

Though restraint and religion were on the low and high end of the alpha range

respectively, neither were the most popular coping mechanisms. The most popular coping mechanisms were positive growth with a mean of 11.1, then acceptance with a mean of 10.7, and lastly, planning with a mean of 10.3. The least used coping mechanism reported by respondents was denial with a low mean of 5.7 . 
TABLE 4.3: COPE Inventory Subscales

\begin{tabular}{|c|c|c|}
\hline \multicolumn{2}{|l|}{ Emotion Focused } & \multirow{2}{*}{$\begin{array}{l}\text { Problem Focused } \\
\text { Name }\end{array}$} \\
\hline Name & $\alpha$ & \\
\hline Denial & .718 & Active Coping \\
\hline I say to myself "this isn't real" & & I concentrate my efforts on doing something about it. \\
\hline I refuse to believe that it has happened & & I take additional action to try to get rid of the problem. \\
\hline I pretend that it hasn't really happened & & I take direct action to get around the problem. \\
\hline I act as though it hasn't even happened & & I do what has to be done, one step at a time. \\
\hline Religion & .927 & Planning \\
\hline I put my trust in God & & I make a plan of action. \\
\hline I seek God's help & & I try to come up with a strategy about what to do. \\
\hline I try to find comfort in my religion & & I think about how I might best handle the problem \\
\hline I pray more than usual & & I think hard about what steps to take. \\
\hline Emotional Support & .856 & Social Support \\
\hline I discuss my feelings with someone & & I try to get advice from someone about what to do. \\
\hline I try to get emotional support from friends or & & I talk to someone to find out more about the situation. \\
\hline relatives & & I talk to someone who could do something concrete about the \\
\hline I get sympathy and understanding from someone & & problem. \\
\hline I talk to someone about how I feel & & I ask people who have had similar experiences what they did. \\
\hline Positive Growth & .764 & Restraint \\
\hline I try to grow as a person as a result of the experience & & I restrain myself from doing anything too quickly. \\
\hline I try to see it in a different light, to make it seem & & I hold off doing anything about it until the situation permits. \\
\hline more positive & & I make sure not to make matters worse by acting too soon. \\
\hline $\begin{array}{l}\text { I look for something good in what is happening } \\
\text { I learn something from the experience }\end{array}$ & & I force myself to wait for the right time to do something. \\
\hline Acceptance & .771 & \\
\hline I get used to the idea that it happened. & & \\
\hline I accept it has happened and that it can't be changed & & \\
\hline I accept the reality of the fact that it happened & & \\
\hline I learn to live with it & & \\
\hline Humor & .889 & \\
\hline I laugh about the situation & & \\
\hline I make jokes about it & & \\
\hline I kid around about it. & & \\
\hline I make fun of the situation. & & \\
\hline
\end{tabular}

$\frac{\alpha}{.624}$

I try to get advice from someone about what to do.

I talk to someone who could do something concrete about the roblem

people who have had similar experiences what they did.

hold off doing anything about it until the situation permits.

make sure not to make matters worse by acting too soon.

ore positive

look for something good in what is happening

cceptance

get used to the idea that it happened.

acept happened and that it can't bro

learn to live with it

I make fun of the situation. 
Another important independent variable is the magnitude of exposure to trauma. which measures the frequency and recency of violent and traumatic events experienced by the correctional officers. This variable comes from the Violence, Injury, and Death Exposure Scale also known as VIDES (Denhof \& Spinaris, 2014). This scale was developed to determine the magnitude of direct and indirect trauma exposure. The VIDES consists of 12 items, in which seven are direct exposure items and the remaining five are indirect exposure items. Direct exposure to trauma includes being physically assaulted, encountering deceased individuals, or witnessing attempted or completed suicides. Indirect trauma exposure includes situations like witnessing an assault, learning about any of the direct trauma incidents (Denhof \& Spinaris, 2016). Each item asks how many times the respondent has experienced a specific event. The item responses are recoded on a Likert scale, where 0 = "Never", 1 = "Once", 2 = "2-3 Times", 3 = "4-6 Times", $4=$ "7-9 Times", and $5=$ "10+ Times." In addition to measuring exposure, the VIDES also measures recency of the experience. The recency component of the measure asks when the most recent exposure of each event occurred. It is measured on a Likert scale, where 0 = "Never", 1 = "1-30 Days Ago", 2 = "2-3 Months Ago", 3 = "4-6 Months Ago", 4 = "7-12 Months Ago", and 5 = "More Than a Year Ago." The above Likert scales were used to create ease of responding for the participants in the study. Denhof and Spinaris (2014) created a proper Response-to-Numeric Score Conversion Key, to which the variables of the VIDES have been aligned. To calculate the magnitude of exposure to trauma, the scores from both frequency of exposure and recency are summed. This is done for all twelve items on the VIDES. Once the response from each individual item is determined, they are added together and then divided by 12 . The result of this division is 
the VIDES score, also called the magnitude of exposure to trauma. Denhof and Spinaris (2014) note that exposure scores $>1$ and $<2$ are slight exposure, $\geq 2$ and $<3$ are fair exposure, $\geq 3$ and $<4$ are moderately high exposure, $\geq 4$ and $<5$ are high exposure, and that scores that are $\geq 5$ are extreme exposure. The mean for the current sample is 3.2 , which indicates that correctional officers have experienced moderately high amounts of trauma exposure. The standard deviation for the VIDES is 1.38 and the minimum is 1.00 and the maximum is 6.28 .

\section{TABLE 4.4: Exposure Score Interpretation}

VIDES Average Score

\section{Exposure Magnitude}

$>1-<2$

$\geq 2-<3$

$\geq 3-<4$

$\geq 4-<5$

$\geq 5$
Slight

Fair

Moderately High

High

Extreme

Control Variables. Control variables for the current analysis include basic demographic information such as age, which is presented in years, gender of the respondent, which is binary with $0=$ female and $1=$ male. Marital status is also included as a binary variable of $0=$ not married and $1=$ married. Security level was also included as a control variable and is measured as $0=$ minimum or medium security facilities and $1=$ maximum security facilities. Next, correctional experience is also measured in years. Finally, rank, is measured in a Likert-type scale where 1= "Officer", 2 = "Sergeant", 3= "Lieutenant", and 4= "Captain."

\section{Analytic Strategy}

In order to address the proposed research questions, multiple analyses were be conducted. First, frequencies were conducted using IBM SPSS Statistics 26. The dependent variables, outlined above, are continuous in nature, allowing for the use of 
linear regression for the analytic models. In total, eight linear regression models were analyzed. Two sets of models for each dependent variable were examined — one set with only main effects of all key independent variables and controls and another set of models exploring possible moderation effects of various coping mechanisms on the relationship between exposure to trauma and PTSD, while controlling for all other factors.

TABLE 4.5: Proposed Main Effects Models

\begin{tabular}{|c|c|c|c|c|}
\hline & Model 1 & Model 2 & Model 3 & Model 4 \\
\hline $\begin{array}{l}\text { Dependent } \\
\text { Variables }\end{array}$ & TRUAMA & TRAUMA & PCL-5 Score & PCL-5 Score \\
\hline \multirow[t]{5}{*}{$\begin{array}{l}\text { Key Independent } \\
\text { Variables }\end{array}$} & Social support & $\begin{array}{l}\text { Positive } \\
\text { growth }\end{array}$ & Social support & $\begin{array}{l}\text { Positive } \\
\text { growth }\end{array}$ \\
\hline & Planning & Acceptance & Planning & Acceptance \\
\hline & Active coping & Religion & Active coping & Religion \\
\hline & Restraint & $\begin{array}{c}\text { Emotional } \\
\text { support } \\
\text { Denial } \\
\text { Humor }\end{array}$ & Restraint & $\begin{array}{c}\text { Emotional } \\
\text { support } \\
\text { Denial } \\
\text { Humor }\end{array}$ \\
\hline & $\begin{array}{l}\text { Exposure to } \\
\text { trauma }\end{array}$ & $\begin{array}{l}\text { Exposure to } \\
\text { trauma }\end{array}$ & $\begin{array}{l}\text { Exposure to } \\
\text { trauma }\end{array}$ & $\begin{array}{l}\text { Exposure to } \\
\text { trauma }\end{array}$ \\
\hline \multirow[t]{5}{*}{ Control Variables } & Age & Age & Age & Age \\
\hline & Gender & Gender & Gender & Gender \\
\hline & Marital Status & Marital Status & Marital Status & Marital Status \\
\hline & Security Level & Security Level & Security Level & Security Level \\
\hline & $\begin{array}{c}\text { Correctional } \\
\text { Experience } \\
\text { Rank }\end{array}$ & $\begin{array}{c}\text { Correctional } \\
\text { Experience } \\
\text { Rank }\end{array}$ & $\begin{array}{c}\text { Correctional } \\
\text { Experience } \\
\text { Rank }\end{array}$ & $\begin{array}{c}\text { Correctional } \\
\text { Experience } \\
\text { Rank }\end{array}$ \\
\hline
\end{tabular}

For each dependent variable-TRAUMA from TSI-2, and the PCL-5 score-two main effect models and two models with interaction effects were analyzed. The first main effect model includes the problem-focused coping mechanisms, which are social support, planning, active coping, and restraint, and all controls, while the second main effect 
model includes all emotion-focused coping mechanisms, which are positive growth, acceptance, religion, emotional support, denial, and humor, and all controls. To understand whether the relationship between exposure to violence and trauma, as measured by magnitude of exposure to trauma, and severity of PTSD symptoms is moderated by specific coping mechanisms, another set of linear regression models, including interaction effects, were conducted. These subsequent models explored include interaction effects of coping mechanisms and exposure to trauma on PTSD for both problem-focused coping and emotion-focused coping for both dependent variables.

Only the coping mechanisms that were determined to have significant main effects on PTSD symptoms are analyzed at this stage. Interaction terms were created by mean centering the significant coping mechanisms and multiplying those variables by the trauma exposure variable. The results of the main effects models and the moderation models are discussed in the next chapter.

FIGURE 4.1: Moderation Pathway Analysis

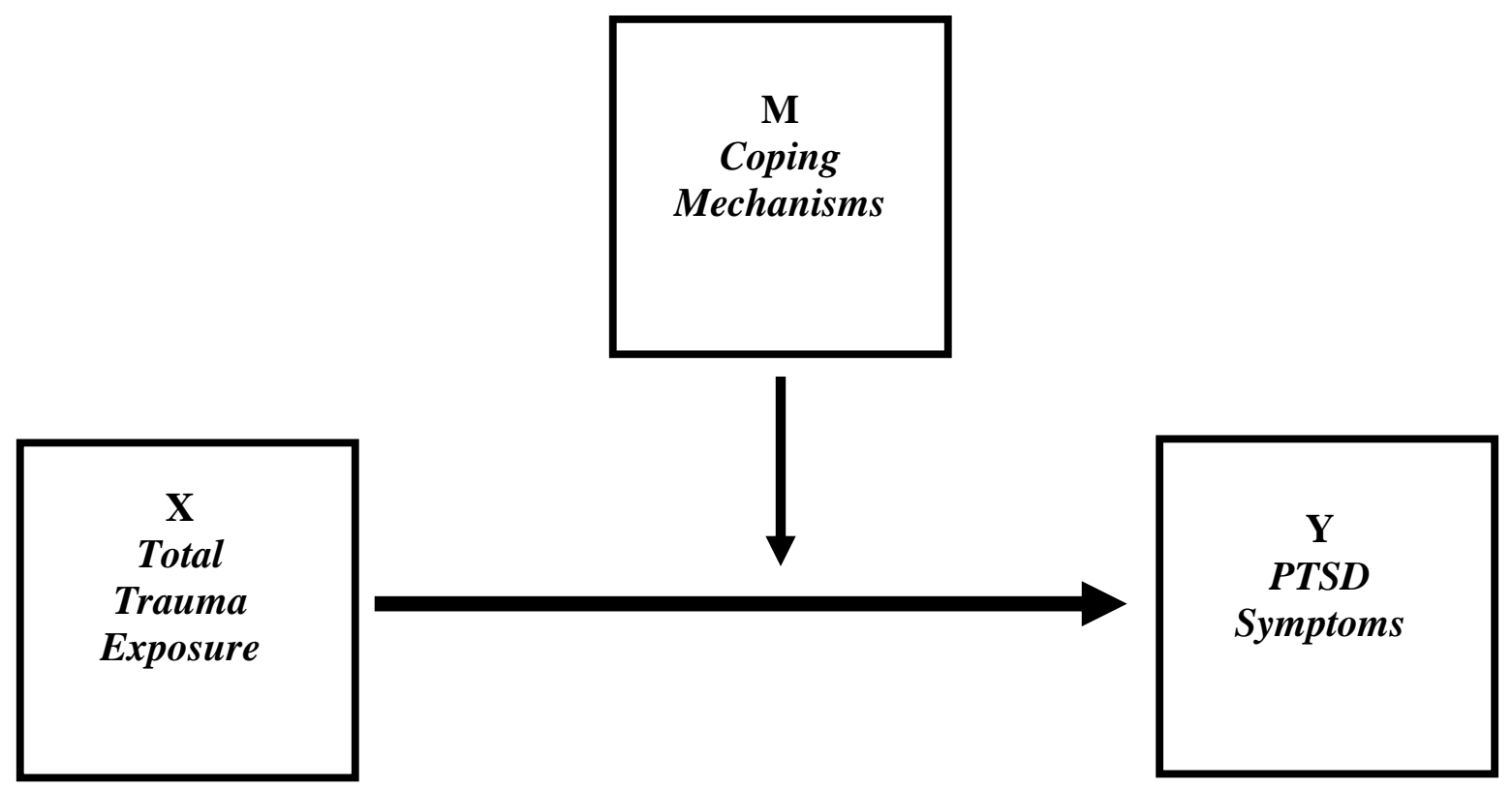




\section{CHAPTER 5. ANALYSES AND RESULTS}

This chapter presents the analysis and the results for the current dissertation. First, detailed descriptive statistics, including the prevalence of PTSD and usage of coping mechanisms are presented. Second, the results of the four linear regression main effects models are presented and discussed. Finally, the linear regression models that contain the interaction effects of a coping mechanism*trauma exposure are explored and presented.

\section{DESCRIPTIVE STATISTICS}

The average age of respondents was 37.6 years old. The youngest serving officer was 21 years old while the oldest serving officer was 77 years old. The sample was approximately $74 \%$ male and $26 \%$ female, which is typical gender makeup for correctional institutions. Approximately $50 \%$ of the sample were married, the other $50 \%$ were single, widowed, or divorced. Of the total sample, approximately $15 \%$ were employed at Kentucky State Penitentiary, the maximum-security correctional facility. The other $85 \%$ of the sample were employed at other institutions, which are classified as medium-security facilities or medium security/maximum security. Correctional officers in this sample, on average, had a little over 6 years or 81 months of correctional experience, with the newest officers being employed for half a month, to veteran officers who have been working in the correctional system for over 30 years. A majority of the sample, approximately $76 \%$, were non-supervisor officers. The remaining $24 \%$ of respondents held a position of sergeant, lieutenant, or captain. 
A more in-depth univariate analysis of the key independent variables and dependent variables of the sample is provided below. Table 5.1 outlines all of the descriptive statistics for the current sample. 
TABLE 5.1: Descriptive Statistics

\begin{tabular}{|c|c|c|c|c|c|}
\hline Variables & Scale & Mean & S.D. & Range & $\mathbf{N}$ \\
\hline \multicolumn{6}{|l|}{ Dependent Variables } \\
\hline$\overline{\text { TRAUMA }}$ & (Continuous score) & 54.3 & 10.7 & $36-82$ & 224 \\
\hline PCL-5 Score & (Continuous score) & 30.1 & 17.9 & $0-78$ & 242 \\
\hline Independent Variables & (Summed, "I don't usually do this at all" $=1$, "I usually do this a & & & & \\
\hline Problem-Focused Coping & $\begin{array}{l}\text { little bit" = } 2 \text {, "I usually do this a medium amount" }=3 \text {, and "I } \\
\text { usually do this a lot" }=4 \text { ) }\end{array}$ & & & & \\
\hline Social Support & & 8.9 & 3.2 & $4-16$ & 243 \\
\hline Planning & & 10.3 & 2.9 & $4-16$ & 243 \\
\hline Active Coping & & 9.8 & 2.5 & $4-16$ & 243 \\
\hline Restraint & & 9.2 & 2.4 & $4-16$ & 243 \\
\hline Emotion-Focused Coping & $\begin{array}{l}\text { (Summed, "I don't usually do this at all" }=1 \text {, "I usually do this a } \\
\text { little bit" }=2 \text {, "I usually do this a medium amount" = 3, and "I } \\
\text { usually do this a lot" }=4 \text { ) }\end{array}$ & & & & \\
\hline Positive Growth & & 11.1 & 2.7 & $4-16$ & 243 \\
\hline Acceptance & & 10.7 & 2.9 & $4-16$ & 243 \\
\hline Religion & & 9.0 & 4.2 & $3-16$ & 243 \\
\hline Emotional Support & & 7.7 & 3.4 & $3-16$ & 243 \\
\hline Denial & & 5.7 & 2.1 & $3-16$ & 243 \\
\hline Humor & & 9.7 & 3.6 & $4-16$ & 243 \\
\hline Magnitude of Exposure to Trauma & (Continuous score) & 3.2 & 1.4 & $1-6.28$ & 243 \\
\hline \multicolumn{6}{|l|}{ Control Variables } \\
\hline Age & (Age in years) & 37.6 & 12 & $21-77$ & 243 \\
\hline Gender & $(0=$ Male, $1=$ Female $)$ & .74 & .44 & $0-1$ & 243 \\
\hline Marital Status & $(0=$ Single, $1=$ Married $)$ & .50 & .50 & $0-1$ & 242 \\
\hline Security Level & $(0=$ Minimum, Medium, $1=$ Maximum $)$ & .15 & .36 & $0-1$ & 243 \\
\hline Correctional Experience & (Months of total correctional work) & 81 & 77 & $.5-394$ & 242 \\
\hline Rank & (1= Officer, $2=$ Sergeant, $3=$ Lieutenant, $4=$ Captain $)$ & 1.4 & .79 & $0-4$ & 242 \\
\hline
\end{tabular}


PTSD PREVALENCE

Both of the PTSD symptomology measures - from the TSI-2 and the PCL-5-are continuous variables measuring the severity of PTSD symptoms. However, it is important to understand the proportion of the sample that would be considered to have clinical levels of PTSD symptoms and would likely receive a PTSD diagnosis if seen by a clinician. According to the TSI-2 manual the TRAUMA scores are broken into three categories of severity (Briere, 2011) The first category refers to individuals who are considered "normal" and have no clinical levels of PTSD symptoms. The second category, problematic, refers to individuals who are "of PTSD concern" and likely to have clinical implications. These individuals display PTSD symptoms, but not as severe as the final category. This category is comprised of individuals who are demonstrate severe clinically elevated symptoms and represent extreme concern. Table 5.2 displays the prevalence of these categories within the current. A majority of the sample fell into the "normal" category, meaning they did not have detectable levels of PTSD symptoms. Of more interest to the current dissertation are the other categories. Approximately $9 \%$ of the sample had T-scores between 60 and 64, indicating that they are of PTSD concern and likely to have clinical implications.

\section{TABLE 5.2: Prevalence Rates of PTSD Symptoms, TSI-2}

\begin{tabular}{llc}
\hline \multicolumn{1}{c}{ T-Score } & \multicolumn{1}{c}{ Category } & \% of Sample affected \\
\hline $\mathrm{T}=\leq 59$ & Normal & $\mathbf{6 7 . 1 \%}$ \\
$\mathrm{T}=60-64$ & Problematic & $\mathbf{9 . 1 \%}$ \\
$\mathrm{T}=\geq 65$ & Clinically Elevated & $\mathbf{1 6 \%}$ \\
\hline
\end{tabular}

Finally, $16 \%$ of the sample fell into the most severe category, which indicates that they suffer from clinically elevated symptoms of PTSD. According to Briere (2011), this 
means that $25 \%$ of the sample are "of PTSD concern" and likely to receive a PTSD diagnosis if assessed by a clinician. The categories, for the purpose of this dissertation, are only for describing the sample, as the current analysis uses the continuous variable of PTSD symptoms (TRAUMA) to examine severity. The average trauma score, which is depicted in table 4.5, for the current sample was 54.3. This mean falls into the normal category, but as table 5.1 shows, approximately 1 in 4 officers in the sample suffer from clinical levels of PTSD symptoms.

The PCL-5 score is also a continuous variable, where the higher the score, the more severe the PTSD symptoms. The PCL-5 has scores that range from 0-80. Research has determined that the accurate cutoff scores for indicating clinical levels of PTSD symptoms are between 31 and 33. In order to avoid presumption of symptoms, a cutoff score of 31 has been chosen for the current analysis. Like the TSI-2, individuals who score 31 or below are considered "normal," or having subthreshold levels of PTSD symptoms. Individuals who scored 32 or higher are determined to have detectable levels of PTSD symptoms. Table 5.3 outlines the PCL-5 and the prevalence rates of PTSD symptoms among the sample.

TABLE 5.3: Prevalence rates of PTSD Symptoms, PCL-5

\begin{tabular}{llc}
\hline PCL-5 Score & Category & \% of Sample affected \\
\hline $0-31$ & Normal & $\mathbf{5 4 . 3 \%}$ \\
$\geq 32$ & $\begin{array}{l}\text { Threshold levels of } \\
\text { PTSD }\end{array}$ & $\mathbf{4 4 . 4 \%}$ \\
\hline
\end{tabular}

When examining the PCL-5 scores, a much higher proportion of the sample met the threshold for clinical levels of PTSD compared to the TSI-2. Approximately 54\% of the sample scored normal and the remaining $44.4 \%$ scored a 32 or higher, indicating that 
they met the threshold, or demonstrated detectable levels of PTSD symptoms. The average PCL-5 score was 30.1, which puts the majority of the sample in the normal category for PTSD symptoms. Still, the remainder of the sample have detectable levels of PTSD symptoms.

\section{EXPOSURE TO TRAUMA}

The exposure to trauma variable was assessed by using the VIDES. The current sample suffered from varying levels of exposure to trauma. Table 5.4 contains the categories of the VIDES and where officers within the sample fell. Approximately 24\% of the sample fell into the lowest trauma exposure category, which is "slight" exposure. Another $21.8 \%$ fell into "fair" category of magnitude exposure. Approximately $20 \%$ of the sample fell into the "moderately high" category of trauma exposure. The average trauma exposure score for the entire sample was 3.2, falling into this "moderately high" category. The two highest trauma exposure categories, "high" and "extreme" had a 21\% and $11 \%$ prevalence rate in the sample, respectively.

TABLE 5.4: VIDES Prevalence

\begin{tabular}{ccc}
\hline VIDES Range & Category & \% of Sample Affected \\
\hline$>1-<2$ & Slight & 24.3 \\
$\geq 2-<3$ & Fair & 21.8 \\
$\geq 3-<4$ & Moderately High & 20.2 \\
$\geq 4-<5$ & High & 21.8 \\
$\geq 5$ & Extreme & 11.1 \\
\hline
\end{tabular}

The items on the VIDES, as mentioned above, are broken down into direct and indirect trauma exposure. The three most prevalent direct traumatic events that officers in this sample indicated were: 1) being threatened with violence or death; 2) witnessing someone being physically injured; and 3) witnessing suicide attempts that did not end in death. Further, $70.4 \%$ of the sample had been threatened with violence or death at least 
once, and $35.4 \%$ of that indicated that they had been threatened more than 10 times. Approximately $76 \%$ of the officers in the sample reported that they had witnessed someone being physically injured and $26 \%$ of officers reported this experience at least 10 times. Finally, about $68 \%$ of the sample indicated that they witnessed a suicide attempt that did not result in death and $22 \%$ of these officers had witnessed 10 or more suicide attempts. The three most common indirect traumatic events that officers in this sample reported were: 1) hearing about someone being physically harmed without witnessing it directly; 2) hearing about someone being threatened with harm without witnessing it directly; and, 3) witnessing a threat of violence or death at someone other than themselves. A majority of the sample, approximately $86 \%$, had heard about someone being physically harmed without witnessing it directly at least once, and $40 \%$ of the officers experienced this at least 10 times. Another $82 \%$ of the sample had heard about someone being threatened with harm without witnessing it directly at least once in their correctional career, and $38 \%$ of these officers experienced this at least 10 times. Finally, approximately $73 \%$ of the sample had witnessed a threat of violence or death directed at someone else at least once, and $30 \%$ of these officers had experienced this at least 10 times.

\section{COPING PREVALENCE}

Of the 15 coping subscales that Carver et al. (1989) identified, only ten had appropriate Cronbach alphas to be included in the multivariate analysis. The sample displayed a wide range of coping mechanisms. In order to calculate the coping subscales, each item in the subscale were summed together. The higher the sum, the more the coping mechanism was used by the officer. The top three coping mechanisms were positive growth, acceptance, and planning. These are, arguably, prosocial or adaptive 
coping mechanisms. Humor, religion, and active coping were also highly used among officers within this sample. As mentioned before, the coping mechanisms were determined to be either problem-focused or emotion-focused by Carver et al. (1989). The most prominent problem-focused coping mechanisms were planning and active coping with means of 10.3 and 9.8, respectively. Restraint and social support were used fairly often as well, with means of 9.2 and 8.9. The three most utilized emotion-focused coping mechanisms were positive growth $($ mean $=11.1)$, acceptance $($ mean $=10.7)$, and humor (mean $=9.7)$. Denial was reported as being utilized the least among the sample with a mean of 5.7. All ten of the coping mechanisms with appropriate alpha's were included in the main effect models. The results from the main effect models are discussed in the next section, followed by the models exploring possible interactions between the exposure to trauma and coping.

\section{Main Effect Models}

\section{MULTIVARIATE STATISTICS}

Essentially, two iterations of linear regression models were conducted—first with only main effects and the second iteration explored potential interaction effects. Due to having two dependent variables and two categories of coping mechanisms, a total of four main effect models are presented. Models 1 and 2 include TRAUMA, or the PTSD symptomology measure from the TSI-2 and Models 3 and 4 include the PCL-5 score as the measure of PTSD symptomology. For each dependent variable, two models are presented —one for problem-focused coping and the other for emotion-focused coping.

Model 1 contains all of the problem- focused coping mechanisms with acceptable Cronbach alphas, which include social support, planning, active coping, and restraint, the total trauma exposure variable, and the control variables of gender, age, marital 
status, rank, correctional experience, and security level of the institution. Model 2 is identical to model one except for this model focuses on the emotion-focused coping with acceptable alphas. These with the include growth, denial, religion, humor, emotional support, and acceptance. Table 5.4 presents the results of these two models.

The first model, focusing on the problem-focused coping mechanisms, revealed two of the four coping strategies were significantly related to TRAUMA. First, planning was negatively associated with TRAUMA, indicating that as planning as a coping technique increased, the TRAUMA scores decreased, or was associated with fewer PTSD symptoms. The other significant coping mechanism was social support, which was positively associated with PTSD symptoms. This indicates that relying more heavily on social support is significantly associated with higher TRAUMA scores. The variable with the strongest relationship with TRAUMA was exposure to trauma. As expected, as an officer's exposure to trauma increased, so did their TRAUMA score. None of the control variables were significantly associated with TRAUMA. Model one had an $\mathrm{R}^{2}$ of .174, indicating that approximately $17 \%$ of the variation in the sample in explained in this model. 
TABLE 5.5: Main Effects Models for TRAUMA

\begin{tabular}{|c|c|c|c|c|}
\hline \multirow{2}{*}{ Variables } & \multicolumn{2}{|c|}{ Model 1} & \multicolumn{2}{|c|}{ Model 2} \\
\hline & B & $\mathbf{S E}$ & B & $\mathbf{S E}$ \\
\hline \multicolumn{5}{|l|}{ Problem-Focused } \\
\hline Active Coping & .521 & .397 & -- & -- \\
\hline Restraint & .324 & .310 & -- & -- \\
\hline Planning & $-1.54 * *$ & .337 & -- & -- \\
\hline Social Support & $.545^{*}$ & .268 & -- & -- \\
\hline \multicolumn{5}{|l|}{ Emotion-Focused } \\
\hline Growth & -- & -- & -.335 & .321 \\
\hline Denial & -- & -- & $1.58 * *$ & .323 \\
\hline Religion & -- & -- & .051 & .174 \\
\hline Humor & -- & -- & .059 & .219 \\
\hline Emotional Support & -- & -- & -.110 & .227 \\
\hline Acceptance & -- & -- & .196 & .296 \\
\hline Exposure to Trauma & $2.64 * *$ & .552 & $2.95 * *$ & .488 \\
\hline Gender & -2.46 & 1.59 & -2.16 & 1.61 \\
\hline Age & .001 & .078 & .031 & .080 \\
\hline Marital Status & -.015 & 1.38 & -.481 & 1.38 \\
\hline Security Level & -1.44 & 1.83 & -.829 & 1.83 \\
\hline Correctional Experience & -.014 & .013 & -.020 & .013 \\
\hline \multirow[t]{2}{*}{ Rank } & .038 & .977 & .168 & 1.00 \\
\hline & \multicolumn{2}{|c|}{$\mathrm{R}^{2}=.174$} & \multicolumn{2}{|c|}{$\mathrm{R}^{2}=.190$} \\
\hline
\end{tabular}

$* * p \leq 0.01,{ }^{*} p \leq 0.05$

In Model 2 there was only one significant coping mechanism--denial. Denial was positively associated with TRAUMA, indicating that as the use of denial increases, so do the PTSD symptoms. Similar to Model 1, exposure to trauma was positively associated with TRAUMA, demonstrating that as an officer's exposure to trauma increases, so does their PTSD symptoms. Again, none of the control variables were significant. The $\mathrm{R}^{2}$ for Model 2 was .190, meaning that approximately $19 \%$ of the variance was explained in this model.

Models 3 and 4, displayed below in Table 5.5, examined the relationships between all of the independent variables presented in Models 1 and 2, but with the PCL-5 
score as the dependent variable. Similar to Model 1, which also focused on problemfocused coping, planning had a negative coefficient, indicating that as planning increased, the severity of PTSD symptoms decreased. Another coping mechanism, restraint, approached the .05 level of significance with a $p$-value of .057 . The coefficient for restraint was positive, indicating that as officers used more restraint, they experienced higher levels of PTSD symptoms. Exposure to trauma was also positively and significantly associated with the PCL-5 score, which is expected given previous research as well as previous models in the current analysis. Unlike the models with the TRAUMA dependent variable, gender had a negative significant effect, indicating that women were more likely than men to suffer from increased PTSD symptoms. No additional control variables were significant. The $\mathrm{R}^{2}$ for Model 3 was .213 meaning that approximately $21 \%$ of the variance in the sample was explained in the model. 
TABLES 5.6: Main Effects Models for PCL-5

\begin{tabular}{lcccc}
\hline & \multicolumn{2}{c}{ Model 3 } & \multicolumn{2}{c}{ Model 4 } \\
\hline Variables & B & SE & B & SE \\
\cline { 2 - 6 } Problem-Focused & & & & \\
$\quad$ Active Coping & .292 & .633 & -- & -- \\
Restraint & $.94 \dagger^{\dagger}$ & .491 & -- & -- \\
Planning & $-2.18^{* *}$ & .542 & -- & -- \\
Social Support & .282 & .428 & -- & -- \\
& & & & \\
Emotion-Focused & & & & \\
$\quad$ Growth & -- & -- & $-1.08^{*}$ & .494 \\
Denial & -- & -- & $2.73^{*}$ & .265 \\
Religion & -- & -- & .043 & .265 \\
Humor & -- & -- & .305 & .335 \\
Emotional Support & -- & -- & $-.686 \dagger$ & .349 \\
Acceptance & -- & -- & .541 & .457 \\
& & & & \\
Exposure to Trauma & $4.24^{*}$ & .879 & $2.95^{*}$ & .871 \\
Gender & \multicolumn{2}{c}{} & \\
Age & $-5.12^{*}$ & 2.49 & $-4.92^{*}$ & 2.45 \\
Marital Status & -.214 & .118 & -.131 & .115 \\
Security Level & .317 & 2.17 & -.125 & 2.10 \\
Correctional Experience & -.934 & 2.97 & .023 & .994 \\
Rank & -.025 & .019 & -.031 & .019 \\
& -.487 & 1.52 & -.669 & 1.49 \\
\hline
\end{tabular}

${ }^{* *} \mathrm{p} \leq 0.01,{ }^{*} \mathrm{p} \leq 0.05, \dagger \leq 0.06$

The final main effects model, Model 4, explored the emotion-focused coping mechanisms with the PCL-5 score. This model showed the most significant effects among the coping mechanisms. Three separate coping mechanisms, growth, denial, and emotional support were significant. Growth had a negative and significant relationship with the PCL-5 score, that is, as the use of positive reinterpretation and growth-based coping increased, PTSD symptoms decreased. Denial was positively and significantly related to PCL-5 scores, indicating that higher levels of denial are also associated with suffering from higher levels of PTSD symptoms. This relationship corroborates other research indicating that using denial as a coping mechanism has negative impacts on 
mental health, PTSD included. Another coping mechanism to draw attention to in Model 4 was emotional support, which was borderline significant $(p$-value $=.051)$ also with a negative coefficient. This relationship shows that as emotional support coping increases, the presence of PTSD symptoms decreases. Like the previous model, gender was the only significant control variable. The negative correlation indicates that women suffer from significantly higher PCL-5 scores. The $\mathrm{R}^{2}$ for Model 4 was .282 indicating that approximately $28 \%$ of the variance in the sample is explained by this model.

In summary, there were multiple problem-focused and emotion-focused coping mechanisms that had a significant relationship with PTSD symptoms. The analyses using TRAUMA as the dependent variable had three significant coping mechanisms and the PCL-5 models had five significant coping mechanisms. Research question one asked whether problem-focused coping mechanisms were significantly associated with each of the PTSD variables, TRAUMA and PCL-5 scores. In models examining TRAUMA, planning and social support were significant. Among the models exploring PCL-5 scores, restraint and planning were significant. The second research question sought to explore whether there were significant associations between emotion-focused coping mechanisms and TRAUMA and PCL-5 scores. Findings for the TRAUMA models indicate that denial is the only significant emotion-focused coping mechanisms. Among PCL-5 models, growth, denial, and emotional support were found to be significant.

\section{Interaction Effects}

In order to answer research questions three and four, coping mechanisms that were significantly related to the PTSD symptom measures-TRAUMA and PCL-5

score - in the main effect models were used to create interaction terms with the exposure to trauma. The goal is to uncover whether the relationship between these coping 
mechanisms and PTSD symptoms are moderated by the officer's exposure to trauma. There were multiple coping mechanisms with significant effects in the previous models; and therefore, a number of interaction terms were created and analyzed. The terms were created by mean centering the coping mechanism score and multiplying this variable by the total exposure to trauma variable (i.e., denial*exposure to trauma).

Within the TRAUMA models, there were three significant direct effects between coping and PTSD. They include planning, social support, and denial. Table 5.7 outlines the results for the problem-focused interaction model with TRAUMA as the dependent variable.

Table 5.7: Problem-Focused Interaction Effects with TRAUMA

\begin{tabular}{lcccc}
\hline Variables & \multicolumn{2}{c}{ Model 5 } & \multicolumn{2}{c}{ Model 6 } \\
\hline & B & SE & B & SE \\
\cline { 2 - 5 } Planning & $-1.38^{*}$ & .581 & -- & -- \\
Planning*Exposure to Trauma & .176 & .160 & -- & -- \\
Social Support & -- & -- & -.035 & .560 \\
Social Support*Exposure to Trauma & -- & -- & .023 & .163 \\
Exposure to Trauma & $2.75^{* *}$ & .559 & $2.36^{* *}$ & .570 \\
Age & .001 & .079 & -.005 & .081 \\
Gender & $-3.21^{*}$ & 1.59 & -2.54 & 1.65 \\
Marital Status & -.164 & 1.39 & -.200 & 1.44 \\
Security Level & -1.34 & 1.86 & -.977 & 1.91 \\
Correctional Experience & -.015 & .013 & -.017 & .013 \\
Rank & -.238 & 1.00 & -.506 & 1.02 \\
& \multicolumn{2}{c}{$\mathrm{R}^{2}=.138$} & \multicolumn{2}{c}{$\mathrm{R}^{2}=.088$} \\
\hline
\end{tabular}

$* * \mathrm{p} \leq 0.01, * \mathrm{p} \leq 0.05$

Model 5 explored the interaction term for planning. The interaction term of planning*exposure to trauma was not significant. Exposure to trauma remained significant in this model. Finally, for model five, gender was significant and negative, once again indicating that women were more likely to suffer from PTSD symptoms than 
men. This is different than the main effects model in which gender was insignificant. The $\mathrm{R}^{2}$ for Model 5 is .138 , showing that $13.8 \%$ of the variance in the sample was explained in this model. Model 6 examined the interaction term social support*exposure to trauma. This interaction term was also found to be insignificant in this model. The only significant variable in this model was the exposure to trauma, which has consistently been associated with either PTSD symptom measure in all previous models. The $\mathrm{R}^{2}$ for Model 6 is .088, indicating that a small amount of the variance, approximately $9 \%$, is explained in the model.

Model 7 revealed the only significant emotion-focused coping mechanism, denial. This model indicated that the positive effect of the exposure to trauma on PTSD symptoms (TRAUMA) strengthened as the use of denial as a coping mechanism increased. This was the only significant interaction term in the current analysis. As with all previous models' exposure to trauma remained positive and significant. However, none of the control variables were significant in this model. The $\mathrm{R}^{2}$ for Model 7 was .196, signifying that approximately $19 \%$ of the variance in the sample is explained by this model. Table 5.8 outlines the model with the denial interaction term. 
Table 5.8: Emotion-Focused Interaction Model with TRAUMA

\begin{tabular}{lcc}
\hline Variables & \multicolumn{2}{c}{ Model 7 } \\
\hline & B & SE \\
\cline { 2 - 3 } Denial & .154 & .779 \\
Exposure to Trauma & $2.15^{* *}$ & .534 \\
Denial*Exposure to Trauma & $.450^{*}$ & .229 \\
Age & .006 & .077 \\
Gender & -1.72 & 1.54 \\
Marital Status & -.388 & 1.35 \\
Security Level & -.856 & 1.79 \\
Correctional Experience & -.017 & .013 \\
Rank & .116 & .957 \\
\end{tabular}

$* * p \leq 0.01, * p \leq 0.05$

The PCL-5 models demonstrated more coping mechanisms that were significant than the TSI-2 models. For problem-focused coping mechanisms, the significant main effects included planning and restraint. The interaction terms for both planning and restraint were created, and then analyzed in Models 8 and 9. Table 5.9 presents the models with these problem-focused interaction terms.

Table 5.9: Problem-Focused Interaction Models with PCL-5

\begin{tabular}{|c|c|c|c|c|}
\hline \multirow[t]{2}{*}{ Variables } & \multicolumn{2}{|c|}{ Model 8} & \multicolumn{2}{|c|}{ Model 9} \\
\hline & B & SE & B & SE \\
\hline Planning & -1.16 & .917 & -- & -- \\
\hline Planning*Exposure to Trauma & -.114 & .254 & -- & -- \\
\hline Restraint & -- & -- & 1.54 & 1.13 \\
\hline Restraint*Exposure to Trauma & -- & -- & -.421 & .328 \\
\hline Exposure to Trauma & $4.37^{*}$ & .882 & $3.65^{*}$ & .907 \\
\hline Age & -.208 & .117 & -.226 & .121 \\
\hline Gender & $-5.51^{*}$ & 2.50 & -4.25 & 2.58 \\
\hline Marital Status & .227 & 2.18 & -.438 & 2.28 \\
\hline Security Level & -.774 & 2.98 & .155 & 3.07 \\
\hline Correctional Experience & -.027 & .019 & -.030 & .020 \\
\hline \multirow[t]{2}{*}{ Rank } & -.569 & 1.54 & -1.46 & 1.56 \\
\hline & \multicolumn{2}{|c|}{$\mathrm{R}^{2}=.195$} & \multicolumn{2}{|c|}{$\mathrm{R}^{2}=.141$} \\
\hline
\end{tabular}

$* * \mathrm{p} \leq 0.01, * \mathrm{p} \leq 0.05$ 
Unfortunately, even though both planning and restraint had significant main effects in previous models, their interaction terms did not produce any significant effects. For Model 8, which examined planning, the interaction term was insignificant. Exposure to trauma remained significant in this model. Gender was also significant and negative, which has been consistent with previously examined PCL-5 models. Approximately 19\% of the variance in the sample was explained by Model 8. Model 9, exploring a possible moderating effect for restraint with the exposure to trauma, was also nonsignificant. In fact, the only significance that was displayed in this model was on the exposure to trauma variable. Gender was insignificant, which is different from the main effects model where gender was significant. The $\mathrm{R}^{2}$ for Model 9 indicated that $14 \%$ of the variance was explained.

The main effects emotion-focused models for the PCL-5 yielded three significant effects including growth, denial, and emotional support. After creating the interaction terms for each coping mechanism and running them through analyses, it was found that none of the interaction terms were significant. Table 5.10 provides the linear regressions for each of the coping mechanisms in models 10,11 , and 12 .

Model 10, which analyzed growth, did not show significance in the interaction terms. Gender was negative and significant in this model, reiterating the risk of being female in relation to developing PTSD symptoms. Approximately 17\% of the variance within the sample was explained through this model $\left(\mathrm{R}^{2}=.167\right)$. Denial was examined in Model 11. Although the TSI-2 interaction model found denial*exposure to trauma to be significant, the same relationship was not found in the PCL-5 interaction model. In fact, the only significant variable in Model 11 was exposure to trauma. Model 11 explained 
$23.5 \%$ of the variance in the sample $\left(\mathrm{R}^{2}=.235\right)$. Finally, emotional support was analyzed in Model 12. This model also did not find significance among the interaction term emotional support*exposure to trauma. Once again, the exposure to trauma was positive and significant. Gender was significant and negative. The final $\mathrm{R}^{2}$ for the current analysis indicates that Model 12 explained $15.6 \%$ of the variance within the sample $\left(R^{2}=.156\right)$.

In summary, Models 5 through 12 explored possible moderating effects of the coping mechanisms that were found to be significant in the main effect models. These models were run with the intention to answer research questions three and four., which seek to explore the moderation effects of problem-focused and emotion-focused coping on the relationship between exposure to trauma and PTSD. There were no significant interaction terms among the problem-focused variables in both the TSI- 2 models and the PCL-5 models. For the PCL-5 model there were no significant interaction terms for the emotion-focused variables. However, there was one significant emotion-focused interaction term within the TSI-2 model. The interaction term denial*exposure to trauma was positive and significant. The fact that there was only one significant interaction term, which indicates that coping does not consistently moderate the relationship between exposure to traumatic events and the development of PTSD symptoms. The next chapter focuses on the discussion surrounding the findings of the current analysis. Additionally, limitations and policy implications are presented. 
TABLE 5.10: PCL-5 Interaction Effects, Emotion-Focused

\begin{tabular}{lcccccc}
\hline Variables & \multicolumn{2}{c}{ Model 10 } & \multicolumn{2}{c}{ Model 11 } & \multicolumn{2}{c}{ Model 12 } \\
\hline & $\mathrm{B}$ & $\mathrm{SE}$ & $\mathrm{B}$ & $\mathrm{SE}$ & $\mathrm{B}$ & $\mathrm{SE}$ \\
\cline { 2 - 7 } Growth & -1.58 & .956 & -- & -- & -- & -- \\
Growth*Exposure to Trauma & .116 & .284 & -- & -- & -- & -- \\
Denial & -- & -- & 1.84 & 1.24 & -- & -- \\
Denial*Exposure to Trauma & -- & -- & .267 & .366 & & \\
Emotional Support & -- & -- & -- & -- & -.257 & .804 \\
Emotional Support*Exposure to Trauma & -- & -- & -- & -- & -.171 & .246 \\
Exposure to Trauma & $3.85^{* *}$ & .882 & $3.45^{* *}$ & .851 & $3.56^{* *}$ & .896 \\
Age & -.203 & .119 & -.192 & .115 & -.207 & .120 \\
Gender & $-5.89^{*}$ & 2.56 & -3.06 & 2.44 & $-5.51^{*}$ & 2.58 \\
Marital Status & .238 & 2.22 & -.222 & 2.13 & -.064 & 2.24 \\
Security Level & .369 & 3.04 & .747 & 2.91 & -.549 & 3.06 \\
Correctional Experience & -.033 & .020 & -.028 & .019 & -.028 & .020 \\
Rank & -.777 & 1.57 & -.761 & 1.48 & -1.84 & 1.56 \\
& \multicolumn{2}{c}{$\mathrm{R}^{2}=.167$} & & $\mathrm{R}^{2}=.235$ & & $\mathrm{R}^{2}=.156$ \\
\hline
\end{tabular}

$* * p \leq 0.01, * p \leq 0.0$ 


\section{CHAPTER 6: DISCUSSION AND CONCLUSION}

This chapter provides a deeper discussion of the findings from the analysis with a focus on how this work contributes to the existing literature. This research has implications for improving the mental health of correctional officers; and therefore, this chapter also focuses on implications for policy and practice. Lastly, limitations of the current analysis are discussed and directions for future research are explored.

\section{SUMMARY OF FINDINGS}

There were multiple important findings derived from this dissertation. First, it was reaffirmed that correctional officers are at a much higher risk than the general population for suffering PTSD. In this sample approximately $25 \%$ of the sample suffered from PTSD symptoms according to the TRAUMA variable. PCL-5 scores indicated that approximately $44.4 \%$ of the sample suffered from PTSD symptoms. These prevalence rates are similar to previous research regarding PTSD among correctional officers where PTSD rates ranged from 33\%-34\%, or 1 in 3 officers (Spinaris et al., 2012; Swartz et al., 2017). Second, exposure to trauma was significant across all models. Additionally, exposure to trauma was the only consistently significant variable across all models and the strongest predictor of PTSD symptoms. This is unsurprising, as previous research has consistently found that the magnitude of exposure to trauma is strongly correlated with the likelihood and level of PTSD symptoms (Denhof \& Spinaris, 2016; Spinaris et al., 2012; Swartz et al, 2017). Further, experiencing trauma is a requirement for developing 
PTSD, so it makes sense that the more trauma one endures the more severe their PTSD symptoms.

Third, the analysis revealed that there were several demographics and occupationrelated variables that were not important. Across all models, there were a surprising number of insignificant control variables. Research regarding age among correctional officers reveals that this characteristic is not significantly related to PTSD symptoms (Swartz et al., 2017). The current analysis corroborates the finding that age does not have a significant correlation with PTSD symptoms. Further, marital status has been relatively unexplored in its relationship to PTSD among correctional officers. There is, however, literature exploring marital functioning among veterans, and it has been found that veterans with PTSD are more likely to get a divorce and express less intimacy in their relationships (Cook, Riggs, Thompson, Coyne, \& Sheikh, 2004). Therefore, the significance could be absent because PTSD affects marriage and not necessarily the other way around.

Other job-related control variables, such as security level, correctional experience, and rank were also insignificant. These variables were expected to be important for multiple reasons. For example, research has found that individuals who work in a maximum-security facility experience more violent and traumatic events; and therefore, have increased levels of PTSD (Swartz et al., 2017). However, the traumatic experiences officers are reporting should be captured by the exposure to trauma variable, which is why security level may not reach significance. Second, this could be due to the fact that only $15 \%$ of the sample worked at a maximum-security facility. 
Next, correctional experience, the length of time an officer has served, was not significant in the analyses from the current study. Logically, it makes sense that the longer one serves, the more trauma they would be exposed to; and therefore, the more likely they would be to experience PTSD symptoms. Previous research has indicated that longer correctional careers were significantly related to social and emotional isolation, avoidant behaviors, and depression (Spinaris et al., 2013). Therefore, it is somewhat unexpected that correctional experience was not significant here. However, because the data from this study sought to explore symptoms from officers at all timepoints during their career, there is a possibility that the number of officers early in their career have not experienced enough cumulative trauma to trigger a PTSD significance. Furthermore, the inclusion of exposure to trauma could be pulling all of the significance of this variable. For example, the longer one works in the prison, the more exposure, and therefore the higher rates of trauma and PTSD. Additionally, it could be that officers who are equipped to stay in the profession and deal with the daily traumas do so, and officers who are more vulnerable to the negative effects of the job leave earlier in their careers.

The final control variable that was not significant was rank. This is unexpected because previous research has found that rank in the military was significantly related to PTSD symptoms. Rank has not been studied in correctional research yet, but corrections does utilize a paramilitary structure. Relatedly, Gates et al., (2012) noted that individuals who were of a lower military rank, had a moderately increased risk of PTSD development. The same could be said for correctional officers, as line officers tend to be the first to respond to critical incidents. However, among the current sample, rank was 
not significant. The reason for this insignificance is still unknown, however further examination of the correctional population could provide answers.

The fourth major finding was that further descriptive exploration found that there were coping mechanisms that were used more frequently than others. This is an important finding because other research has indicated that how individuals cope can affect different aspects of their mental health including depression, anxiety, and PTSD. This contributes to the current correctional officer literature because an extensive study of correctional officer coping mechanisms has not been explored until now. The first set of linear regression models, those that explored the main effects between coping and PTSD symptoms, yielded multiple significant effects for both the TSI-2 and the PCL-5. More so, this study expands on the coping and PTSD literature by evaluating how coping directly affects PTSD symptoms among a correctional officer population. In further multivariate analysis, there was one significant interaction term, denial, revealing that the exposure to trauma puts those at an even higher risk for PTSD symptoms if they rely upon denial as a coping mechanism.

The current dissertation aimed to answer four main research questions. The following sections outline the answers to the research questions and table 6.1 summarizes these findings.

\section{Research Question 1: Problem-Focused Coping and PTSD}

The first research question sought to understand the relationship between problem-focused coping mechanisms and PTSD symptoms. Model 1 addressed this research question by analyzing the relationships between the problem-focused coping mechanisms with TRAUMA, the measure of PTSD symptoms from the TSI-2, while 
controlling for the exposure to trauma, and additional control variables. Similarly, Model 3 examined the same model as Model 1 but predicting PTSD symptoms from the PCL-5. Only one problem-solving coping mechanism demonstrated a consistent relationship across both PTSD assessments. The coping mechanism, planning, demonstrated a significant and negative relationship with both PTSD measures. That is, officers are more likely to suffer from increased PTSD symptoms when they do not utilize planning coping mechanisms. The planning coping mechanism asks about how the officer plans to handle the stressor. Therefore, officers who did not think about what steps to take or how to handle their stresses were likely to suffer from increased PTSD symptoms. The National Institute of Mental Health (2019) notes that having strategies, one of which could be planning, to get through traumatic events serves as a resiliency factor and could possibly contribute to lower levels of PTSD. This illustrates that if the use of planning as a coping mechanism in response to trauma could be increased among correctional officers, it could potentially insulate them from developing PTSD symptoms.

Two additional problem-solving coping mechanisms were significantly associated with one of the two PTSD symptom measures. In the TRAUMA model, social support, was significant and positive, which is somewhat unexpected. Traditionally, research has found that traumatized adults benefit from increased social support (Brewin, Andrews, \& Valentine, 2000). One study focusing on prison officers found that social support within the prison moderated relationships between perceived physical health and increased psychological distress (Harvey, 2014). Harvey (2014) also found that social support from significant others did not have an impact on perceived physical health and psychological distress. More so, officers who utilize seeking social support, but do not find the support 
they are looking for, can lead them to feel dissatisfied with their friends and family relationships, causing them to cease reaching out for support, further isolating the officers (Flynn, Kecmanovic, \& Alloy, 2010; Harvey, 2014). Unfortunately, the benefits that other populations have seen regarding increased social support lowering PTSD symptoms has not been shown with this sample of correctional officers.

The other significant coping mechanism was in the PCL-5 model and was restraint. Restraint was positively associated with PCL-5 scores. In other words, as officers utilized more restraint to cope, they were more likely to suffer from PTSD symptoms. Research regarding how restraint impacts PTSD has not yet been explored. However, restraint could be seen as a form of suppression, in that the officer is not acting to face their stressors. This suppression can interrupt the way traumatized individuals revisit their trauma related thoughts which can possibly increase the likelihood of PTSD development. Individuals who have trauma-interrupted thoughts have more psychological symptoms of stress and PTSD (Beck et al., 2006).

Gender was not significant among the TRAUMA models; however, it was significant and negative in the PCL-5 models, indicating that being female was associated with a higher risk of suffering from PTSD symptoms. This is somewhat surprising because previous research, concerning correctional officers, has indicated that common demographic factors, gender included, have not place correctional staff at a higher risk for suffering from PTSD. (Spinaris et al., 2012; Swartz et al., 2017). However, this finding is supported among the broader PTSD literature, where women are more likely to suffer from PTSD than men (Kessler et al., 1995; McLean et al., 2011). As to why gender was significant in the PCL-5 models and not the TRAUMA models, it is possibly due to 
the increased number of cases included in the PCL-5 models, compared to the TRAUMA models. Due to the nature of the TSI-2 there was more missing data in the TRAUMA models.

Although there were significant coping mechanisms in Models 1 and 3, there were also some unexpected insignificant variables. In Models 1 and 3, active coping was not significant. This is interesting, as active coping has been shown to reduce depressive and PTSD symptoms among other populations (Clift \& Maratos, 2020). In Model 1, the TRAUMA model, restraint was insignificant. This is interesting because the same variable was significant in the PCL-5 model. It is definitely possible that the restraint variable is not being picked up in the PCL-5 model.

Within the models analyzing main effects, there were three significant coping mechanisms. They are planning, social support, and restraint. Planning was significant in both the TRAUMA model and the PCL-5 model. Social support was significant in the TRAUMA model, Finally, restraint was significant in the PCL-5 model.

\section{Research Question 2: Emotion-Focused Coping and PTSD}

Research question two sought to explore the relationship between emotionfocused coping mechanisms and PTSD symptoms. Models 2 and 4 address this research question by exploring the relationships between the emotion-focused coping mechanisms, and using the TSI-2 TRAUMA score and the PCL-5 score, respectively, while controlling for exposure to trauma and other relevant controls. In model 2, denial was the only significant coping mechanism. In both models, denial was significant and positive. Officers who used denial as a coping mechanism placed them at a higher risk to suffer from increased PTSD symptoms. Research on military veterans has posited that this 
finding could be related to not seeking PTSD treatment because they are in denial about the severity of their symptoms (Kaplan, 2008). Because undiagnosed PTSD rarely resolves itself, it makes sense that as individuals fail to seek treatment, they suffer from increased severity of PTSD as is supported in the current research.

Model 4 revealed the most significant relationships of any of the models in the current analysis. In addition to denial, which is discussed above, Model 4 also indicated that growth and emotional support were significantly related to PTSD. As officers utilized growth, the intention of turning the stressor into a learning situation or a positive reinterpretation, the less likely they were to suffer from PTSD. This finding is expected, as the National Institute of Mental Health (2019) found that individuals who try to learn something from their experiences were more resilient to developing PTSD. Therefore, a coping program that emphasizes the use of growth as a coping mechanism among correctional officers could help officers be more resilient and decrease the likelihood of developing symptoms of PTSD.

Emotional support, the final significant coping mechanism in the model was negative. Therefore, as emotional support among officers increased, PTSD symptoms decreased. This finding is unsurprising as emotional support has been found to be a successful part of PTSD treatment. Emotional support can include talking to someone about the situation, However, research on PTSD has found that Cognitive Processing Therapy, which focuses on the discussion of feelings and thoughts surrounding PTSD is effective in decreasing PTSD symptoms (Tran, Moulton, Santesso, \& Rabb, 2016). Therefore, talking about feelings regarding PTSD has been determined to decrease PTSD symptoms. It stands to reason that officers who do not utilized emotional support are 
likely to suffer from increased PTSD symptoms. Exposure to trauma was significant in Model 2 and Model 4, which is consistent with other models presented. Finally, gender was significant, and this has been consistent throughout the across the PCL-5 models.

The current analysis revealed that some emotion-focused coping mechanisms were significantly associated with PTSD symptoms. Specifically, denial, was related to increased PTSD symptoms. Growth and emotional support were negative, meaning that when officers did not utilize them, they had increased levels of PTSD.

\section{Research Question 3: Exploration of Problem-Focused Coping as a Moderator}

Research questions three and four explored whether coping moderated the relationship between exposure to trauma and PTSD symptoms. Research question three focused on problem-focused coping mechanisms as a moderator and research question four focused on the emotion-focused coping mechanisms. There were three significant problem-focused coping mechanisms in the main effect models. In the main effects TRAUMA model, planning and social support were significant. In the PCL-5 models, planning and restraint were significant. Four interaction terms were created and four interaction terms were analyzed. None of the models produced significant interaction terms. Across all the models, exposure to trauma was significant, indicating that is the strongest and most consistent predictor of PTSD symptoms.

Model 5 analyzed planning*exposure to trauma with the TRAUMA variable and Model 8 analyzed planning*exposure to trauma with the PCL-5 variable. Both of these interaction terms were insignificant. This finding is interesting, as the NIMH (2019) argues that planning is a resiliency factor that can insulate individuals from suffering 
from PTSD. It is logical to believe that officers who utilize planning will fare better than those who do not when exposed to comparable levels of trauma. However, the insignificance of these interaction terms shows that the relationship exposure to trauma has on PTSD symptoms is not weakened by the use of planning to cope.

Model 6 analyzed the interaction term for social support, which was also insignificant. Social support does not moderate the relationship between exposure to trauma and PTSD. The usage of social support among correctional officers does not have an effect on the strength of the relationship between exposure to trauma and PTSD symptoms.

Model 9 focused on restraint. The interaction term of restraint*exposure to trauma was not significant. While the direct effect within the PCL-5 model indicated significance, there was no such relationship when looking at restraint as a moderator. Restraint, which shows to have an impact on how individuals handle their traumatic thoughts, does not have an effect on the strength of the relationship between exposure to trauma and PTSD, even though there is a direct effect between restraint and PTSD symptoms. The only significant variable in model nine was exposure to trauma, which is expected.

Unfortunately, none of the problem-focused coping mechanisms moderated the relationship between trauma and PTSD symptoms in this analysis. Regardless of the fact that most of the coping mechanisms explored did not, affect the strength of the relationship between exposure to trauma and PTSD symptoms, these coping mechanisms did have significant main effects; and therefore, are valuable for future research and programming. 


\section{Research Question 4: Exploration of Emotion-Focused Coping as a Moderator}

The last research question focused on whether any of the emotion-focused coping mechanisms that had been significant in the main effect models, moderated the relationship between the exposure to trauma and the PTSD measures. There were three significant emotion-focused coping mechanisms in the main effect models. Denial was significant in both the main effect TRAUMA model and the main effect PCL-5 model. Then, in the main effect PCL-5 model, growth and emotional support were also significant. This means that four interaction models were analyzed - one for each of the coping mechanisms.

Of the four models, only the TRAUMA model with the interaction term denial*exposure to trauma was positive and significant. Essentially, this significance means that denial moderates the relationship between exposure to trauma and PTSD symptoms. In other words, as a correctional officer's use of denial as a coping mechanism increases, the relationship between exposure to trauma and PTSD symptoms strengthens. This effect is unique because it indicates that officers who use denial, when exposed to similar levels of trauma, are more likely to suffer from PTSD symptoms than officers who do not use denial as a coping mechanism. Therefore, using denial actively increases a traumatized officer's likelihood of developing PTSD symptoms. It becomes imperative, then, to decrease the use of denial among correctional officers. This relationship indicates that denial is of special interest to research and programming for officers, because increased use of denial has been related to increased anxiety and 
increased suicidal ideation, and now, PTSD symptoms (Khazem et al., 2015; Liverant et al. (2004).

The final models analyzed the potential moderating effects for emotion-focused coping, exposure to trauma, and their interaction terms under the PCL-5 dependent variable, all of which were nonsignificant. The models explored growth*exposure to trauma, denial*exposure to trauma, and emotional support*exposure to trauma, respectively. None of these interaction terms were significant. Because of these findings, emotion-focused coping mechanisms do not consistently moderate the relationship between exposure to trauma and PTSD symptoms.

Among the emotion-focused coping mechanisms that were significant, only one of the interaction terms, denial*exposure to trauma, was significant. Further, it was only significant in the model where TRAUMA was the dependent variable and not in the PCL5 model. Consequently, there is not consistency across PTSD assessments when analyzing whether denial moderates the effect of exposure to trauma on PTSD symptoms. Unfortunately, it does not appear that emotion-focused coping mechanisms consistently moderate the relationship between exposure to trauma and PTSD symptoms. However, encouraging or training officers to use mechanisms other than denial could possibly lead to a decrease in PTSD symptoms.

Table 6.1 summarizes the findings of the current analysis. The remainder of this chapter focuses on limitations, policy and practical implications, and directions for future research. 
Table 6.1: Summarization of Findings

Research Question

RQ1: Are problem-focused coping mechanisms associated with the number of PTSD symptoms experienced by correctional officers?

RQ2: Are emotion-focused coping mechanisms associated with the number of PTSD symptoms experienced by correctional officers?

RQ3: Do the problem-focused coping mechanisms that are associated with PTSD symptoms moderate the relationship between the amount of trauma/violence exposure and PTSD symptoms?

RQ4: Do the emotion-focused coping mechanisms that are associated with PTSD symptoms moderate the relationship between the amount of trauma/violence exposure and PTSD symptoms?

\section{Findings}

Yes; For the TSI-2 planning and social support were significant. For the PCL-5 restraint and planning were significant.

Yes; For the TSI-2 denial was significant. For the PCL-5 growth, denial, and emotional support were significant.
No; There were no significant interaction terms among the problem-focused coping mechanisms, regardless of dependent variable.
Somewhat; Only one emotion-focused coping mechanism, denial, had a significant interaction term in the model examining the TSI-2. None of the other interaction terms were significant, regardless of dependent variable.

\section{LIMITATIONS}

Although it was the cognizant goal of the principal investigator and research team to follow best practice in their design and study implementation, the current study is not without limitations. The first limitation of the current study is that it is cross-sectional in nature. The current analysis provides only a snapshot of the very dense data. Because 
there is only one timepoint included in the current analysis, temporal order cannot be determined and causal inferences cannot be made.

Second, all of the data included in the current analysis is self-report data. Though the research team members explained that data would be kept confidential, and emphasized the importance of honesty, issues of memory and perception of the questions asked are inherent to survey research. As mentioned earlier, the survey was extremely extensive. A host of issues can come up with an extensive survey, including interpretation issues, assessment confusion, and survey fatigue.

Third, the violent and traumatic events measured by the TSI- 2 and the PCL-5 occurred in the past. The TSI-2 asks respondents to think back six months while the PCL5 has responders focus on the past month. Regardless, the officer must go back in their memory approximately 1-6 months to retrieve information, and are expected to accurately articulate the experiences on the survey. This situation could lead to officers over- or underestimating their trauma exposure due to their current state of mind. While the TSI-2 has multiple validity and reliability scales to combat this issue, the PCL-5 does not. Although there are issues with both assessments, they are both considered to be valid for use in examining PTSD and PTSD symptoms among multiple populations, officers included.

While some may argue that there could be a generalizability issue with only using correctional officers from seven prisons in one state, this author does not believe that there is an issue with generalizability in the current analysis. The current sample is very close in characteristics to other correctional officer samples, both state and nationwide; and therefore, the sample overall is representative of the larger officer population. For 
example, the Bureau of Labor Statistics notes that the correctional officer population for the year 2020 was $31.7 \%$ female, which is relatively close to the current sample's percentage, 26\% (BLS, 2020). However, as prefaced above, Swartz's original study of Kentucky correctional officers indicated that the sample was $78 \%$ male and $22 \%$ female. The average age for the current sample was 37.6 years old. This is almost identical to Swartz's study of officers in 2017, where the average age of officers was 37.2 years old. Therefore, the sample is generalizable in terms of gender makeup and age. There is additional evidence supporting that this sample is generalizable in other instances as well. Because the VIDES scores and PTSD prevalence rates were extremely similar to other state and national samples, this demonstrates that the level of trauma exposure is likely generalizable to correctional officers outside of this department of corrections. Denhof and Spinaris (2016), which has been previously mentioned, found that $22.5 \%$ of their sample had a VIDES score indicative of high exposure to trauma. In the current sample, approximately $21.8 \%$ of the sample had VIDES scores of high trauma exposure. Finally, the prevalence rates for PTSD among the different correctional officer samples are similar as well. In Spinaris et al., (2012) prevalence rates were approximately $27 \%$. Denhof and Spinaris (2016) found that 33.7\% of their correctional officer sample met the criteria for PTSD. Finally, the current sample indicated that $25 \%$ of correctional officers suffer from PTSD symptoms when measured by the TSI-2 and 44\% when measuring symptoms with the PCL-5. The similarity in prevalence rates also points to generalizability. 


\section{IMPLICATIONS FOR POLICY \& PRACTICE}

Previous research has indicated that correctional officers suffer from increased levels of PTSD (Denhof \& Spinaris, 2016; Spinaris et al., 2012; Swartz et al., 2017). Therefore, the next logical step is to explore the factors that impact correctional officers' likelihood of developing PTSD. While the research has demonstrated that exposure to trauma is a top factor in determining whether officers develop PTSD, not many other potential contributing factors have been explored. Contributing to this gap in the literature is the goal of this dissertation. One of the implications of the finding that officers suffer from increased exposure to trauma and increased PTSD symptoms is that research must now turn to try to understand what insulates officers from developing PTSD symptoms. Across other first responder populations, coping has been explored as a factor that contributes to the likelihood of PTSD development. However, coping has been rarely explored among correctional officer populations and had been unexplored in relation to PTSD until the current analysis. Therefore, it would be advantageous to take the results of the current analysis and explore possible policy and practice implications.

The current dissertation did reveal support for various coping mechanisms influencing the magnitude of PTSD symptoms suffered. For example, as officers increasingly use denial, they suffer from increased levels of PTSD symptoms. Even more so, denial has a significant impact on the relationship between exposure to trauma and PTSD in the TSI-2 models. These findings identify reducing the use of denial as a form as coping as a very important target for treatment. Additionally, use of other seemingly adaptive coping mechanisms, such as social support, had a positive relationship with PTSD, indicating that as officers used social support they reported increased PTSD 
symptoms. Therefore, one of the first implications is addressing how officer's cope with their job. Training officers on how to handle their trauma through coping mechanisms is extremely important. Department of Corrections should seek out programming that focuses on implementation of adaptive coping mechanisms. For example, programs that educate officers about the harm of maladaptive coping, such as denial, and an emphasis on teaching officers how to utilize their prosocial coping mechanisms, such as planning, emotional support, and growth could produce decreased PTSD symptoms. One such program that focuses on coping and more is mindfulness-based stress reduction.

In a program focusing on how to cope with stress through mindfulness meditation, participants in the experimental group listened to multiple lectures about stress and coping, had physiological metrics taken, and practiced mindfulness meditation. Those who participated in the program had significantly lower stress, depression, and anxiety scores (Kang, Choi, \& Ryu, 2009). Mindfulness has been studied extensively among populations similar in structure to corrections, including military veterans. For example, Stephenson et al., (2017) found that veterans who screened positively for PTSD benefited from participating in a mindfulness-based stress reduction (MBSR) program. Furthermore, mindfulness has been studied among police officers. Krick and Felfe (2020) found that mindfulness-based interventions lead to reduction in physical strain and negative affect.

The study from which the data for the current dissertation came seeks to understand how a MBSR program would impact correctional officer PTSD. If this program, which is specifically created to correctional officers, is effective, there would be marked decreases in PTSD prevalence among the sample. Due to the success of 
mindfulness programs among other first responder populations, more mindfulness-based interventions should be added into correctional preservice and in-service training. Providing officers with increased MBSR and coping education in the preservice academy would allow for officers to enter their career with tools to manage and respond to the traumas they will inevitability face, possibly insulating them prior to exposure. Additionally, providing refresher treatments and programming throughout an officer's career can allow for continued development of prosocial coping mechanisms.

Next, department of corrections can look to the number of violent and traumatic events that officers experience to better understand policy and practice surrounding critical incidence responses. It has been shown that officers experience traumatic events more frequently than other populations, and that the compounding experiences of multiple traumatic events is related to increased PTSD symptoms. Therefore, it would be advantageous for correctional departments to develop programming in which repeatedly traumatized officers could participate to better handle their experiences in the prison setting. The chronic, repeated traumas that officers face could be classified as a complex trauma exposure or complex PTSD (CPTSD). Complex trauma is defined as a type of trauma that occurs repeatedly and cumulatively over a period of time within specific contexts (Courtois, 2004). Because this is similar to the traumas that officers face, they may benefit from treatment that has been successful among others who have experienced CPTSD. Although treatments for CPTSD are still being developed, cognitive behavioral therapy has been shown to be successful, as well as deconditioning and resolution of the trauma, and self-regulation (Courtois, 2004). Department of Corrections should continue to invest in accessible therapy options for their officers. Since correctional officers have 
been historically hesitant in participating in Employee Assistant Programs, Department leaders should do their best to provide options for officers that prioritize privacy and confidentiality (Lerman, 2017). These options may include therapist options off prison grounds, conducted by individuals unrelated to the prison system to alleviate the concerns regarding confidentiality. Further, Department of Corrections can encourage officers to utilize online therapy, through a forum such as BetterHelp.com or TalkSpace.com. These outlets allow for individuals to speak to licensed therapists from their homes, on their own time, allowing for ultimate privacy and confidentiality. Due to the inflexibility of a correctional officer's job, this may be a good option for officers.

Individuals who utilize both MBIs and therapy options have shown improvement with their PTSD symptoms, anxiety, depression, and even physical symptoms of stress. High levels of stress among correctional officers has been shown in the research to contribute to job burnout (Lambert et al., 2015). There are multiple consequences of job burnout including increased turnover among staff and increased absenteeism. Both of these consequences put intense stress on the prison and the officers who do show up for work on any given day. Therefore, it should be a goal of correctional departments to decrease job stress and job burnout. One of the ways that this can be achieved is through continued investment in programs that focus on providing mindfulness-based interventions and confidential therapy options for their officers.

\section{DIRECTIONS FOR FUTURE RESEARCH}

There are multiple opportunities for future research regarding correctional officers, their trauma exposure, coping, and PTSD symptoms. First, while research has 
established that increased amounts of trauma exposure is related to PTSD, we know much less regarding which specific types of traumatic events may have the most impact on a future PTSD diagnosis. For example, do attempted suicides in which the officer must save the inmate cause more trauma than witnessing an attack by inmates on another officer? These questions can be researched and answered to better understand how correctional departments should respond to certain critical incidents.

Next, coping should be explored on a more in-depth basis. While it has been determined that the current sample is representative of the larger correctional officer population as a whole, more research can be done with different coping assessments to see if the same effects remain across measurements. Specifically, the exploration of individual traumas should be explored within the realm of coping. For example, officers in the current sample were asked to identify their typical coping mechanisms when they face adversity. Identifying specific coping mechanisms that officer utilize after certain traumatic events would be a logical advancement of the coping literature. More so, there is a need for qualitative data to better understand how correctional officers respond to their traumas. Both focus groups and interviews should be utilized for complete understanding of trauma responses by officers.

The current analysis revealed that coping does not consistently moderate the relationship between exposure to trauma and PTSD symptoms. There may be, however, other moderators that have significant impacts on that relationship. These moderators should be explored. The impact of depressive symptoms would be a logical place to start, because approximately half of people who are diagnosed with PTSD are also diagnosed with Major Depressive Disorder (MDD) (Flory \& Yehuda, 2015). An exploration of how 
depressive symptoms impact the relationship between exposure to trauma and PTSD may shed light on how officers respond to their trauma.

Finally, future research should seek to implement programming to help correctional officers cope with their trauma. Programming focusing on mindfulness has been shown to be effective in other paramilitary structured organizations, such as military veterans and police officers. Mindfulness-based interventions for correctional officers have begun to be explored on a state-level, but more programming is needed. Further, evaluations of programming are necessary to determine effectiveness, where effectiveness is the decrease in PTSD symptoms and prevalence among correctional officers.

\section{CONCLUSIONS}

Although research regarding PTSD and first responders has received increased attention over the past decades, correctional officers have been underacknowledged in this category until rather recently. Thankfully, academic research has begun to fill this gap in the literature. Unfortunately, research has shown that correctional officers suffer from PTSD at higher rates than those in the general population due to the chronic traumatic nature of their work. Now that PTSD rates among correctional officers have been thoroughly identified, in both state-wide studies (Denhof \& Spinaris, 2016; Swartz et al., 2017) and a national study (Spinaris et al., 2012), research can shift focus to understanding what factors have influences on severity of PTSD and PTSD symptoms.

Consequently, the current dissertation sought to fill gaps in both the correctional literature, the PTSD literature, and the coping literature by examining the relationships between coping and PTSD symptoms among correctional officers. Utilizing survey responses of approximately 245 correctional officers across seven Kentucky prisons, the 
current analysis revealed some important findings regarding coping and PTSD among correctional officers. These questions were answered using two PTSD assessments, a coping assessment, and a trauma exposure assessment (Briere, 2011; Carver 1989; Denhof \& Spinaris, 2014; Weathers et al., 2015). First, there are significant relationships between problem-focused coping mechanisms and PTSD symptoms. Second, there are also multiple emotion-focused coping mechanisms that have direct relationships with PTSD symptoms. Third, none of the significant problem-focused coping mechanisms acted as a significant moderator on the relationship between exposure to trauma and PTSD symptoms. Finally, denial was shown to have a positive significant moderating effect on the relationship between exposure to trauma and PTSD symptoms. These results provide multiple implications for the mental health and overall wellbeing of correctional officers and provide next steps for continuing the coping research.

Correctional officers have typically not been recognized as first responders; however, as the work correctional officer do and the risk involved are better understood, it is clear that they should be considered first responders. Research has begun to outline and acknowledge the important and difficult job they perform on a daily basis. Correctional officers, who often suffer silently, deserve access to training and treatment to prevent and mitigate the devastating symptoms of PTSD, as well as depression and anxiety. It is the overall goal of this dissertation to shed light on the current issues that correctional officers face so that relevant policies and practices may be introduced to reduce the amount of stress and PTSD from which correctional officers suffer. Unfortunately, many of the stressors that correctional officers face such as violence, overcrowding, being under-staffed, and under-compensated, will not be going away anytime 
soon. Therefore, the goal is to arm correctional officers with tools that will keep them well, both physically and mentally as they perform their duty to protect the inmates they supervise, their brothers and sisters in blue, and the community as a whole. 


\section{REFERENCES}

Aaron, J. D. K. (2000). Stress and coping in police officers. Police Quarterly, 3(4), 438450.

Abel, M. H. (2002). Humor, stress, and coping strategies. Humor (15)4, 365-381.

Adams, S., (2015). America's most dangerous jobs. Forbes Magazine. Retrieved from: https://www.forbes.com/sites/susanadams/2015/07/23/americas-most-dangerousjobs/?sh=1e81005e57ce

American Psychiatric Association. (2013). Diagnostic and statistical manual of mental disorders ( $5^{\text {th }}$ ed.). Arlington, VA: American Psychiatric Publishing.

Astor-Dubin, L. \& Hammen, C. (1984). Cognitive versus behavioral coping responses of men and women: A brief report. Cognitive Therapy and Research, (8)1, 85-90.

Auerbach, C., Beckerman, N. L., \& Blanco, I. (2013). Women coping with chronic disease: The psychosocial impact of lupus. Journal of Social Service Research, 39(5), 606-615.

Aupperle, R. L., Melrose, A. J., Stein, M. B., Paulus, M. P. (2012). Executive function and PTSD: Disengaging from trauma. Neuropharmacology, 62, 686-694.

Beck, J. G., Gudmundsdottir, B., Palyo, S., Miller, L. M., \& Grant, D.M. (2006). Rebound effects following deliberate thought suppression Does PTSD make a difference? Behavioral Therapy 37(2), 170-180

Benight, C. C., Freyaldenhoven, R. W., Hughes, J., Ruiz, J. M., Zoschke, T. A., \& Lovallo. (2000). Coping self-efficacy and psychological distress following the 
Oklahoma City bombing. Journal of Applied Social Psychology, 30(7), 1331-1344.

Billings, A. G., \& Moos, R. H. (1981). The role of coping responses and social resources in attenuating the stress of life events. Journal of Behavioral Medicine, 4, 139157.

Bishop, G. D., Tong, E. M. W., Diong, S. M., Enkelmann, H. C., Why, Y. P., Khader, M., Ang, J. C. H. (2001). The relationship between cooping and personality among police officers in Singapore. Journal of Research in Personality, 35, 353374.

Blake, D. D., Keane, T. M., Wine, P. R., Mora, C., Taylor, K. L., \& Lyons, J. A. (1990). Prevalence of PTSD symptoms in combat veterans seeking medical treatment. Journal of Traumatic Stress, 3(1), 15-27.

Blevins, C. A., Weathers, F. W., Davis, M. T., Witte, T. K., \& Domino J. L. (2015). The posttraumatic stress disorder checklist for DSM-5 (PCL-5): Development and initial psychometric for evaluation. Journal of Traumatic Stress, 28, 489-498.

Boden, M. T., Bonn-Miller, M. O., Vujanovic, A. A., \& Drescher, K. D. (2012). A prospective investigation of changes in avoidant and active coping and posttraumatic stress disorder symptoms among military veteran. Journal of Psychopathology and Behavioral Assessment, 34, 433-439.

Boden, M. T., Kimerling, R., Kulkarni, M., Bonn-Miller, M. O., Weaver, C., \& Trafton, J. (2014). Coping among military veterans with PTSD in substance use disorder treatment. Journal of Substance Abuse Treatment, 47, 160-167. 
Boffa, J. W., Stanley, I. H., Hom, M. A., Norr, A. M., Joiner, T. E., \& Schmidt, N. B. (2017). PTSD symptoms and suicidal thoughts and behaviors among firefighters. Journal of Psychiatric Research 84, 277-283.

Boudoukha, A. H., Altintas, E., Rusinek, S., Fantini-Hauwel, C., \& Hautekeete, M. (2013). Inmates-to-staff assaults, PTSD and burnout: profiles of risk and vulnerability. Journal of Interpersonal Violence, 28(11), 2332-2350.

Bovin, M. J., Marx, B. P., Weathers, F. W., Gallagher, M. W., Rodriguez, P., Schnurr, P. P., \& Keane, T, M. (2016). Psychometric properties of the PTSD checklist for Diagnostic and Statistical Manual of Mental Disorders- Fifth Edition (PCL-5) in veterans. Psychological Assessment, 28(11), 1379-1391.

Bower, J. (2013). Correctional officer wellness and safety literature review. Office of Justice Programs.

Brewin, C. R., Andrews, B., \& Valentine, J. D. (2000) Meta-analysis of risk factors for posttraumatic stress disorder in trauma-exposed adults. Journal of Consulting and Clinical Psychology, 68(5), 748-766

Briere, J. (2011). Trauma Symptom Inventory- 2 (TSI-2). Lutz, FL: Psychological Assessment Resources, Inc. Retrieved from http://www.parnic.com/Products/Product.aspx?ProductID=TSI-2

Briere J., Elliot, D. M., Harris, K., \& Cotman, A. (1995). Trauma symptom inventory: Psychometrics and association with childhood and adult victimization in clinical samples. Journal of Interpersonal Violence, 10(4), 387-401.

Bureau of Labor Statistics (2020). Retrieved from https://www.bls.gov/cps/cpsaat11.htm 
Cadamuro, A., Versari, A., Vezzali, L., Giovannini, D., \& Trifiletti, E. (2015). Cognitive performance in the aftermath of a natural disaster: The role of coping strategies, theory of mind, and peer social support. Child Youth Care Forum, 44, 93-113.

Caplan, R. D. (1983). Person-environment fit: Past, present, and future. In C. L. Cooper (Ed.), Stress Research (pp. 35-78). New York: Wiley.

Carlson, J. R., Anson, R. H., \& Thomas, G. (2003). Correctional officer burnout and stress: Does gender matter? The Prison Journal, 83(3), 277-288.

Carver, C. S. (1997). You want to measure coping but your protocol's too long: Consider the Brief COPE. International Journal of Behavioral Medicine, 4, 92-100.

Carver, C. S., Scheier, M. F., \& Weintraub, J. K. (1989). Assessing coping strategies: A theoretically based approach. Journal of Personality and Social Psychology, $56(2), 267-283$.

Chamberlain, M. J. A., \& Green, H. J. (2010). Stress and coping strategies among firefighters and recruits. Journal of Loss and Trauma, 15, 548-560.

Cohen, S., \& Edwards, J. R. (1989). Personality characteristics as moderators of the relationship between stress and disorder. In R. W. J. Neufeld (Ed.), Advances in the investigation of psychological stress (pp. 235-283). New York: Wiley

Contractor, A. A., Armour, C., Shea, M. T., Mota, N., \& Pietrzak, R. H. (2016). Latent profiles of DSM-5 PTSD symptoms and the "big five" personality traits. Journal of Anxiety Disorders, 37, 10-20.

Cook, J. M., Riggs, D. S., Thompson, R., Coyne, J. C., \& Sheikh, J. I. (2004). Posttraumatic stress disorder and current relationship functioning among World War II ex-prisoners of war. Journal of Family Psychology, 18, 36-45. 
Costello, E., Bogue, J. E., Sarma, K., \& McGuire, B. E. (2015). Chronic pain in Irish prison officers: Profile and predictors of pain-related disability and depression. Pain Medicine, 16, 2292-2301.

Courtois, C. A. (2004). Complex trauma, complex reactions: Assessment and treatment. Psychotherapy: Theory, Research, Practice, Training, 41(4), 412-425

Cullen, F., Link, B., Wolfe, N., \& Frank, J. (1985). The social dimensions of correctional officer stress. Justice Quarterly, 2, 505-533.

Davidson, J. R. T. (2000). Trauma: The impact of post-traumatic stress disorder. Journal of Psychopharmacology, 14(2), S5-S12.

Delahaij, R., \& Van Dam, K. (2017). Coping with acute stress in the military: The influence of coping style, coping self-efficacy, and appraisal emotions. Personality and Individual Differences 119, 13-18.

DeLongis, A., Lazarus, R.S., \& Folkman, S. (1988). The impact of daily stress on health and mood: Psychological and social resources as mediators. Journal of Personality and Social Psychology, 54, 486-495.

Denhof, M. D., \& Spinaris, C. G. (2013). Depression, PTSD, and Comorbidity in United States Corrections Professionals: Prevalence and Impact on Health and Functioning. Retrieved from: https://desertwaters.com/wpcontent/uploads/2013/09/Comorbidity_Study_09-03-131.pdf

Denhof, M. D., \& Spinaris, C. G. (2014). The Violence, Injury, and Death Exposure Scale (VIDES). Retrieved from https://desertwaters.com/wpcontent/uploads/2014/01/VIDES_Data_Sheet.pdf 
Denhof, M, D., \& Spinaris, C. G. (2014). Occupational stressors in corrections organizations: Types, effects, and solutions. National Institute of Corrections. Retrieved from https://info.nicic.gov/nicrp/system/files/028299.pdf

Denhof, M. D., \& Spinaris, C. G. (2016). Prevalence of Trauma-Related Health Conditions in Correctional Officers: A Profile of Michigan Corrections Organization Members. Retrieved from http://www.mcoseiu.org/files/2016/05/MCO-Paper_FINAL.pdf

Dignam, J. T., Barrera, M., \& West, S. G. (1986). Occupational stress, social support, and burnout among correctional officers. American Journal of Community Psychology, 14(4). 177-193.

Dollard, M. F. \& Winefield, A. H. (1996). A test of demand-control/support model of work stress in correctional officers. Journal of Occupational Health Psychology, $3(3), 243-264$.

Edens, J. F., Otto, R. K., Dwyer, T. J. (1998). Susceptibility of the trauma symptom inventory to malingering. Journal of Personal Assessment, 71(3), 379-392.

Elhai, J. D., Gray, M. J., Kashdan, T. B., \& Franklin, L. C. (2005). Which instruments are most commonly used to assess traumatic event exposure and posttraumatic effects? A survey of traumatic stress professionals. Journal of Traumatic Stress, $18(5), 541-545$.

Faulk, K. E., Gloria, C. T., \& Steinhardt, M. A. (2013). Coping profiles characterize individual flourishing, languishing, and depression. Anxiety, Stress, \& Coping, 26(4), 378-390. 
Flory, J. D. \& Yehuda, R. (2015). Comorbidity between post-traumatic stress disorder and major depressive disorder: Alternative explanations and treatment considerations. Dialogues in Clinical Neuroscience, 17(2), 141-150.

Flynn, M., Kecmanovic, J., \& Alloy, L. B. (2010). An examination of integrated cognitive-interpersonal vulnerability to depression: The role of rumination, perceived social support, and interpersonal stress generation. Cognitive Therapy and Research, 34(5), 456-466

Folkman, S. \& Lazarus, R. S. (1980). An analysis of coping in a middle-aged community sample. Journal of Health and Social Behavior 21(3), 219-239.

Folkman, S. \& Lazarus, R. S. (1985). If it changes it must be a process: Study of emotion and coping during three stages of a college examination. Journal of Personality and Social Psychology 48(1), 150-170.

Folkman, S., Lazarus, R. S., Gruen, R. J., \& DeLongis, A. (1986). Dynamics of a stressful encounter: Cognitive appraisal, coping, and encounter outcomes. Journal of Personality and Social Psychology, 50, 992-1012.

Fjeldheim, C. B., Nothling, J., Pretorius, K., Basson M., Ganasen, K., Heneke, R., Cloete, K. J., \& Seedat, S. (2014). Trauma exposure, posttraumatic stress disorder and the effect of explanatory variables in paramedic trainees. BMC Emergency Medicine, 14(11), 1-7.

Folwell, A., \& Kauer, T. (2018). 'You see a baby die and you're not fine:' a case study of stress and coping strategies in volunteer emergency medical technicians. Journal of Applied Communication Research, 46(6), 723-743. 
Frazier, P. A. \& Burnett, J. W. (1994). Immediate coping strategies among rape victims. Journal of Counseling and Development, 72, 633-639.

Gates, M. A., Holowka, D. W., Vasterling, J. J., Keane, T. M., Marx, B. P., \& Rosen, R. C. (2012). Posttraumatic stress disorder in veterans and military personnel: Epidemiology, screening, and case recognition. Psychological Services, 9, 361382

Garnefski, N., Legerstee, J., Kraaij, V., van den Kommer, T., \& Teerds, J. (2002). Cognitive coping strategies of depression and anxiety: A comparison between adolescents and adults. Journal of Adolescence, 25(6), 603-611.

Goulette, N., Denney, A. S., \& Crow, M. S. (2020). "Anything can happen at any time": Perceived causes of correctional officer injuries. Criminal Justice Review, 1-17.

Greenglass, E., Schwarzer, R., Jakubiec, D., Fiksenbaum, L., \& Taubert, S. (1999). The proactive coping inventory (PCI): A multidimensional research instrument, presented at International Conferences of the Stress and Anxiety Research Society (STAR), Cracow, Poland, 1999.

Griffin, M. L. (2006). Gender and stress: A comparative assessment of sources of stress among correctional officers. Journal of Contemporary Criminal Justice, 22(1), 425.

Griffin, M. L., \& Hepburn, J. R. (2006). The effect of gang affiliation on violence misconduct among inmates during the early years of confinement. Criminal Justice and Behavior, 33, 419-448.

Gruen, R. J., Folkman, S., \& Lazarus, R. S. (1988). Centrality and individual differences in the meaning of daily hassles. Journal of Personality, 56, 743-762. 
Harvey, J. (2014). Perceived physical health, psychological distress, and social support among prison officers. The Prison Journal, 94(2), 242-259

Higgins, E. M., Swartz, K., \& Roberts, A. (2021). How conflict 'bleeds over' for correctional staff: Exploring work-family conflict through correctional subculture. Journal of Crime and Justice, 1-17.

Hogan, N. L., Lambert, E. G., Jenkins, M., Wambold, S. (2006). The impact of occupational stressors on correctional staff organization commitment: A preliminary study. Journal of Contemporary Criminal Justice, 22(1), 44-62.

Hooker, K., Fraizer, L. D., \& Monahan, D. J. (1994). Personality and coping among caregivers of spouses with dementia. The Gerontologist, 34(3), 386-392.

James, D., \& Glaze, L. E. (2006). Mental Health Problems of Prison and Jail Inmates. Washington, DC: Bureau of Justice Statistics.

James, L., \& Todak, N. (2018). Prison employment and post-traumatic stress disorder: Risk and protective factors. American Journal of Industrial Medicine, 61, 725732.

Jeavons, S., De L. Horne, D. J., \& Greenwood, K. M. (2000). Coping style and psychological trauma after road accidents. Psychology, Health and Medicine, $5(2), 213-221$.

Jonsson, A., \& Segesten, K (2004). Daily stress and concept of self in Swedish ambulance personnel. Prehospital Disaster Med, 19, 226-234.

Kardiner, A. (1941). The traumatic neuroses of war. New York: Hoeber. 
Kessler, R. C., Sonnega, A., Bromet, E., Hughes, M., \& Nelson, C. B. (1995).

Posttraumatic stress disorder in the national comorbidity survey. Archives of General Psychiatry, 52, 1048-1060

Khazem, L. R., Law, K. C., Green, B. A., \& Anestis, M. D. (2015). Examining the relationship between coping strategies and suicidal desire in a sample of United States military personnel. Comprehensive Psychiatry, 57, 2-9.

Kirmeyer, S. L., \& Diamond, A. (1985). Coping by police officers: A study of role stress and type A and type B behavior patterns. Journal of Occupational Behaviour, 6, 183-195.

Kolchakian, M. R. \& Sears, S. F. (1999). Religious coping in college students. Journal of Religion and Health 38(2), 115-125.

Krick, A. \& Felfe, J. (2020). Who benefits from mindfulness? The moderating role of personality and social norms for the effectiveness on psychological and physiological outcomes among police officers. Journal of Occupational Health Psychology, 25(2), 99-112.

Kuiper, N. A., Rod, M. A., Olinger, J. L. (1993). Coping humor, stress, and cognitive appraisals. Canadian Journal pf Behavioral Science, 25, 81-96.

Kunst, M. J. J., Bogaerts, S., \& Winkel, F. W. (2009). Peer and inmate aggression, type D-personality and post-traumatic stress among Dutch prison workers. Stress and Health, 25(5), 387-395. doi:10.1002/smi.1247

Lambert, E. G., Altheuner, I., \& Hogan N. L. (2006). Exploring the relationship between social support and job burnout among correctional staff. Criminal Justice and Behavior, 37(11), 1217-1236. 
Lambert, E. G., Barton-Bellessa, S. M., \& Hogan, N. L. (2015). The consequences of emotional burnout among correctional staff. SAGE Open, April-June, 1-15.

Lambert, E. G., Edwards, C., Camp, S. D., \& Saylor, W. G. (2005). Here today, gone tomorrow, back again the next day: Antecedents of correctional absenteeism. Journal of Criminal Justice, 33, 165-175.

Lambert, E. G. \& Hogan, N. L. (2010). Wanting change: The relationship of perceptions of organizational innovation with correctional staff job stress, job satisfaction, and organizational commitment. Criminal Justice Police Review, 21(2), 160-184.

Lambert, E. G. \& Hogan, N. L. (2010). Work-family conflict and job burnout among correctional staff. Psychological Reports, 106(1), 19-26.

Lambert, E. G., Hogan, N. L., Allen, R. I. (2006). Correlates of correctional officer job stress: The impact of organizational structure. American Journal of Criminal Justice, 30(2), 227-246.

Lambert, E. G., Hogan, N. L., \& Barton, S. M. (2004). The nature of work-family conflict among correctional staff: An exploratory examination. Criminal Justice Review, 29(1), 145-172.

Lambert, E. G., Hogan, N. L., Barton-Bellessa, S. M., \& Jiang, S. (2012). Examining the relationship between supervisor and management trust and job burnout among correctional staff. Criminal Justice and Behavior, 39(7), 938-957.

Lambert, E. G., Hogan, N. L., Camp, S. D., \& Ventura, L. A. (2006). The impact of work-family conflict on correctional staff: A preliminary study. Criminology \& Criminal Justice, 6(4), 371-387. 
Lambert, E. G., Hogan, N. L., Jiang, Shanhe, J. (2010). A preliminary examination of the relationship between organizational structure and emotional burnout among correctional staff. The Howard Journal of Criminal Justice, 49(2), 125-146.

Lambert, E. G., Hogan, N. L., \& Tucker, K. A. (2009). Problems at work: Exploring the correlates of role stress among correctional staff. The Prison Journal, 89(4), 460481.

Lambert, J. E., Benight, C. C., Harrison, E., \& Cieslak, R. (2012). The firefighter coping self-efficacy scale: measure development and validation. Anxiety, Stress, \& Coping, 25(1), 79-91.

Lazarus, R. S. (1966). Psychological stress and the coping process. New York: McGrawHill.

Lazarus, R. S. (1990). Theory-based measurement. Psychological Inquiry, 1, 3-13.

Lazarus, R. S., Deese, J., \& Olser, S. F. (1952). The effects of psychological stress upon performance. Psychological Bulletin, 49, 253-317.

Lazarus, R. S., DeLongis, A., Folkman, S., \& Gruen, R. (1985). Stress and adaptational outcomes: The problem of confounded measures. American Psychologist, 7, 770779.

Lazarus, R. S., \& Folkman, S. (1987). Transactional theory and research on emotions and coping. European Journal of Personality, 1, 141-170.

LeBlanc, V. R., Rehehr, C., Birze, A., King, K., Scott, A. K., MacDonald, R., \& Tavares, W. (2011). The association between posttraumatic stress, coping, and acute stress responses in paramedics. Traumatology, 17(4), 10-16. 
Lee, J. H., Park, S., \& Sim., M. (2018). Relationship between ways of coping and posttraumatic stress symptoms in firefighters compared to the general population in South Korea. Psychiatry Research, 270, 649-655.

Lefcourt, H.M, Davison, K., Prkachin, K. M., \& Mills, D. E. (1997). Humor as a stress moderator in the prediction of blood pressure obtained during five stressful tasks. Journal of Research in Personality, 31, 523-542.

Lehman, E. C. (1972). An empirical note on the transactional model of psychological stress. The Sociological Quarterly, 13, 484-495.

Lerman, A. E. (Nov. 2017). Officer health and wellness: Results from the California correctional officer survey. Retrieved from: https://gspp.berkeley.edu/assets/uploads/research/pdf/executive_summary_08142 018.pdf

Liverant, G. I., Hofmann, S. G., \& Litz, B. T. (2004). Coping and anxiety in college students after the September $11^{\text {th }}$ terrorist attacks. Anxiety, Stress \& Coping, 17(2), 127-139.

Lord, B. D. \& Gramling, S. E. (2014). Patterns of religious coping among bereaved college students. Journal of Religious Health, 53, 157-177.

McCrae, R. R., \& Costa, P. T. (1986). Personality, coping, and coping effectiveness in an adult sample. Journal of Personality, 54, 53-64.

McGrath, J. E. \& Beehr, T. A. (1990). Time and the stress process: Some temporal issues in the conceptualization and measurement of stress. Stress Medicine, 6, 93-104. 
McLean, C. P., Asnaani, A., Litz, B. T., \& Hofmann, S. G. (2011). Gender differences in anxiety disorders: Prevalence, course of illness, comorbidity and burden of illness. Journal of Psychiatric Research, 45(8), 1027-1035

Monson, C. M., Friedman, M. J., La Bash, H. A. J. (2007). A psychological history of PTSD. In Keane, T. M., Friedman, M. J., \& Resick, P. A., Handbook of PTSD: Science and practice (pp. 37-52). The Guilfod Press.

Moskowitz, J. T., Hult, J. R., Bessolari, C., \& Acree, M. (2009). What works in coping with HIV? A meta-analysis with implications for coping with serious illness. Psychological Bulletin, 135(1), 121-141.

National Institute of Mental Health. (2019). Post-Traumatic Stress Disorder. Retrieved from https://www.nimh.nih.gov/health/topics/post-traumatic-stress-disorderptsd/index.shtml Neufeld, R. W. J. (1999). Dynamic differentials of stress and coping. Psychological Review, 106(2), 385-397.

O’Brien, T. B., \& DeLongis, A. (1996). The interactional context of problem-, emotion-, and relationship-focused coping: The role of the Big Five Personality Factors. Journal of Personality, 64, 775-813.

Owen, S. S. (2006). Occupational stress among correctional supervisors. The Prison Journal, 86(2), 164-181.

Padden, D. L., Connors, R. A., \& Agazio, J. G. (2011). Stress, coping, and well-being in military spouses during deployment separation. Western Journal of Nursing Research, 33(2), 247-267. 
Park, M., Change, E. R., \& You, S (2015). Protective role of coping flexibility in PTSD and depressive symptoms following trauma. Personality and Individual Differences, 82, 102-106.

Pearlin, L., Menaghan, E. G., Lieberman, M. A., \& Mullan, J. T. (1981). The stress process. Journal of Health and Social Behavior, 22, 337-356.

Pitman, R. K. (1997). Overview of biological themes in PTSD. Ann N Y Acad Sci 821: 1-9.

Rexrode, K. R., Petersen, S., \& O’Toole, S. (2008). The ways of coping scale: A reliability generalization study. Educational and psychological measurement, $68(2), 262-280$.

Ricciardelli, R., Carleton, R. N., Gacek, J., \& Groll, D. L. (2020). Understanding needs, breaking down barriers: Examining mental health challenged and well-being of correctional staff in Ontario, Canada. Organizational Psychology, 11, 1-10.

Rim, Y. (1988). Sense of humor and coping styles. Personality and Individual Differences, 9, 559-564.

Robinson, H. M., Signman, M. R., \& Wilson, J. P. (1997). Duty-related stressors and PTSD symptoms in suburban police officers. Psychological Reports, 81, 835-845.

Roesch, S. C., Adams, L., Hines, A., Palmores, A., Vyas, P., Tran, C., ... Vaughn, A. A. (2005). Coping with prostate cancer: A meta-analytic review. Journal of Behavioral Medicine, 28(3), 281-293.

Savitsky, B., Findling, Y., Ereli, A., \& Hendel, T. (2020). Anxiety and coping strategies among nursing students during the covid-19 pandemic. Nurse Education in Practice, 46, 1-7. 
Scherer, R. F., Wiebe, F. A., Luther, D.C., Adams, J. S. (1988). Dimensionality of coping: Factor stability using the ways of coping questionnaire. Psychological Reports, 62, 763-770.

Schwarzer, R. (1999b). The Proactive Attitude Scale (PA Scale). (On-Line). Available: http://userpage.fu-berlin.de/ health/proactive.htm.

Schwarzer, R., Cone, J. E., Li, J., \& Bowler R. M. (2016). A PTSD symptoms trajectory mediates between exposure levels and emotional support in police responders to 9/11: Growth curve analysis. BMC Psychiatry, 16, 201, 1-7.

Seyle, H. (1950). Stress and the general adaptation syndrome. British Medical Journal, 1383-1392.

Sinclair, V. G. \& Wallston, K. A. (2004). The development and psychometric evaluation of the brief resilient coping scale. Assessment 11(1), 94-101.

Spinaris, C. G., Denhof, M. D., \& Kellaway, J. A. (2012). Post-Traumatic Stress Disorder in US Corrections Professionals: Prevalence and Impact on Health and Functioning. Retrieved from http://desertwaters.com/wpcontent/uploads/2013/09/PTSD_Prev_in_Corrections_09-03-131.pdf

Spinaris, C. G., Denhof, M. D., \& Morton, G. (2013). Impact of traumatic exposure on corrections professionals. NIC Cooperative. Retrieved from: https://info.nicic.gov/virt/sites/info.nicic.gov.virt/files/06Impact_of_Traumatic_E xposure.pdf

Stephenson, K. R., Simpson, T. L., Martinez, M. E., \& Kearney, D. J., (2017). Changes in mindfulness and posttraumatic stress disorder symptoms among veterans enrolled 
in mindfulness-based stress reduction. Journal of Clinical Psychology, 73(3), 201217.

Suls, J., \& David, J. P. (1996). Coping and personality: Third time's the charm? Journal of Personality, 64(4), 993-1005.

Sundt, J. L. (2009). Good job or dirty work: Public perceptions of correctional employment. Federal Probation, 73(3), 40-45.

Swartz, K., French, A., Roberts, A., \& Tolle, H. (April, 2017). Examining the Prevalence and correlates of PTSD among Kentucky Department of Corrections Staff.

Tartaglini, A. J., \& Safran, D. A. (1997). A topography of psychiatric disorders among correction officers. Journal of Occupational and Environmental Medicine, 39(6), $569-73$.

Thompson, R. J., Mata, J., Jaeggi, S. M., Buschkuehl, M., Joindes, J., \& Gotlib, I. H. (2010). Maladaptive coping, adaptive coping, and depressive symptoms: Variations across age and depressive state. Behaviour and Research Therapy, 48, 459-466.

Tran, K., Moulton, K., Santesso, N., \& Rabb, D. (2016). Cognitive processing therapy for post-traumatic stress disorder: A systematic review and meta-analysis. Ottawa: CADTH; 2016 Mar. (CADTH health technology assessment; no. 141).

U.S. Department of Veterans Affairs. How Common is PTSD in Women? Retrieved from: https://www.ptsd.va.gov/understand/common/common women.asp

Vickovic, S. G., Griffin, M. L., \& Fradella, H. F. (2013). Depictions of correctional officers in newspaper media: An ethnographic content analysis. Criminal Justice Studies, 26(4), 455-477. 
Vitaliano, P. P., Russo, J., Carr, J. E., Maiuro, R. D., \& Becker, J. (1985). The ways of coping checklist: Revision and psychometric properties. Multivariate Behavioral Research, 20, 3-26.

Watson, D., \& Hubbard, B. (1996). Adaptational style and dispositional structure: Coping in the context of the Five-Factor model. Journal of Personality, 64, 737-774.

Weathers, F.W., Litz, B. T., Keane, T. M., Palmieri, P. A., Marx, B. P., \& Schnurr, P. P. (2013). The PTSD checklist for DSM-5 (PCL-5). Scale available from the National Center for PTSD at www.ptsd.va.gov.

West, M. (2002). Sparkling foundations or stagnant ponds: An integrative model of creativity and innovation implementation in work groups. Applied Psychology, $51,355-386$.

Witvliet, C. V. O., Feldman, M. E., \& Beckham, J. C. (2004). Posttraumatic mental and physical health correlates of forgiveness and religious coping in military veterans. Journal of Traumatic Stress, 17(3), 269-273. 


\title{
CURRICULUM VITA
}

\author{
Katie L. Hughes-Taylor, Ph.D. \\ Department of Criminal Justice \\ University of Louisville \\ Brigman Hall 106 \\ Louisville, KY 40292 \\ Email: katie.hughes@1ouisville.edu \\ Phone: (502) 689-4503
}

\section{$\underline{\text { EDUCATION }}$}

Doctor of Philosophy Degree; in progress, Criminal Justice $\quad$ Defense: April $19^{\text {th }}$, 2021

University of Louisville, Louisville, KY

Graduated: May 2021

Dissertation: Correctional Officers' Response to Stress: An

Exploration of the Association Between Violence and Trauma Exposure,

Coping Mechanisms, and PTSD. Prospectus defended 02/2021

Committee: Dr. Kristin Swartz (chair), Dr. Deborah Keeling, Dr. Bradley

Campbell, Dr. Andrew Denney

Master of Science, Criminal Justice

University of Cincinnati, Cincinnati, $\mathrm{OH} \quad$ Graduated: August

2017

Bachelor of Science, Criminal Justice

University of Louisville, Louisville, KY

Graduated: May 2016

AWARDS

Nominee for Faculty Favorite

University of Louisville, Louisville, KY_ Spring 2020

\section{SCHOLARLY WRITINGS}

\section{In progress}

Kristin Swartz, Thomas Baker, William Clay Johnson, and Katie Hughes (2021). Comorbidity of PTSD and Depression. Intend to submit to Criminal Justice and Behavior. 
Katie Hughes and Kristin Swartz (2021). Examining direct versus indirect trauma on PTSD in correctional staff. Intend to submit to Corrections: Policy, Practice, \& Research.

\section{PRESENTATIONS}

\section{Invited Presentations}

April 2018

"Program Evaluation of the Living Room Program", Louisville Metro Police Department, Louisville Metro Department of Corrections and Centerstone Mental Health Services.

\section{Conference Presentations}

September 2018

Katie Hughes and Kristin Swartz. Examining the Unique Effects of Exposure to Suicide and Assault on Correctional Staff's PTSD Risk. Midwestern Criminal Justice Association, Chicago, IL.

October 2018

Katie Hughes and Kristin Swartz. Is this Just Part of the Job?: Understanding the Characteristics of Critical Incidents Most Highly Associated with PTSD among Correctional Staff. American Society of Criminology, Atlanta, GA.

March 2019

Kristin Swartz, Clay Johnson, \& Katie Hughes, Suicidality among Correctional Staff: Examining the Comorbidity of PTSD and Depression. Academy of Criminal Justice Sciences, Baltimore, MD.

November 2019

Katie Hughes and Kristin Swartz, How Do They Face It Day After Day: An Exploration of Correctional Officer Coping Mechanisms. American Society of Criminology, San Francisco, CA.

March 2020

Katie Hughes and Kristin Swartz, An Exploration between the Relationships of Exposure to Violence and Trauma, Coping Mechanisms, and PTSD among Correctional Officers. Academy Criminal Justice Sciences, San Antonio, TX. *Conference cancelled due to COVID-19

Kristin Swartz, Katie Hughes, and Kristyn Lukjan, Toss and Turn, Count Sheep, and Pray for Sleep: Exploring the Relationships between Job-Related Measures and Sleep among Correctional Officers. Academy Criminal Justice 
Sciences, San Antonio, TX. ${ }^{*}$ Conference cancelled due to COVID-19

\section{RESEARCH EXPERIENCE}

2017- Present

2017- Present
Graduate Assistant to Dr. Kristin Swartz

Department of Criminal Justice, University of Louisville

National Institute of Justice, NIJ-2017-11481, "Effects of Mindfulness-Based Stress Reduction in Correctional Officers: A Biopsychosocial Approach." Graduate Assistant $(\$ 677,990)$.

\section{TEACHING EXPERIENCE}

\section{Course Instruction}

University of Louisville

2020-2021 Corrections in the U.S., 3 sections

2021

Independent Study- with undergraduate student

\section{SERVICE}

Professional Organization Service

September $2018 \quad$ Registration Table for Midwestern Criminal Justice Association (MCJA) - Chicago, IL

\section{PROFESSIONAL AFFILIATIONS}

2018- Present

2018- Present

2018- Present
Academy of Criminal Justice Sciences

American Society of Criminology

Midwestern Criminal Justice Association

\section{DEPARTMENT SERVICE}

2019- Present

2020-2021

Last Updated: April 2021
Graduate Student Council (GSC) Representative Volunteer for Research Fund Committee for GSC 